Florida International University FIU Digital Commons

$12-9-2009$

\title{
Roof and Wall Vents Study under Simulated Hurricane Winds
}

Peeyush S. Kawade

Florida International University, piyush_engg8979@yahoo.com

DOI: $10.25148 /$ etd.FI10081216

Follow this and additional works at: https://digitalcommons.fiu.edu/etd

\section{Recommended Citation}

Kawade, Peeyush S., "Roof and Wall Vents Study under Simulated Hurricane Winds" (2009). FIU Electronic Theses and Dissertations. 255.

https://digitalcommons.fiu.edu/etd/255

This work is brought to you for free and open access by the University Graduate School at FIU Digital Commons. It has been accepted for inclusion in FIU Electronic Theses and Dissertations by an authorized administrator of FIU Digital Commons. For more information, please contact dcc@fiu.edu. 


\title{
FLORIDA INTERNATIONAL UNIVERSITY
}

\author{
Miami, Florida
}

\section{ROOF AND WALL VENTS STUDY UNDER SIMULATED HURRICANE WINDS}

A thesis submitted in partial fulfillment of the

requirements for the degree of

MASTER OF SCIENCE

in

CIVIL ENGINEERING

by

Peeyush Sarangpani Kawade

2010 


\section{To: Dean Amir Mirmiran}

College of Engineering and Computing

This thesis, written by Peeyush Sarangpani Kawade, and entitled Roof and Wall Vents Study under Simulated Hurricane Winds, having been approved in respect to style and intellectual content, is referred to you for judgment.

We have read this thesis and recommend that it be approved.

Girma Bitsuamlak

Nakin Suksawang

Arindam Gan Chowdhury, Major Professor

Date of Defense: December 9, 2009

The thesis of Peeyush Sarangpani Kawade is approved.

Dean Amir Mirmiran
College of Engineering and Computing

Florida International University, 2010 


\section{DEDICATION}

This thesis is dedicated to the families and individuals who suffered loss, at any level, as a result of the storms that warranted the need for this research. 


\section{ACKNOWLEDGMENTS}

I would like to thanks my family (present and future) for the love and support they have shown me while working on this thesis, especially when I was unable to spend time with them. I want to thank Sri Sai Baba and Ganpati bapa for the knowledge he has taught me over the past two years, which extends far beyond hurricane research, and for the people he has brought into my life. I hope I have been able to impact their lives as much as they have impacted mine. Swatu, thank you for being a constant source of love, humor, and motivation to me. You are amazing, and it is truly an honor and a privilege to be your man.

To those individuals I have worked closely with IHRC: Walter, Jimmy, Roy, Tuan-Chun Fu, Ivan, Steve, Rayan, Dhawal, Sheikh, and Ruilong-Li thank you for all of the help, laughs, and advice. A very thanks to Dr. Chowdhury for giving me the opportunity to work on my M.S. at IHRC, and for the direction you have given me over the course of this project. Dr. Emil Simiu, thank you for your guidance and openness to answer question during this project. Thank you to Dr. Bitsuamlak and Dr. Suksawang for sitting on my thesis committee and for the knowledge you presented in the classroom throughout my student career at FIU.

Finally, thank you to the hurricane research group at the University of Florida, led by Dr. Gurley. Working with you during hurricane deployments and at WoW development was fun and exciting. 


\section{ABSTRACT OF THE THESIS \\ ROOF AND WALL VENTS STUDY UNDER SIMULATED HURRICANE WINDS}

by

Peeyush Sarangpani Kawade

Florida International University, 2010

Miami, Florida

Professor Arindam Gan Chowdhury, Major Professor

Ventilation might seem like a minor consideration, but when properly installed, it can extend the life of the attic and roof structure of residential buildings saving huge dollar amounts in repair costs. The objectives of this study were to measure the wind effect on different kind of vents as the problem is vents are subjected to high wind loads during hurricane events and often fail causing water penetration and damage of interior contents. Wind-induced failure of rooftop vents during a hurricane may result in large openings in the roof that will allow water to penetrate into the building, a puncturing of the roof membrane, again allowing water infiltration, and detached rooftop vents can pose considerable threats as windborne debris. The study found that water infiltration through a vent system is dependent upon the differential pressure as well as the vent mechanism. For vents experiencing higher differential pressures, vent covers can be used during storms to reduce water infiltration. Active controls can also be designed to close the vents automatically as differential pressure increases based on the wind speed and wind angle of attack. 


\section{TABLE OF CONTENTS}

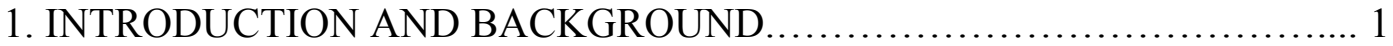

1.1 Roof and Wall Ventilation.......................................... 3

1.2 History and Previous Work......................................... 4

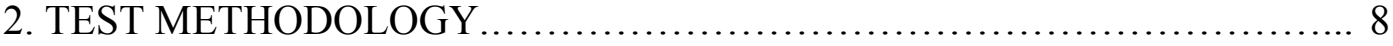

3. THE WoW TESTING APPARATUS ..................................... 8

3.1 Full scale testing equipment (Wall of Wind) ....................... 8

$3.2 \mathrm{WoW}$ flow management techniques............................. 12

3.3 Water Injection System............................................ 16

4. EXPERIMENTAL APPROACH........................................ 18

4.1 Roof and Wall Vents Setup and Instrumentation.................... 18

4.1.1 Pressure Testing.......................................... 20

4.1.2 Water Intrusion Testing.................................. 24

4.2 Experimental Procedure ............................................. 26

4.2.1 Pressure Testing............................................. 26

4.2.2 Water Intrusion Testing................................... 29

5. RESULTS AND DISCUSSION........................................ 30

5.1 Pressure Test Results ........................................... 30

5.1.1 Gable Roof Results.................................... 32

5.1.2 Visualization of Turbine Pressure Coefficients for Gable Roof.............................................. 39

5.1 .3 Hip Roof Results...................................... 43

5.2 Water Intrusion Test Results.................................. 48

5.3 Influence of Reynolds Number on Pressure Distribution over

Cylindrical Vent with Circular Cross Section (Turbine Vent)........... 54

5.4 Uplift and Drag Coefficients......................................... 56

5.4.1 Uplift Coefficients........................................ 56

5.4.2 Drag Coefficients....................................... 57

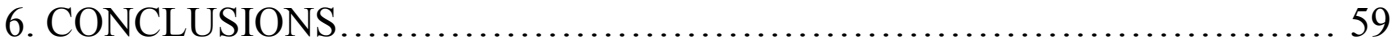

REFERENCES AND RELATED LINKS ................................. 61 


\section{LIST OF FIGURES}

FIGURE

PAGE

Figure 1 Annual number of named storms (BLUE) and major hurricanes (RED) 1944-2005 (source: National Climatic Centre (NCC), 2006)............. 2

Figure 2 Turbine ventilators (Curved and straight vane turbine).............. 4

Figure $3 \quad$ Long Volume Turbine Ventilators.............................. 7

Figure 4 Six-Fan Wall-of-Wind Front View (b) Side View................... 9

Figure $5 \quad$ Six-Fan Wall-of-Wind Side View.............................. 10

Figure $6 \quad$ Chevrolet 502 big block crate engines.......................... 10

Figure $7 \quad$ (a) Setup of fans and blades of Chevrolet 502 crate engines

(b) Control System for the fans and $\ldots \ldots \ldots \ldots \ldots \ldots \ldots \ldots \ldots \ldots \ldots \ldots \ldots$

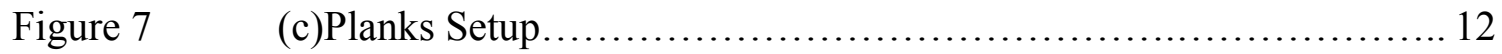

Figure $8 \quad$ (a) WoW Vertical shear velocity profile

(b) WoW Turbulence intensity profiles for the longitudinal direction of

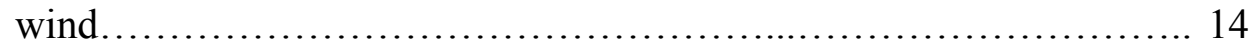

Figure $8 \quad$ (c) Gust factors at height $=9.5 \mathrm{ft}$ and $\mathrm{z}=11 \mathrm{ft}$

(d) WoW power spectral density Vs. the Kaimal and FCMP Curves.... 15

Figure $9 \quad$ (a) WoW, Steel framing and setup............................. 16

Figure 9 (b) Spray nozzles used for water injection system

(c) Water spray from the nozzles.............................. 17

Figure $10 \quad$ Gasoline powered pump.................................... 18

Figure $11 \quad$ Water meter.............................................. 18

Figure $12 \quad 550$-gallon agricultural grade horizontal leg tank.................. 18

Figure $13 \quad$ (a) Gable roof prepared with $30 \mathrm{lb}$ felt paper underlayment

(b) Hip roof prepared with $30 \mathrm{lb}$ felt paper underlayment ............ 19

Figure 14 (a) Turbine, gooseneck \&ridge vent installed on the gable roof specimens

(b) Turbine, gooseneck \& ridge vent installed on the hip roof specimens.................................................. 19 
Figure 15 Wind angle of attack and turbine/goose neck vents locations

Figure 16 Pressure Tab Locations on (a) Turbine ........................... 21

Figure 16 Pressure Tab Locations on (b) Goose Neck Vents.................... 22

Figure 17 (a) Pressure tubing installed within the turbine vent base

(b) Pressure tap installed on gable vent

(c) Turbine vent setup on the roof specimen

(d) Goose neck vent setup on the roof specimen................... 22

Figure $17 \quad$ (e) Pressure tab installation on soffit vent

(f) Transducer installation on soffit vent

(g) Soffit vent installed on a gable roof specimen $\ldots \ldots \ldots \ldots \ldots \ldots \ldots . \ldots 23$

Figure 18 NI 9074 cRIO (Compact RIO).............................. 24

Figure 19 (a) Water collection setup for the gooseneck vent

(b) Water collection setup for turbine vent ...................... 25

Figure 19 (c) \& (d) Bucket setup for ridge vent and setup for gable end vent

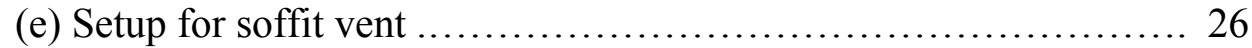

Figure $20 \quad$ Aluminum pan used for water collection........................ 26

Figure $21 \quad$ Angles of attack tested during this study....................... 27

Figure 22 (a) Experimental setup with turbine, gooseneck and gable end vents... 28

Figure 22 (b) Experimental setup showing gable end and soffit vents ............ 28

Figure 23 (a)\& (b) Water intrusion test on gable roof...................... 30

Figure 24 Typical time history pressure data at:

(a) Windward side and (b) Leeward side 31

\section{GABLE ROOF:}

Figure $25 \quad \mathrm{C}_{\mathrm{p}}$ values for "0" degree angle of attack (turbine \& gooseneck vent).... 33

Figure $26 \quad \mathrm{C}_{\mathrm{p}}$ values for "15" degree angle of attack (turbine \&gooseneck vent)... 34

Figure $27 \quad \mathrm{C}_{\mathrm{p}}$ values for " 45 " degree angle of attack (turbine \&gooseneck vent)... 36

Figure $28 \quad \mathrm{C}_{\mathrm{p}}$ values for " 75 " degree angle of attack (turbine \&gooseneck vent)... 37

Figure $29 \quad \mathrm{C}_{\mathrm{p}}$ values for " 90 ” degree angle of attack (turbine \&gooseneck vent)... 39 
Figure $30 \quad$ Average $C_{p}$ values for angle of attack at 0 degree (turbine vent)....... 40

Figure 31 Average $C_{p}$ values for angle of attack at 15 degree (turbine vent)..... 40

Figure 32 Average $C_{p}$ values for angle of attack at 45 degree (turbine vent)....... 41

Figure 33 Average $C_{p}$ values for angle of attack at 75 degree (turbine vent)..... 42

Figure 34 Average $C_{p}$ values for angle of attack at 90 degree (turbine vent)..... 42 HIP ROOF:

Figure $35 \quad C_{p}$ values for " 0 " degree angle of attack (turbine \& gooseneck vent)... 43

Figure $36 \quad \mathrm{C}_{\mathrm{p}}$ values for "15" degree angle of attack (turbine \&gooseneck vent)... 44

Figure $37 \quad C_{p}$ values for " 45 " degree angle of attack (turbine \&gooseneck vent).. 45

Figure $38 \quad \mathrm{C}_{\mathrm{p}}$ values for "75" degree angle of attack (turbine \&gooseneck vent)... 46

Figure $39 \mathrm{C}_{\mathrm{p}}$ values for "90" degree angle of attack (turbine \&gooseneck vent).. 47

Figure 40 Water intrusion test resultsfor gable roof: (a) $9 \mathrm{in} / \mathrm{hr}$ Water intrusion test resultsfor gable roof: (b) $19 \mathrm{in} / \mathrm{hr} \ldots \ldots \ldots \ldots \ldots \ldots . \ldots 49$

Figure $41 \quad \Delta \mathrm{Cp}$ values for gable roof specimen vents........................ 49

Figure 42 Water intrusion test resultsfor hip roof for $19 \mathrm{inch} / \mathrm{hr} \ldots \ldots \ldots \ldots \ldots \ldots \ldots . . .50$

Figure $43 \quad \Delta \mathrm{Cp}$ values for hip roof specimen vents .......................... 50

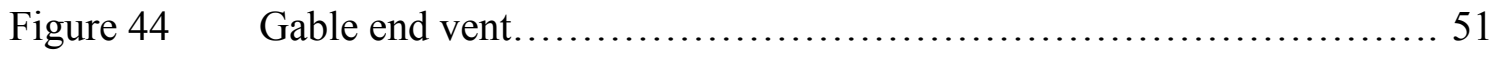

Figure $45 \Delta \mathrm{Cp}$ values for soffit vents for gable roof specimen.................. 52

Figure 46 $\Delta \mathrm{Cp}$ values for ridge vents for gable roof specimen.................. 52

Figure $47 \quad \Delta \mathrm{Cp}$ values for soffit vents for hip roof specimen..................... 53

Figure48 $\quad \Delta \mathrm{Cp}$ values for ridge vent for hip roof specimen.................... 53

Figure 49 Drag Coefficient as a function of Reynolds number (Wang, 2001)....... 54

Figure 50 Cp values distribution along (a) Turbine vent for gable roof, (b) Turbine vent for hip roof, (c) Circular cylinder (Simiu and Scanlan, 1996)..... 56 
Figure 51 Gooseneck vent uplift coefficients for gable roof and hip roof ....... 57

Figure $52 \quad$ Vent drag coefficients for gable roof and hip roof .................. 58 


\section{LIST OF ACRONYMS}

\begin{tabular}{|c|c|}
\hline WOW & Wall of Wind \\
\hline NTC & Net Tropical Cyclone \\
\hline $\mathrm{NHC}$ & National Hurricane Centre \\
\hline NAC & National Academy of Sciences \\
\hline $\mathrm{NCC}$ & National Climatic Centre \\
\hline IHRC & International Hurricane Research Centre \\
\hline FIU & Florida International University \\
\hline $\mathrm{ABL}$ & Atmospheric Boundary layer \\
\hline FCMP & Florida Costal Monitoring Program \\
\hline TI & Turbulence Intensity \\
\hline GF & Gust Factor \\
\hline PSD & Power Spectral Density \\
\hline OD & Outside Diameter \\
\hline cRIO & Compact RIO \\
\hline $\mathrm{Cp}$ & Mean Coefficient \\
\hline$\Delta \mathrm{Cp}$ & Differential Pressure Coefficient \\
\hline $\mathrm{Cd}$ & Drag Coefficient \\
\hline $\operatorname{Re}$ & Reynolds's Number \\
\hline $\mathrm{Cc}$ & Uplift Coefficient \\
\hline
\end{tabular}




\section{INTRODUCTION AND BACKGROUND}

Natural hazards such as earthquakes, landslides, lightning, floods, windstorms and tsunamis, are great threats to the mankind. Such disasters cost high risk to people and their property. Natural disasters can cost billions of dollars in recovery and repairs. The biggest threats among all such hazards are hurricanes (Liu, 2008). According to the Insurance Information Institute, the 2005 Hurricane Season resulted in \$ 57.7 billion dollars in insured losses. A large portion of these losses was attributed to roof damage. Since the mid 1990s the North Atlantic Basin has experienced a substantial increase in tropical cyclone activity fueled primarily by warmer than usual sea surface temperature and decreased wind shear. Goldenberg et al. (2001) concluded that the years 1995-2000 saw the highest mean number of major hurricanes and mean Net Tropical Cyclone (NTC) activity of any 6 consecutive years in the entire 1944-1995 database. The 2004 hurricane season also proved record breaking with four storms affecting the same state, namely Florida, in one season; the last time four storms impacted one state was in 1886 when Texas endured four direct hits. Proportional with increased frequency in hurricane landfall is the increase in damage of economy, destruction of built environment structures (mainly roof structure of residential buildings) and loss of life. The annual average economic losses due to hurricanes increased from \$ 1.3 billion in the years 1949-1989 to \$ 10.1 billion from 1990-1995; with the occurrence of hurricanes Katrina and Rita, the 2005 season set a new record with losses totaling over $\$ 100$ billion (Lott and Ross, 2006).

Historical records show that there has been an increasing trend in the incidence of tropical storms and hurricanes for the period of 1944 to the present time. The number of 


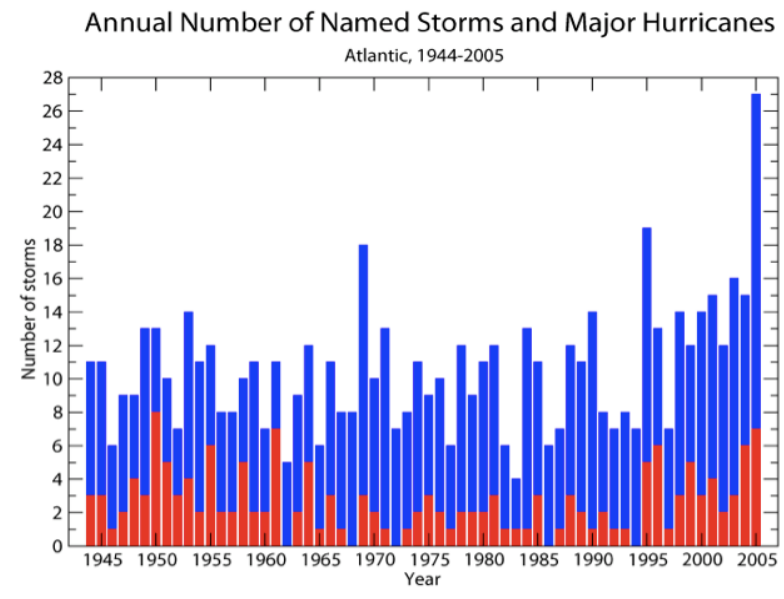

Figure 1. Annual number of named storms (BLUE) and major hurricanes (RED) 1944-2005 (source: National Climatic Centre (NCC), 2006)

major hurricanes and the annual number of named storms has been shown in Figure 1. It appears that in last 3 decades there is an increasing trend in the occurrence of storms, which together with a growing coastal population presents a new challenge for the Civil and Wind engineering communities. According to the Annual Summary for the Atlantic Hurricane Season 2004 (National Hurricane Centre), losses due to hurricanes in the 2004 season were estimated to be $\$ 45$ billion and they also accounted for 3100 casualties, 60 of which happened in the United States (Frankling et al., 2005). The growth of hurricaneinduced losses from $\$ 1.3 /$ year pre-1990 to $\$ 36 \mathrm{~B} /$ year post-2000 is a direct result of over 50 years of accumulated socio-economic decisions to invest in physical infrastructure and community development along coastlines, where now $50 \%$ of the US population lives within 50 miles of the seaboard (National Academy of Sciences, 1999). The 2005 Hurricane season also produced strong storms with devastating power, such as Wilma and Katrina, causing losses over $\$ 100$ billion. The magnitude of the storms can’t be changed, but the magnitude of the impact on population and damages caused by them 
might be minimized by improving construction techniques and materials and by increasing the general awareness of the risks imposed by this natural phenomenon.

\subsection{Roof and Wall Ventilation:}

Typical household activities can cause serious problems to a roof and attic if proper roof ventilation is not provided. For example, in summer, heat build-up encourages the premature aging and cracking of wood and other roofing materials. Unwanted heat also can transfer back down into living areas - which reduces energy efficiency. Similarly, in cold weather, warm air generated by laundry, showers, dish washing and cooking can linger in the house and cause moisture build-up. The only way to combat these problems is to have a balanced ventilated wall and roofing system. That means it's important to have proper ventilation, plus the appropriate amount of attic insulation to maximize performance.

In a balanced system, wind blowing over the ridge creates negative pressure that

draws the warmer air out of the attic. Replacement air then enters through underside of the eave or soffit vents, bathes the underside of the roof, and exits through ridge, roof or gable vents. Even without wind, the natural convection action of rising warm air maintains a continuous airflow along the underside of the roof.

Passive wind driven ventilation looks at devices and methods that are passive in nature and primarily use wind-induced effects as motive forces for providing ventilation. By passive we mean those devices, which generally have no moving parts although some recent modifications and innovations have integrated moving or controlled additions. Roof and wall vents are well known in buildings for ventilation and openings is mainly wind driven; thus this has become a centerpiece for ventilation strategies in buildings (P. 
Karava, T. Stathoupoulous, K. A. Athienitis, 2006). Ventilation might seem like a minor consideration, but when properly installed, it can extend the life of the attic and roof structure of residential buildings: saving huge dollar amounts in repair costs. Ultimately, proper ventilation-along with attic insulation-helps maintain a comfortable temperature inside a home, increase energy efficiency, prevent moisture damage and contribute to the longevity of a roof. However the vents are subjected to wind loading and can be the path for water infiltration during hurricane events. Very limited research has been performed on water intrusion through various types of vents under differential pressures. The current project focuses on the performance of vents under simulated hurricane effects.

\subsection{History and Previous Work:}

A turbine ventilator is a wind-driven air extractor. Its concept was originally patented as early as in 1929 by Meadows (V.H. Meadows, 1929), who described it as a rotary ventilator and first commercialized extensively by Edmonds of Australia since 1934. A turbine ventilator includes a number of vertical vanes (curved or straight blades) in a spherical or cylindrical array mounted on a frame (Figure 2).
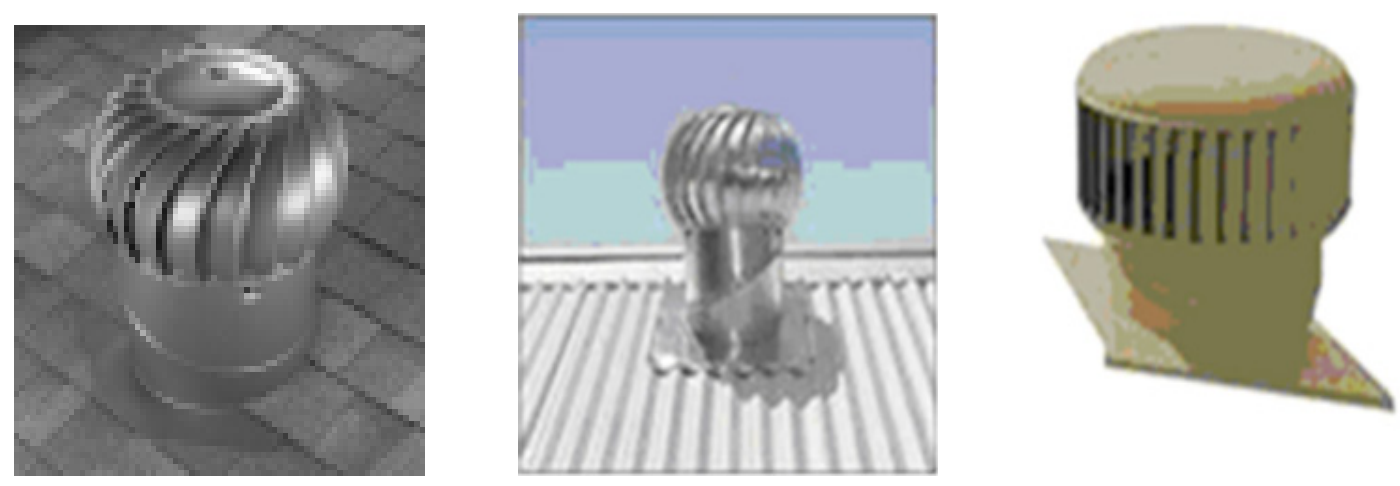

Figure 2: Turbine ventilators (Curved and straight vane turbine) 
A weatherproof dome is on top of the frame. A shaft and bearings connect the top moving section to a base duct. When the wind blows on the aerofoil vanes the resulting lift and drag forces cause the turbine to rotate. Because of this rotation a negative pressure produces inside the turbine, which extracts air. Air enters the turbine axially via the base duct and is then expelled radially. In the absence of the wind, a turbine ventilator facilitates ventilation using stack effects (N. Khan et al, 2008). Lai also investigated the addition of a large turbine ventilator on a dormitory to enhance ventilation for bathrooms, further to the existing extract fans. The conclusions were that the turbine ventilator did add to the ventilation rate significantly and the induced negative pressure helped reduce leakage of odours and moisture to other spaces (48). Dale and Ackerman conducted field measurements of a $305 \mathrm{~mm}$ diameter turbine ventilator in a house, which had two soffit vents with a combined free vent area of $0.08 \mathrm{~m} 2$, installed for attic ventilation. They found that ventilation enhancements were a function of wind direction with the best being wind with more upwind shelter. They also studied the temperature difference caused by the turbine ventilator in the attic and found this to be negligible with a measured temperature decrease of only $0.56{ }^{\circ} \mathrm{C}$. they concluded that over all wind directions and seasons, the attic turbine ventilator investigated increased ventilation rates by $15 \%$ on average as compared to the existing roof soffit vents in the test house (47). An Australian study by Revel compared ventilation rates between two $400 \mathrm{~mm}$ turbine ventilators of straight vane and curved vane design. The study concluded that at all wind speeds the straight vane ventilator significantly outperformed the curved vane ventilator (42). A flow visualization study by Lai shows the airflow pattern around a turbine ventilator. The airflow split into two streams when it flowed through the ventilator. One flow was in the 
direction of rotation and thus became the motive force for rotation and dampened the ventilator rotation. The rotating blades threw the extracted air away to mix into these two wind airflows, which converged in the wake region on the opposite side of the incident wind. The same study tested 3 different sized ventilators of 6,14 and 20 in. diameters under wind speeds of between 10 and $30 \mathrm{~m} / \mathrm{s}$ in Taiwan. Lai found that larger diameter ventilators would induce greater ventilation rates as expected, but surprisingly the difference between the 14 in and 20 in. ventilators was 'insignificant'. Lai also tried adding an inner vane enhancement, which was perceived in Taiwan to add value to the extraction prowess of ventilators. However it was shown there was no significant enhancement to flow rate contrary to popular consumer beliefs although there was some benefit (41). One more experiment was performed on a turbine ventilator but in a different way and in different setup. Havens modeled a turbine ventilator as a combined backward curved centrifugal fan and wind turbine. His rationale for doing this was firstly, the fact that a turbine ventilator captures and uses wind power thus the wind turbine approximation. This model presents the tip speed; which is proportional to the ventilator rotational speed, as a function of wind speed. Secondly, that it pumps air out of an attic whilst spinning, hence the fan analogy of finding the airflow as a function of rotational speed. The model is presented in detail in P. Havens, "A combined fan and wind turbine model for attic turbine ventilator" 2004 (N. Khan et al, 2008). One more study, Ref. S. West, Building \& Environment 36 (1999) 281-289, founded that by increasing the blade height on a given vertical vane ventilator by $50 \%$ a $13.5 \%$ improvement in flow rates can be achieved. These are called Long Volume Turbines (LVT), (Figure 3). 


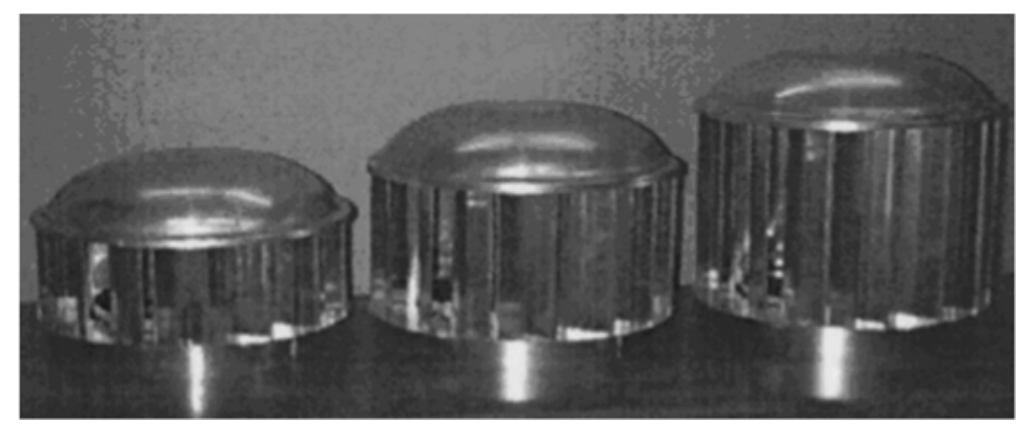

Figure 3: Long Volume Turbine Ventilators.

Another study Ref. D.M.H. Rashid, N.A. Ahmed, Journal of Wind Engineering 2 (2003) 63-72, attempts to investigate the flow field and aerodynamic farces around a rotating ventilator. Although turbine ventilator is quite simple in its design and construction the associated flow is deceptively complex, comprising two separate but interdependent flows, i.e. the free stream air that rotates the ventilator and the extracted air being expelled, as illustrated by Lai (C. Lai, 2005). A same study Ref. D.M.H. Rashid, N.A. Ahmed, Journal of Wind Engineering 2 (2003) 63-72, aimed to investigate the aerodynamic forces acting on the rotating ventilator by using force/torque transducer measurements. Indicative parameters for the drag and lift experienced by the ventilator were examined, notably the force coefficients on the $\mathrm{X}$ and $\mathrm{Y}$ direction, respectively relative to the blades. Results showed that the ventilator tested which was of a vertical blade design, was more efficient at lower wind speeds. Increasing wind speeds may have caused 'flow separation' on the actual blades implying that an improvement in blade aerodynamic design is needed to allow for efficient operation over a greater range of wind speeds. Rotational speed increased linearly with the wind tunnel wind speed and the dome shaped structure was seen to contribute to possible lift in the vertical direction that could cause the ventilator to be sucked off the roof (N. Khan et al, 2008). 


\section{TEST METHODOLOGY:}

A full-scale model representing a typical low-rise building was constructed for the testing purpose. Roof and wall vents were installed on the building model. Wall of Wind (WoW) (6-fan system) was used to determine wind forces and water intrusion through the vents. Pressure differentials for the vents were obtained from a simultaneous project (Bitsuamlak and Tecle, 2009). Transducers installed on the vents measured the windinduced loading and data was acquired using the lab view data acquisition software.

Tests were performed with and without wind-driven rain. Any failure mode and/or water intrusion was recorded. Failure modes of and water intrusion through different kinds of vents were studied and correlated to the wind speed and wind-driven rain intensity. This research provides information that will help to address significant vent damage and secondary water infiltration and debris generation occurring related to the poor performance of roof and wall vents.

\section{THE WALL OF WIND (WoW) TESTING APPARATUS:}

\subsection{Full scale testing equipment -- Wall of Wind (WoW)}

Built by the International Hurricane Research Center (IHRC), the Wall of Wind (WoW) hurricane simulator is a full-scale destructive testing apparatus located at FIU's Engineering Center Campus. This machine is capable of testing a full-scale low-rise building model. The WoW comprises of a 6-fan array and was used for this study. In its original configuration, the 6-fan WoW had the capability of generating $125 \mathrm{mph}$ wind speeds, corresponding to a middle range Category 3 hurricane as defined by the SaffirSimpson hurricane intensity scale (Huang et al., 2009). This integrated system couples hurricane like winds with wind-driven rain in a controlled environment to allow realistic 
simulation of hurricane wind and rain interactions with buildings (Bitsuamlak et al., 2009).

The design for the 6-fan WoW consisted of six individual fan modules. Figure 4a $\& 4 \mathrm{~b}$ shows the 6-fan WoW front view.

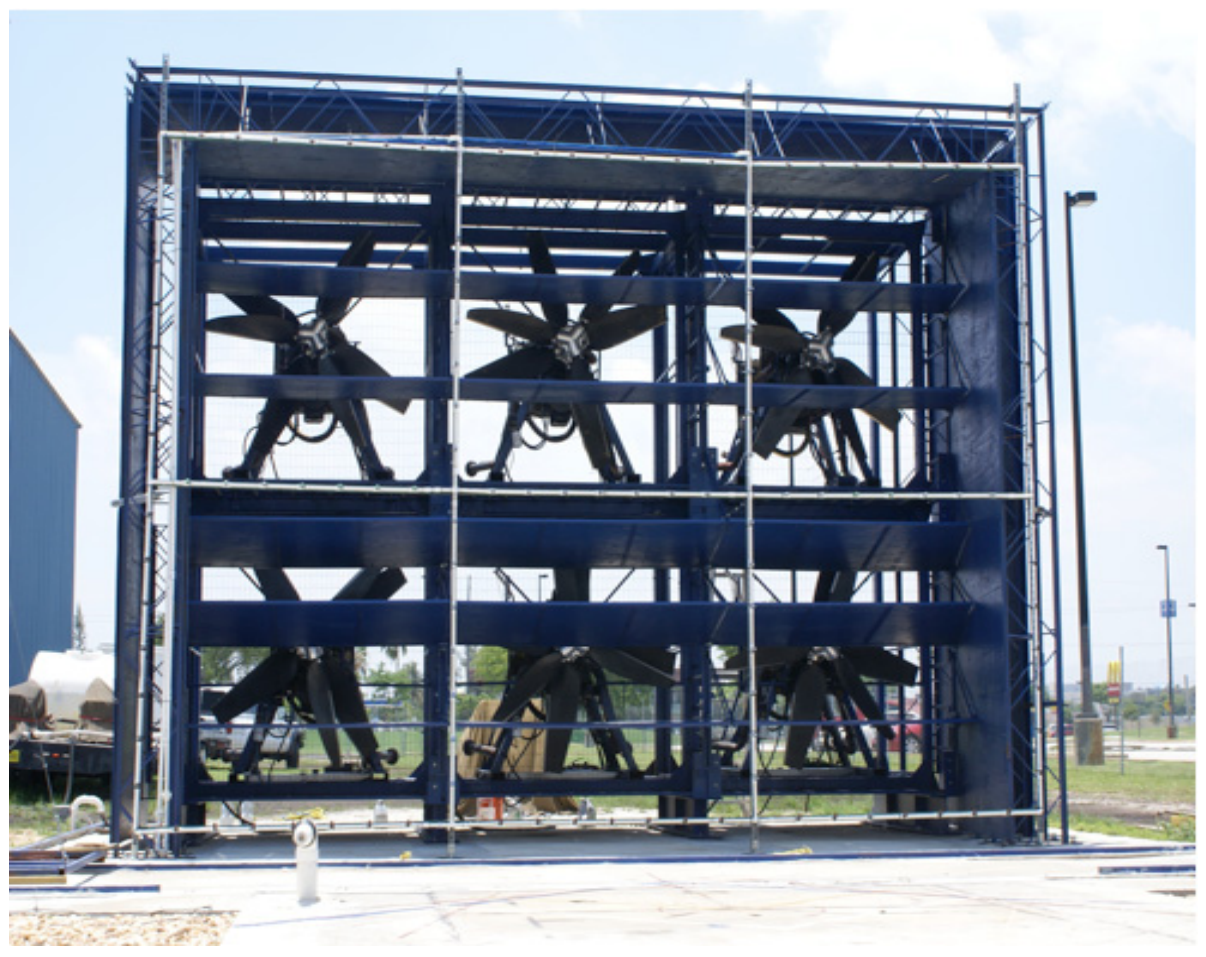

Figure 4. Six-Fan Wall-of-Wind front view.

The cross-sectional area of one fan module measured $2.44 \mathrm{~m}(8 \mathrm{ft})$ high $\times 2.44 \mathrm{~m}(8 \mathrm{ft})$ wide, and these six modules were stacked into a $2 \times 3$ array, giving the 6 -fan WoW a total flow field measuring $4.8 \mathrm{~m}(16 \mathrm{ft})$ high by $6.7 \mathrm{~m}(22 \mathrm{ft})$ wide. The engine frames were designed and built to contain carbureted Chevrolet 502 big block crate engines (Figure 6). Century Drive System SH3 2:1 counter rotating drive units were mounted to each engine, with a set of 4- bladed Sensenich composite airboat propellers installed on the front propeller hub (closest to the engine) and a set of 3-bladed Sensenich composite airboat propellers installed on the rear propeller hub (farthest from the engine). The counter 
rotating setup was made because it reduces the amount of propeller-generated swirl in the flow, and it reduces the overall propeller torque on the engine. Figure $7 \mathrm{a}, \mathrm{b} \& \mathrm{c}$ shows the setup of fans and blades and different components of WoW relevant to the present testing.

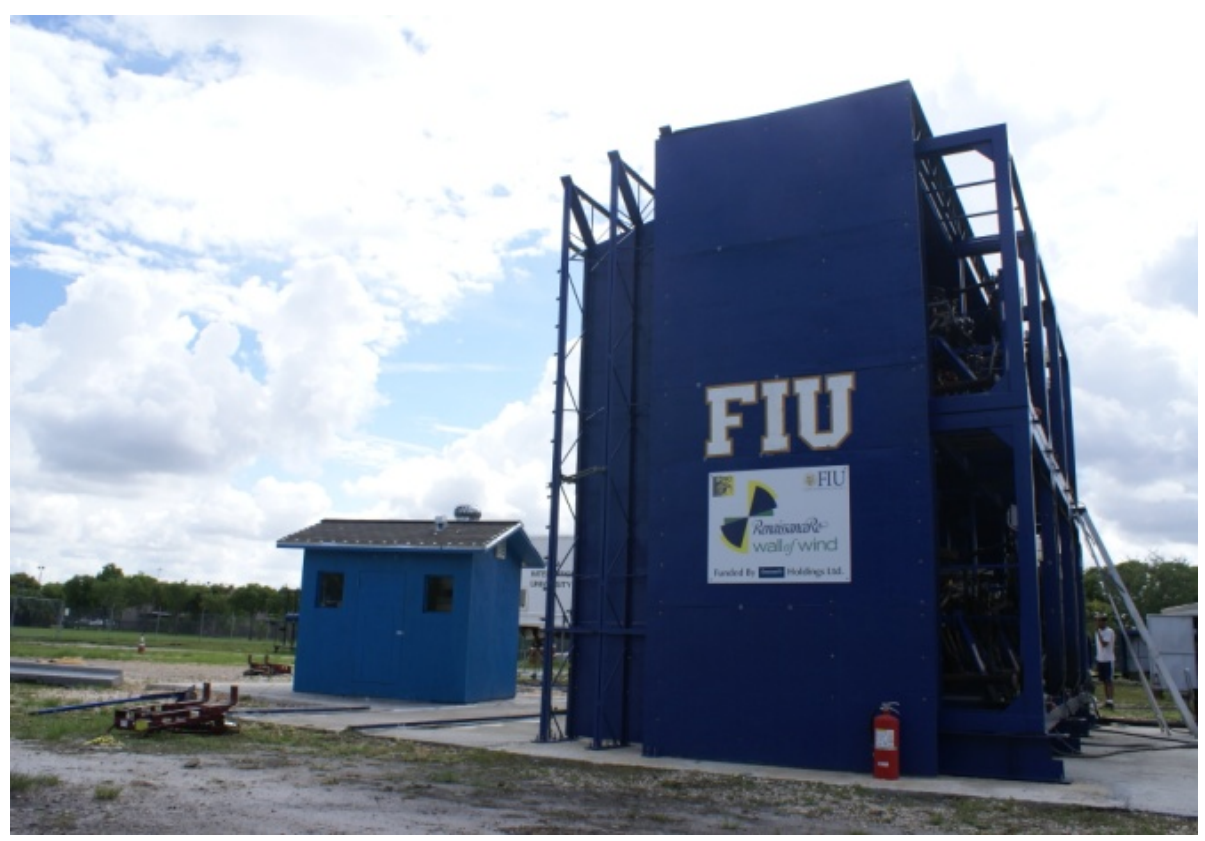

Figure 5. Six-Fan Wall-of-Wind Side View

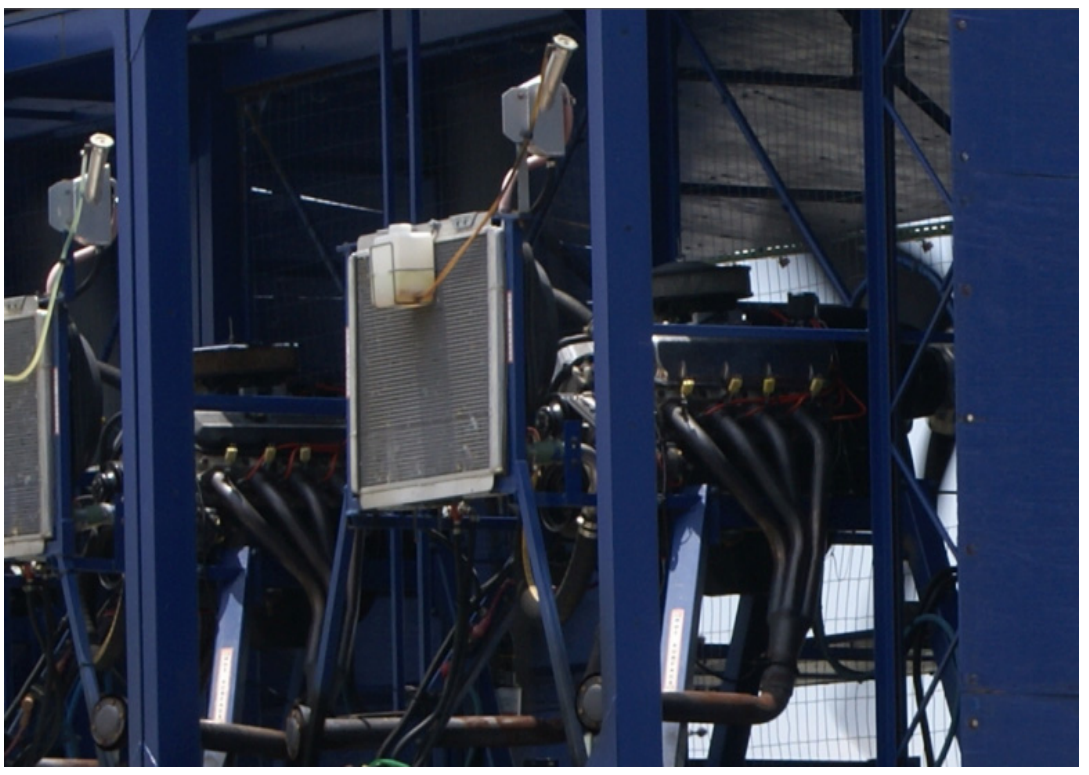

Figure 6. Chevrolet 502 big block crate engines 


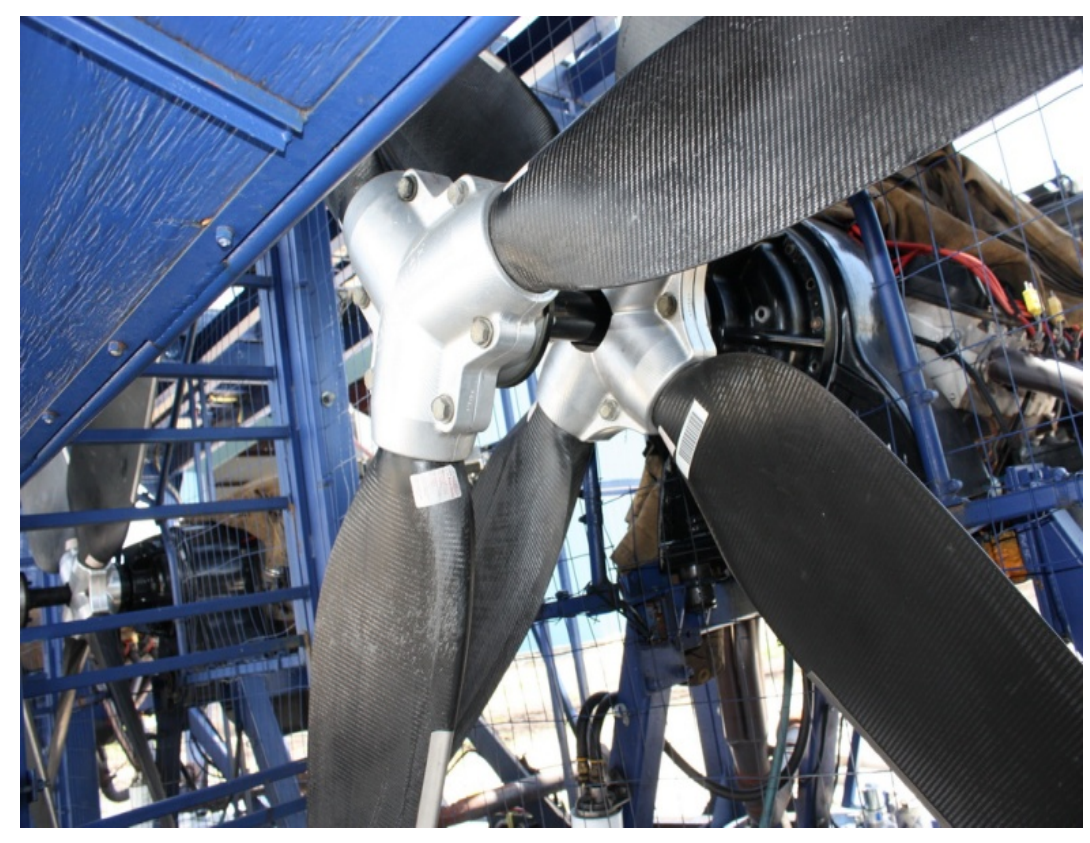

(a)

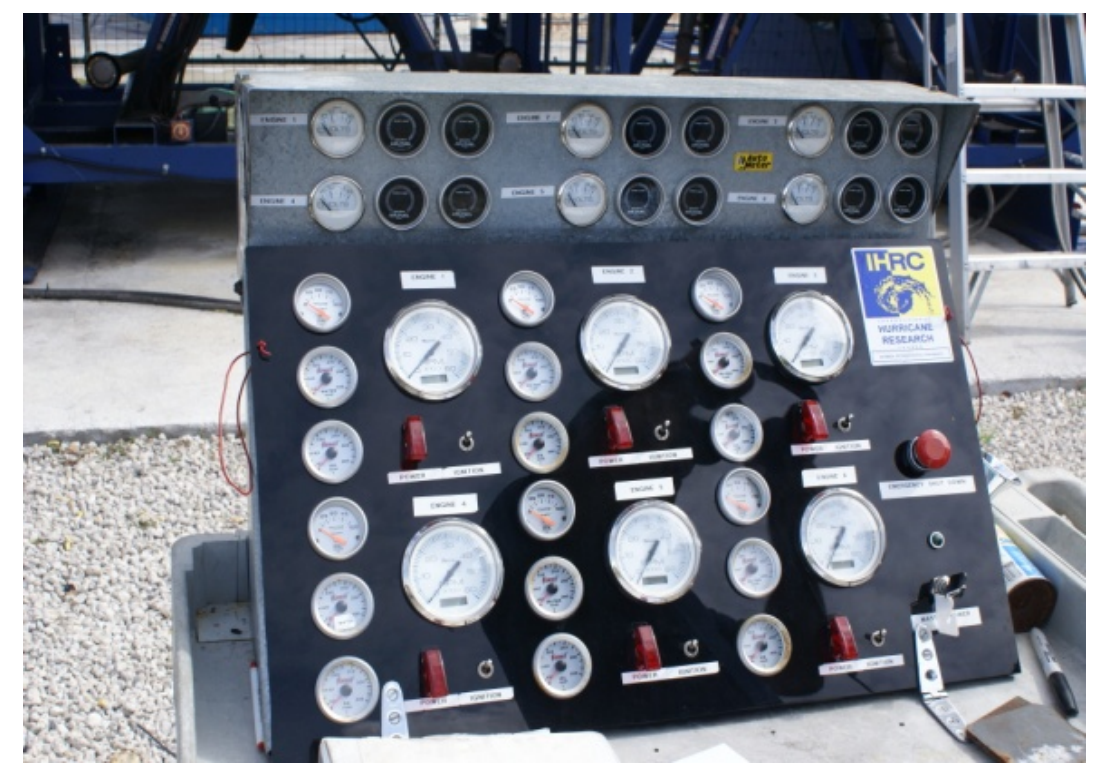

(b) 


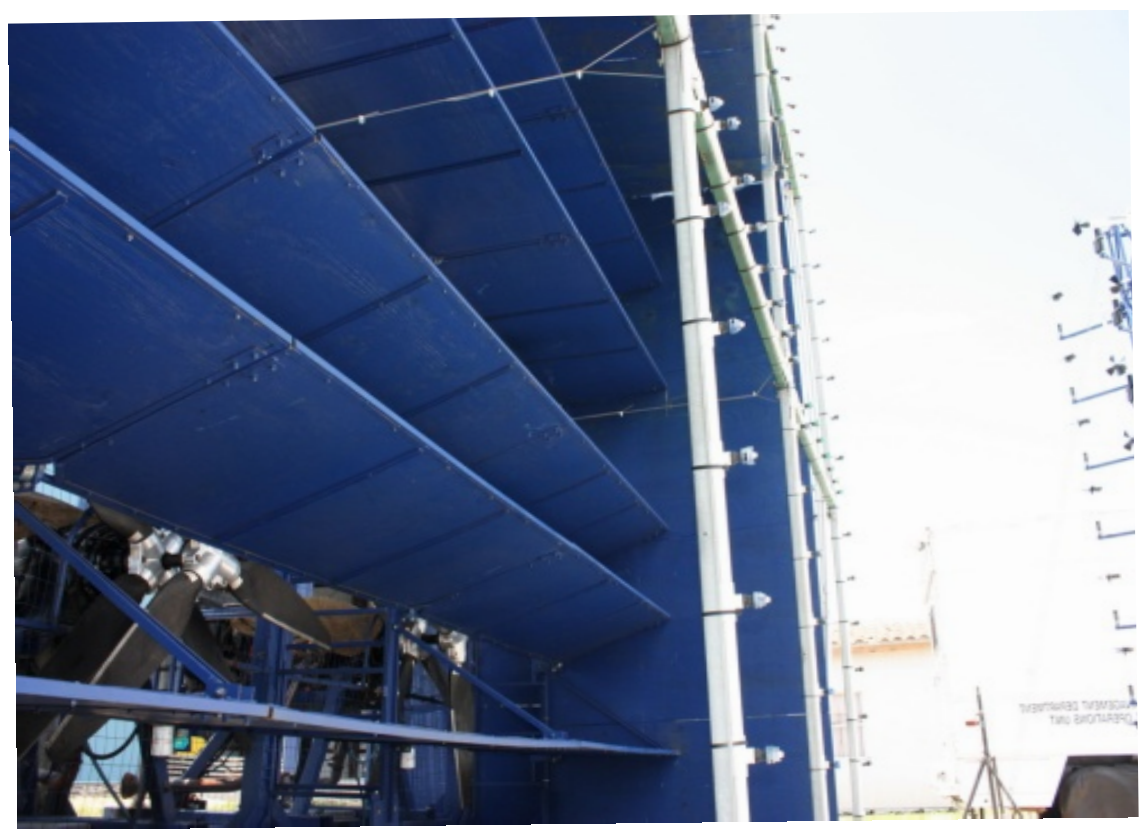

(c)

Figure 7. (a) Setup of fans and blades,

(b) Control System for the fans and

(c) Planks Setup

\subsection{WoW flow management techniques}

\section{Passive Controls:}

Passive controls include (1) a contraction all around the 6-fan system used to point the generated wind towards the test model (Figure $4 \& 5$ ); (2) an outer frame installed outside the 6-fan WoW model acting more like a bell-mouth; (3) raising the fullscale six fans by $0.41 \mathrm{~m}$ (16 in) above the ground to create a wind speed gradient at the bottom, thus simulating an ABL-like flow; and (4) installing five horizontal planks with different inclinations to increase the wind speed with increasing height and generate an 
ABL-like flow. The three bottom horizontal planks were used to redirect the flow from the bottom fans to the top fans. To optimize the locations and inclinations of the planks, series of experiments were carried out. The optimal configuration was determined with the planks located at the heights of $40 \mathrm{in}, 70 \mathrm{in}$, and 94 in $(1.016 \mathrm{~m}, 1.768 \mathrm{~m}$ and 2.376 m) with the inclinations of $-0.5^{0}$ (pointing down), $17^{0}$ (pointing up), and $17^{0}$ (pointing up), respectively. Two additional planks were installed in the upper area to improve the flow. A series of combinations of plank locations and angles were tried to produce the targeted ABL-flow (Huang et al., 2008). The configuration with five planks (i.e.; $-0.5^{0}$, $17^{0}, 17^{0}, 0^{0}$ and $0^{0}$ inclination with centers at $\mathrm{z}=40,70,94,137,168 \mathrm{in}$, respectively) generated the target ABL profile and hence was adopted (Huang et al., 2009).

\section{Active Controls:}

To further enhance the turbulence generation and gust effects for the WoW, rapid variation of the fan engine speed was achieved by servo-control through multiple sinusoidal control functions by adding low frequency fluctuations. Combinations of lowfrequency quasi-periodic waveform signals were designed based on real tropical storm data taken from the Florida Costal Monitoring Program (FCMP), and were used to control the rotational speed of the fans. These active controls helped to improve the turbulence intensities (TI) as well as the power spectral densities (PSD) and the gust factors (GF). Wind flow characteristics generated by a combination of the passive and active controls that are used in the present study are shown in Figure 8 (Huang et al., 2009). 


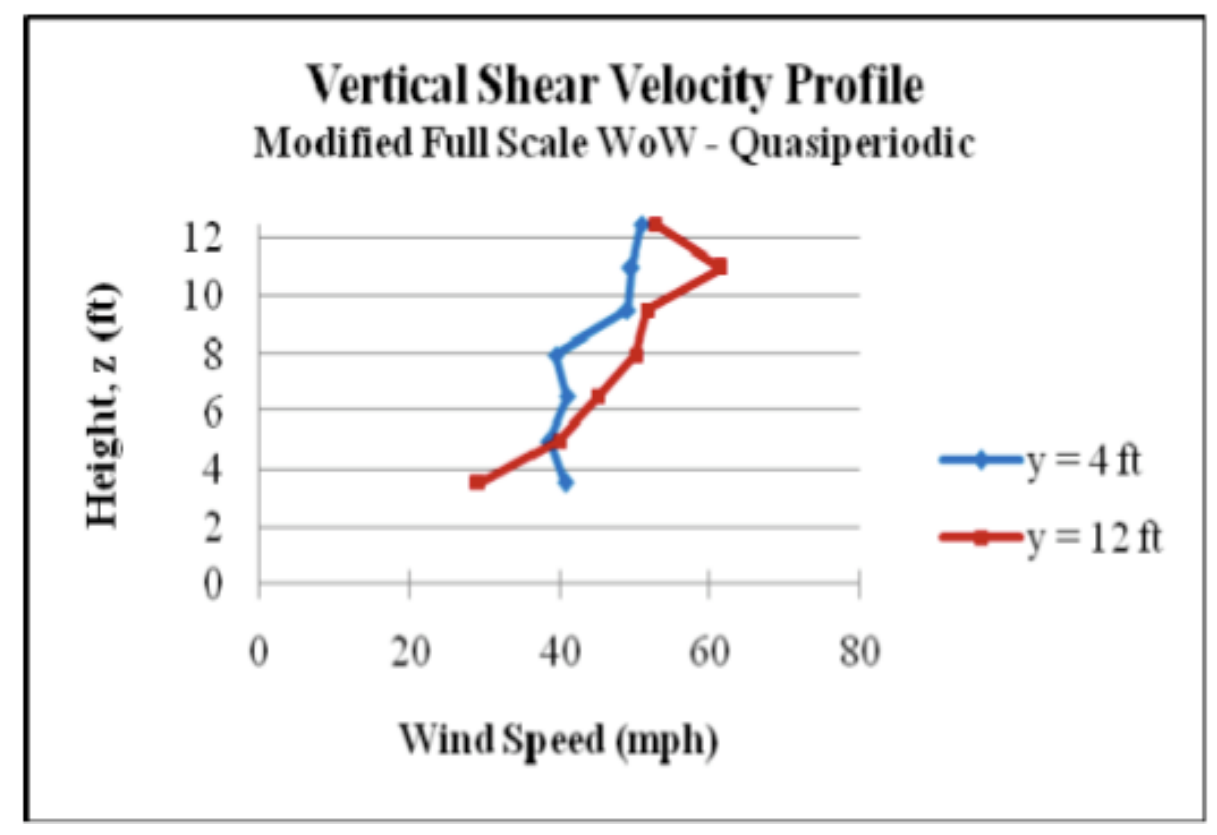

(a)

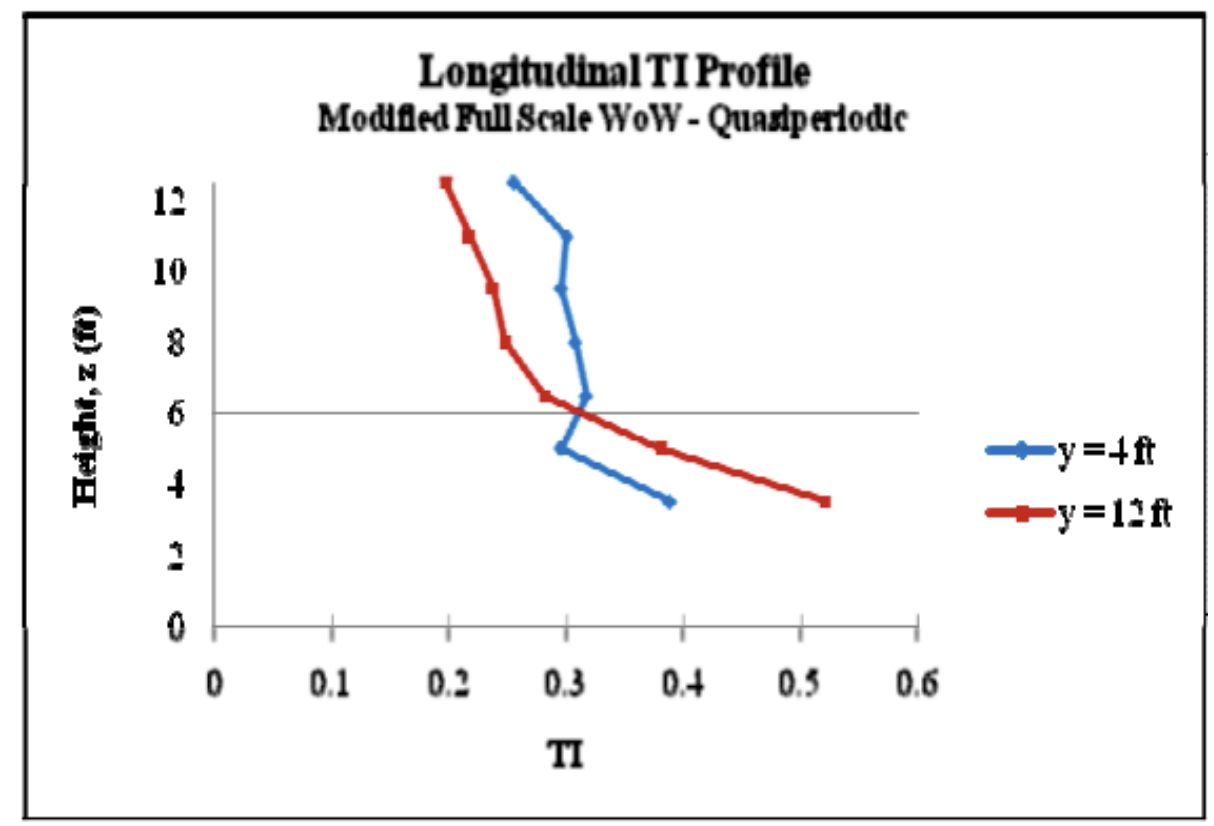

(b) 


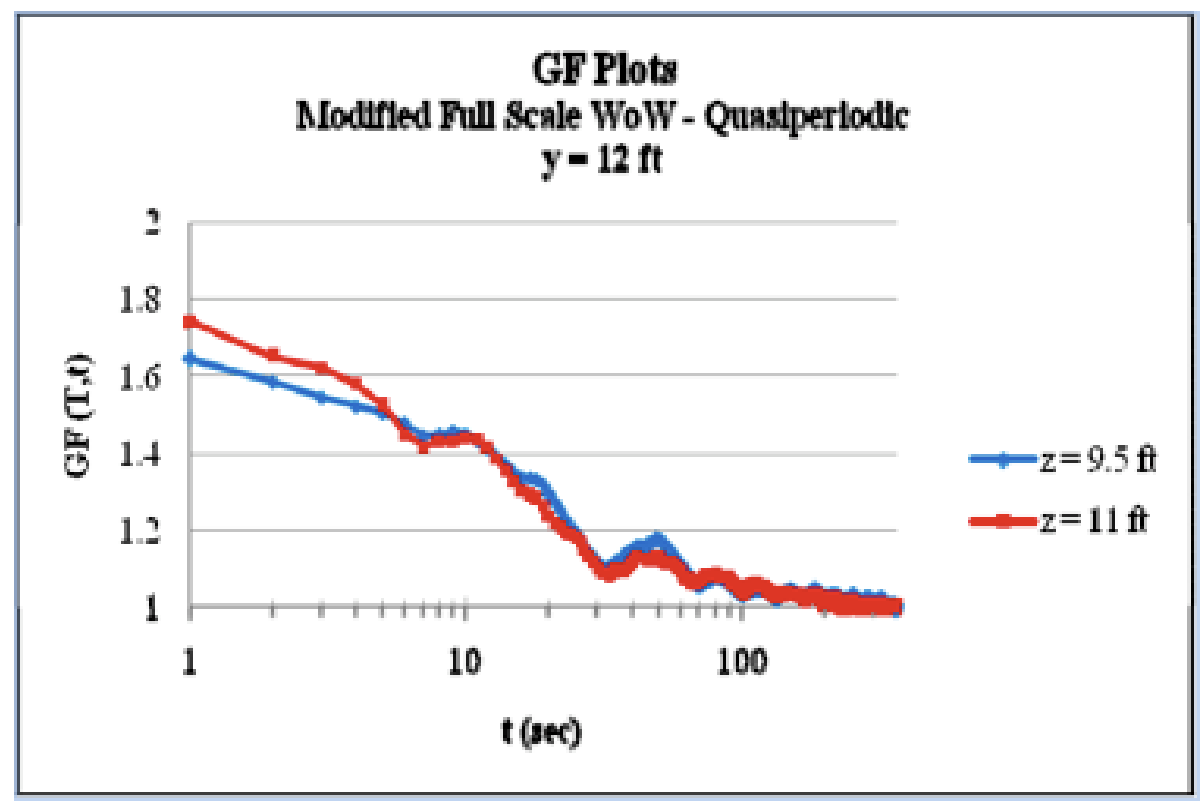

(c)

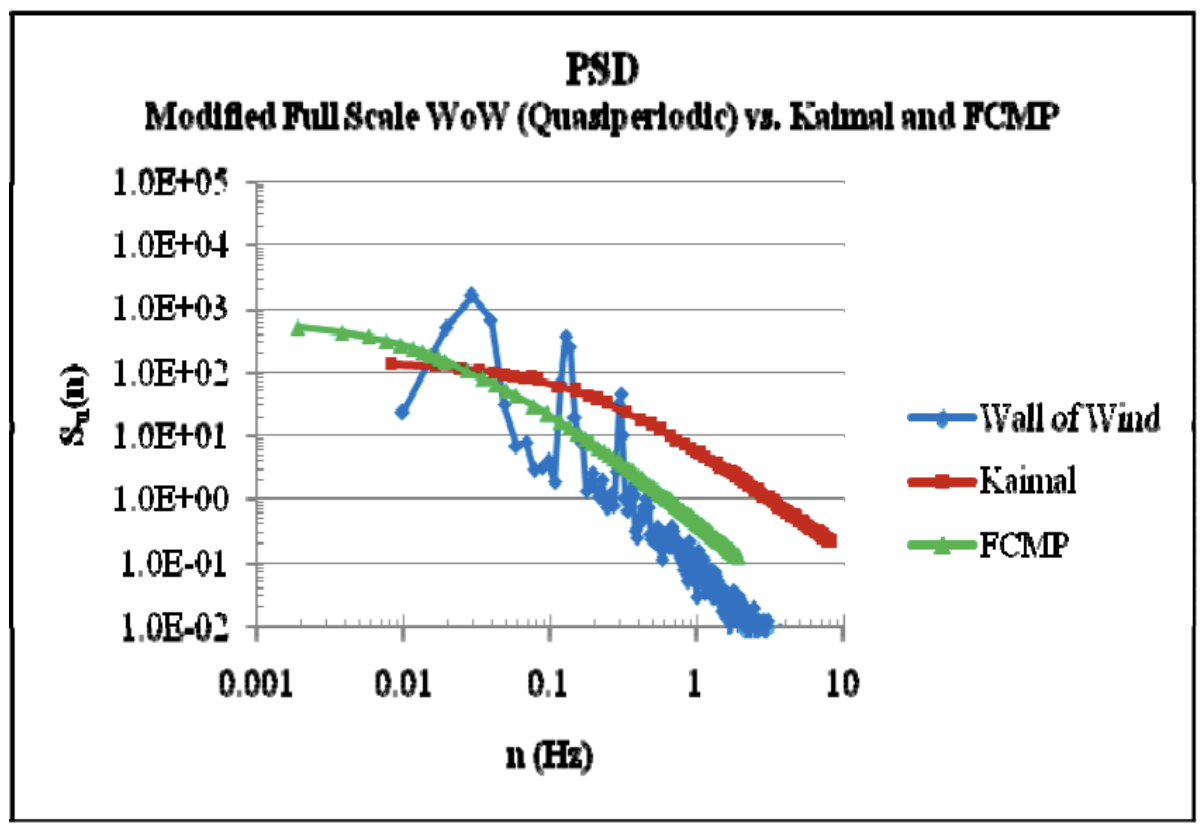

(d)

Figure 8. (a) WoW Vertical shear velocity profile

(b) WoW Turbulence intensity profiles for the longitudinal direction of wind

(c) Gust factors at height $=9.5 \mathrm{ft}$ and $\mathrm{z}=11 \mathrm{ft}$

(d) WoW power spectral density Vs. the Kaimal and FCMP Curves 


\subsection{Water Injection System}

A steel frame was fabricated and installed in front of the 6-fan units. A grid of four columns and three rows of Tee Jet spray nozzles, joined together with high pressure hosing, were mounted vertically to this frame. Figure 9 a, b \& c shows the steel frame system and its details. The spray nozzles on each line were spaced 18 inches apart. In this system, two different types of spray nozzles are used: (i) on inner lines, 8005VX nozzles release 0.5 gallons of water per minute $(0.5 \mathrm{gal} / \mathrm{min})$ at $40 \mathrm{Psi}$, (ii) on outer lines, 8003VX nozzles that release 0.3 gallons of water per minute $(0.3 \mathrm{gal} / \mathrm{min})$ at 40 Psi. A gasoline powered pump (Figure 10) effectively works to overcome the head and preserve the water pressure in the spray injection nozzles located on the upper rows. Water meters are used (Figure 11) to calibrate water rate to generate a specific water rate. Water for the injection system is stored in a 550-gallon agricultural grade horizontal leg tank (Figure 12). The pressurized pump feeds the grid and spray nozzles, spraying the water at specified rate, while the fans blow the wind simultaneously (Bitsuamlak et al., 2009).

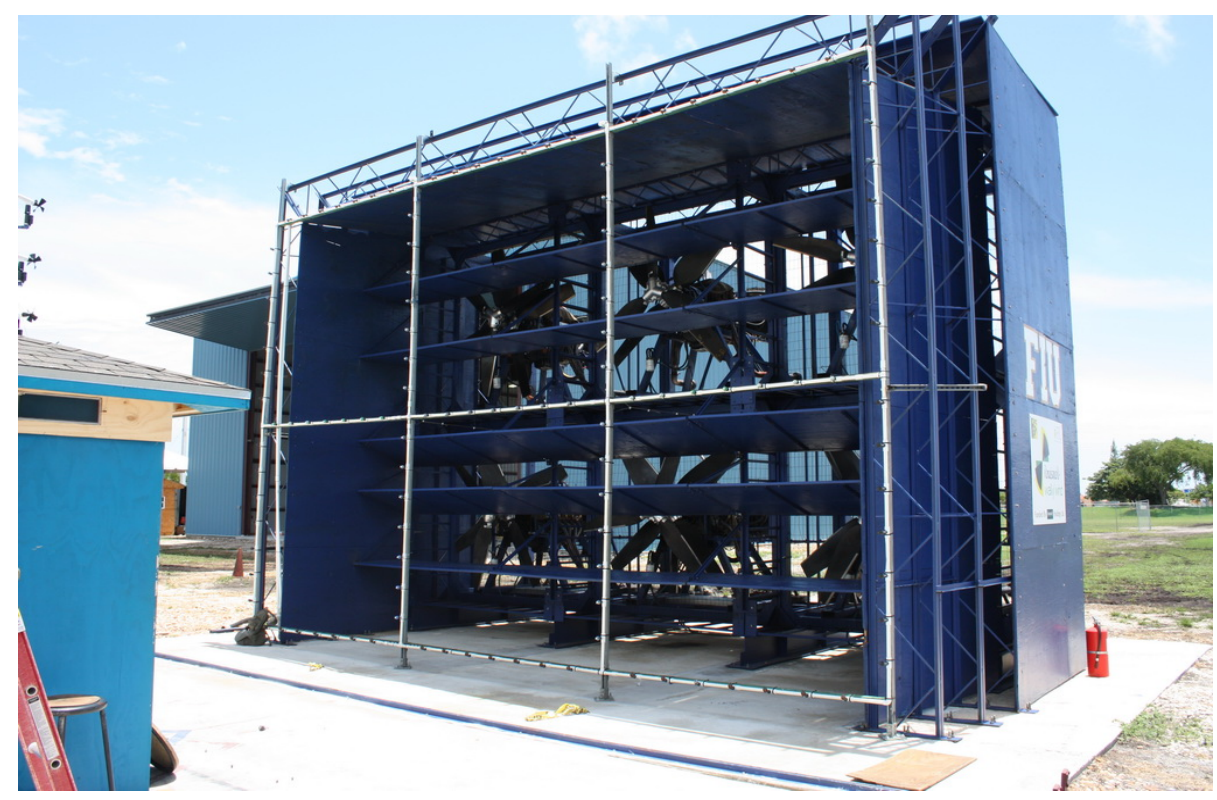

(a) 


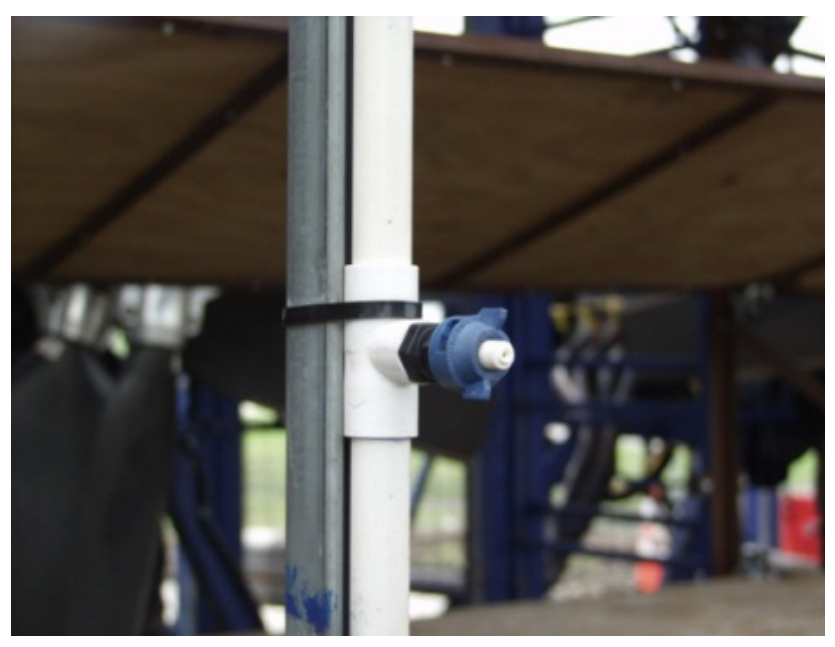

(b)

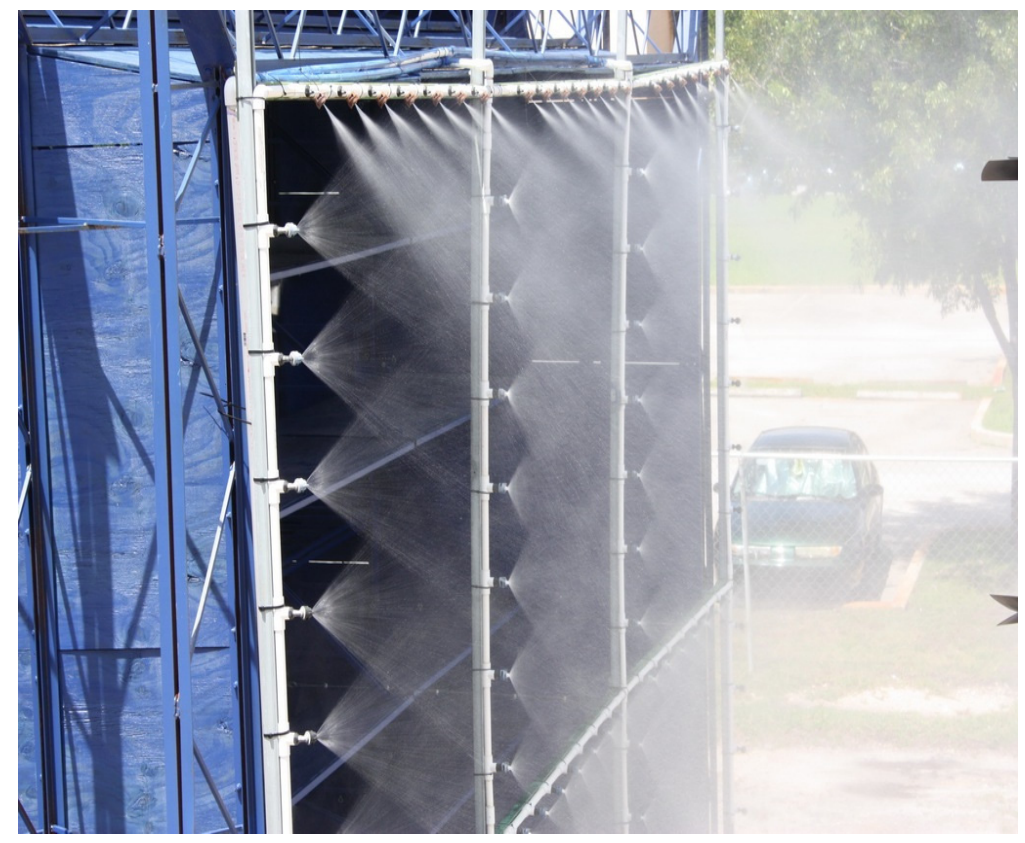

(c)

Figure 9. (a) WoW, Steel framing and setup

(b) Spray nozzles used for water injection system

(c) Water spray from the nozzles 


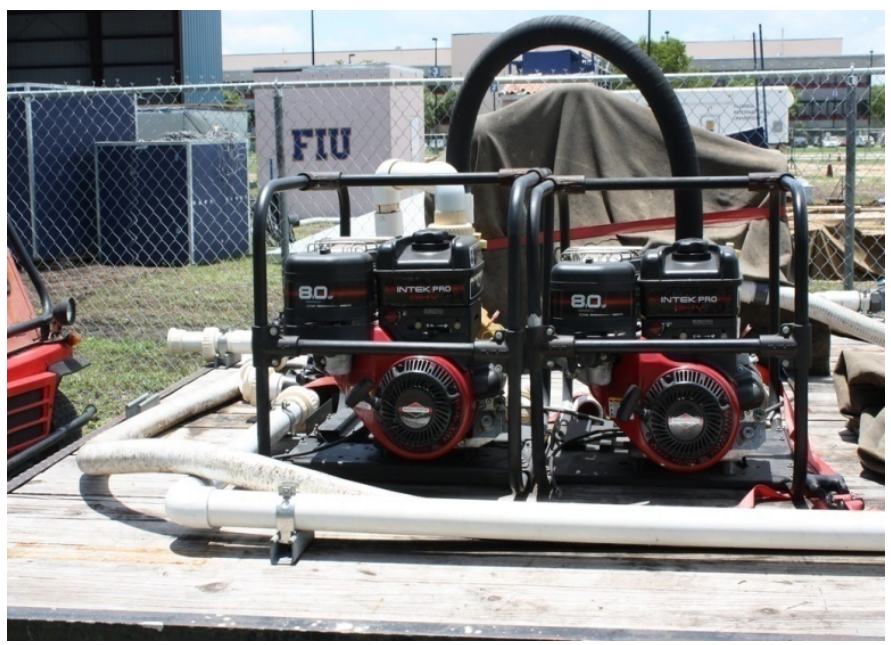

Figure 10. Gasoline powered pump
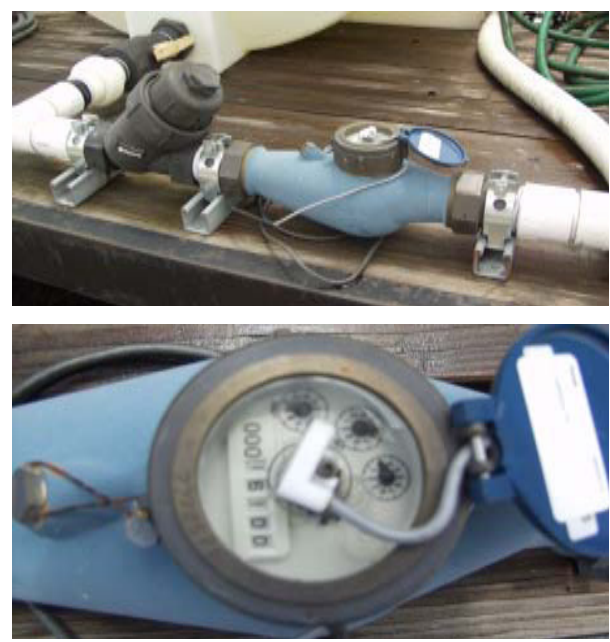

Figure11. Water meter
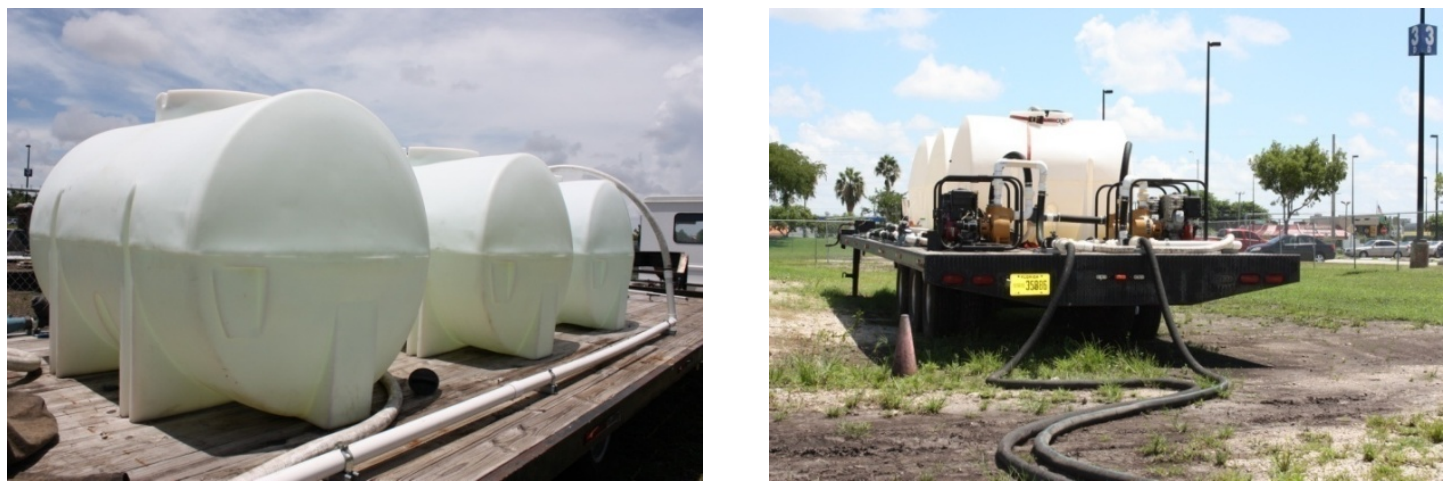

Figure 12. 550-gallon agricultural grade horizontal leg tank

\section{EXPERIMENTAL APPROACH:}

\subsection{Roof and Wall Vents Setup and Instrumentation}

The experimental setup considered two common roof types mounted atop a $9 \mathrm{ft} \mathrm{x}$

$7 \mathrm{ft} x 7 \mathrm{ft}$ (length $\mathrm{x}$ width $\mathrm{x}$ height) building model. Prior to mounting the roof specimens onto the building model, each roof was prepared with $30 \mathrm{lb}$ felt paper underlayment 
(Figure 13 a \& b), covered with 5-tab architectural shingles, and outfitted with the roof and wall vents of interest. For the scope of this study, a $10 \times 4 \times 8$ inch (length $\mathrm{x}$ width $\mathrm{x}$ height) gooseneck vent, a 12-inch turbine vent, a shingle vent II ridge vent, and $16 \times 6$ inch soffit vents were installed on both the gable and hip roof specimens. Additionally, the gable roof specimen contained a $12 \times 12$ inch rectangular gable end vent. Figure 14 shows the installation of the roof vents on the gable roof and hip roof

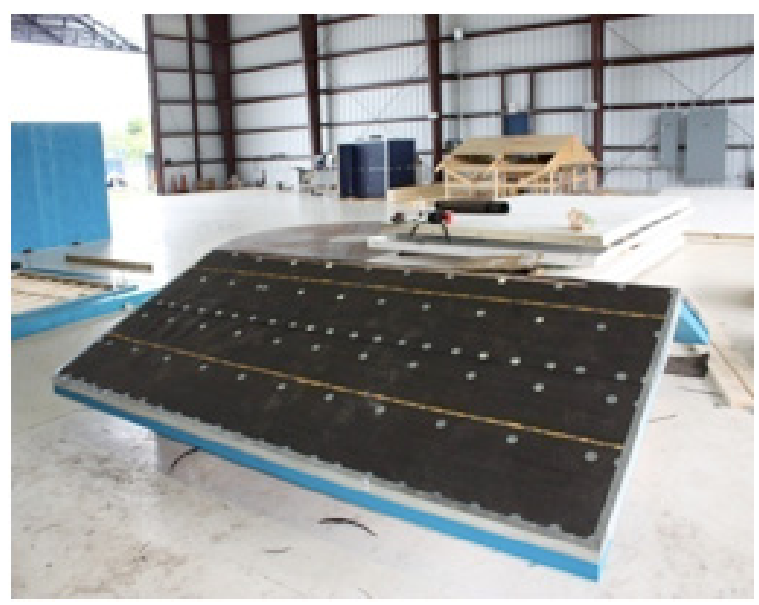

(a)

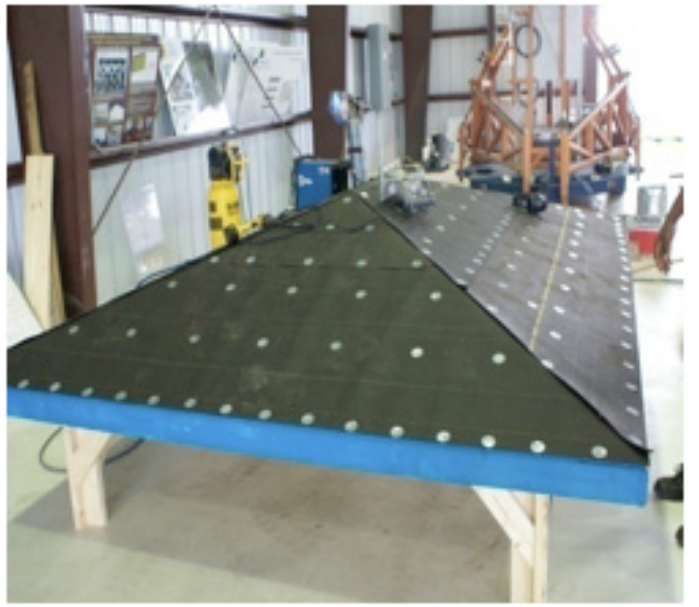

(b)

Figure13. (a) Gable roof prepared with $30 \mathrm{lb}$ felt paper underlayment (b) Hip roof prepared with $30 \mathrm{lb}$ felt paper underlayment

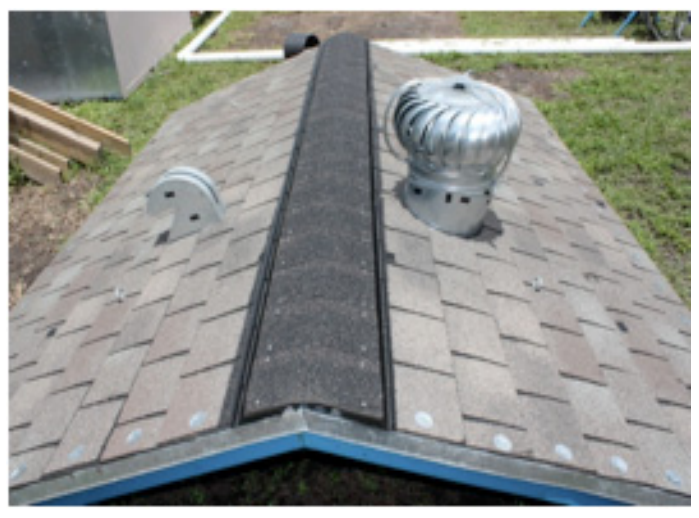

(a)

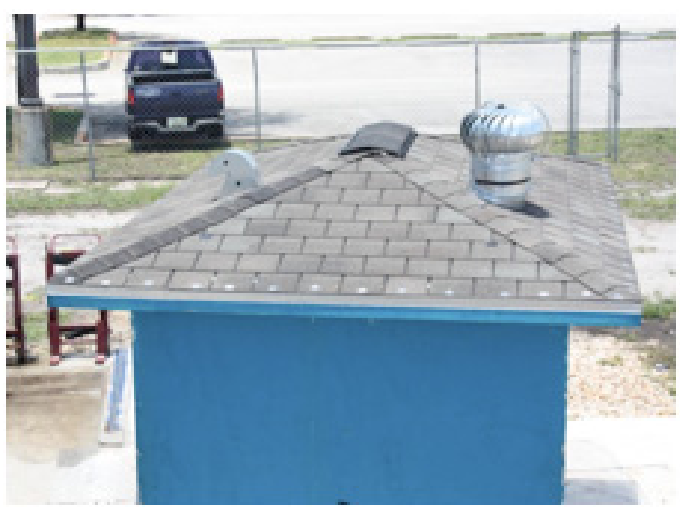

(b)

Figure14. (a) Turbine, gooseneck \& ridge vent installed on the gable roof specimens (b) Turbine, gooseneck \& ridge vent installed on the hip roof specimens 


\subsubsection{Pressure Testing:}

A 16-channel Scanivalve Digital Sensor Array DSA 3217/16PX measured the pressure time histories along the turbine and gooseneck vents according to the tap layout. The Scanivalve device was installed within the attic space of the roof specimens. The pressure taps on the turbine and gooseneck vents were created by gluing small square tabs made of wood or hard plastic onto the inside of the vents at every pressure tap location. Next, a 5/64 inch diameter hole was drilled out at each tap location, and a piece of 5/64 inch outside diameter (O.D.) tubing was glued into each tap. The tubing length between the pressure taps and the Scanivalve was no longer than three feet to minimize signal distortion developed by the tubing. Pressure taps were also installed to measure the external and internal pressure differential across the ridge vent, gable end vent, and soffit vents (Bitsuamlak and Tecle, 2009). Wind attack angle and the locations of the pressure taps on turbine and gooseneck vent are shown in Figures 15 and 16. Figure 17 a to g, shows other details related to the different vents and pressure measurement instrumentation. For the pressure taps installed near the soffit and gable end vents, 5/16 inch O.D. copper taps were installed. Setra 265 differential pressure transducers measured the pressure time histories at these locations. Reference pressure tubing for these transducers was installed in the manner described at length in Blessing (2007). The Setra 265 pressure transducers were connected to an NI 9074 cRIO module, with NI 9205 32-channel analog voltage inputs. Figure 18 shows the NI 9074 cRIO (Compact RIO). NI Lab View software was used to collect and record the data. All measurements were sampled at a rate of $100 \mathrm{~Hz}$ during the experiments. 


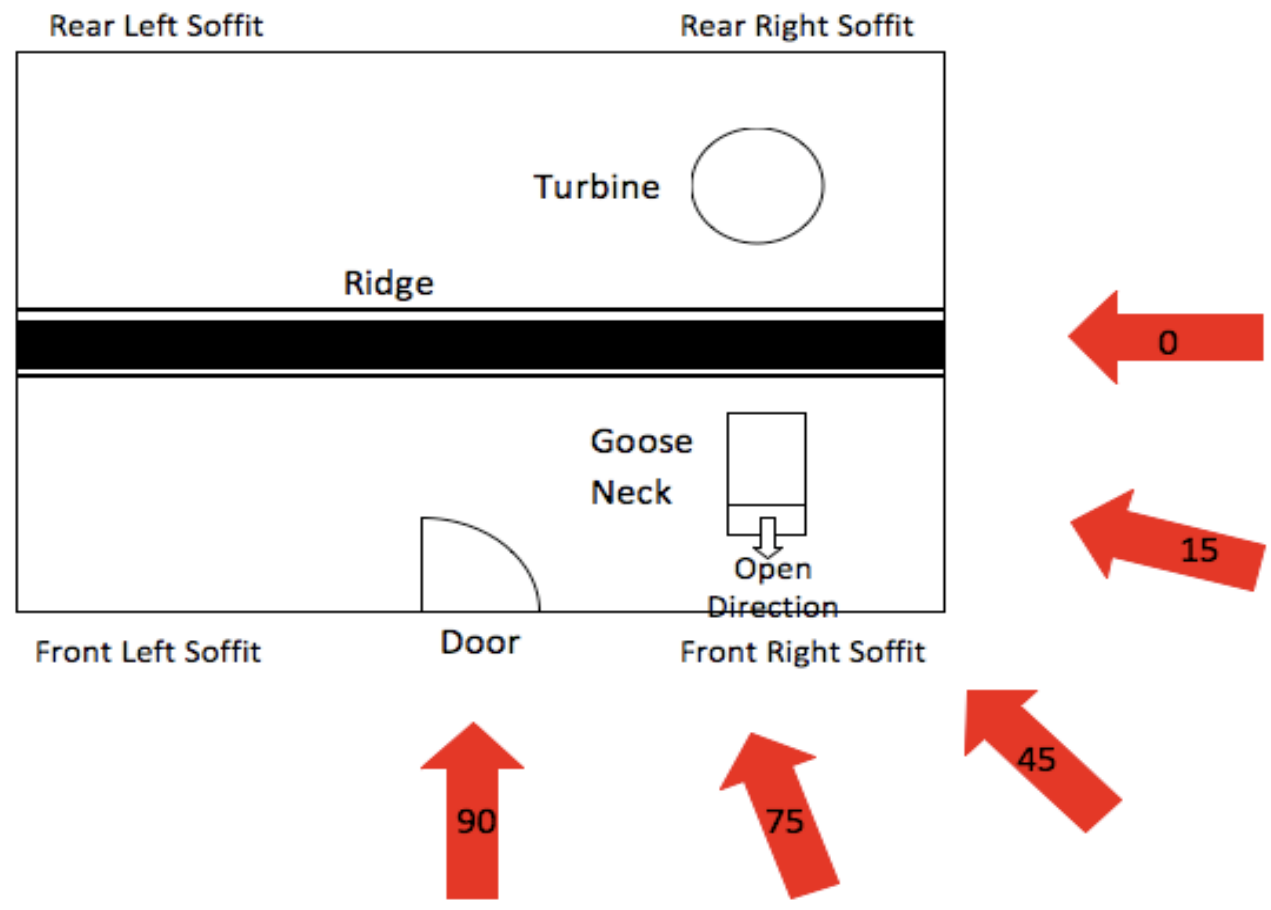

Figure 15. Wind angle of attack and turbine/goose neck vents locations

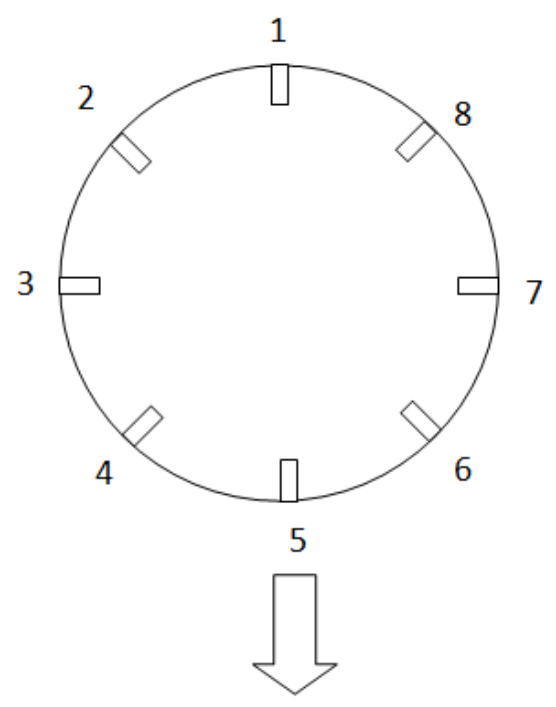

Door Direction

(a) 
Goose Neck Side View

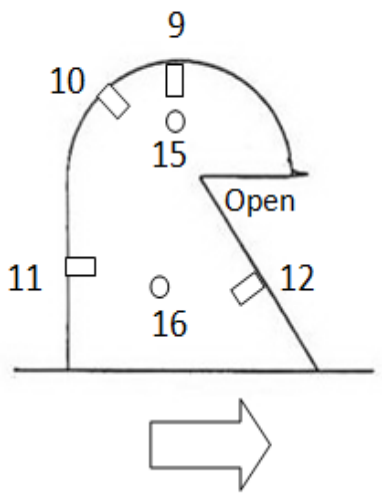

Door Direction
Goose Neck Front View

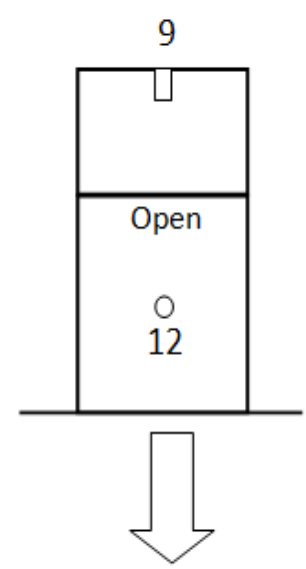

Door Direction
Goose Neck Side View

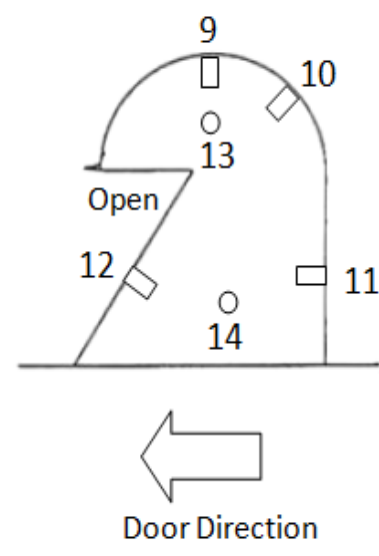

(b)

Figure 16. Pressure Tab Locations on (a) Turbine and (b) Goose Neck Vents

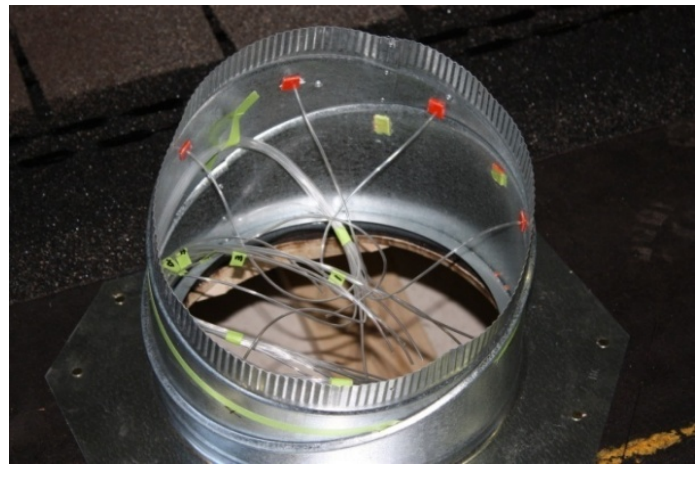

(a)

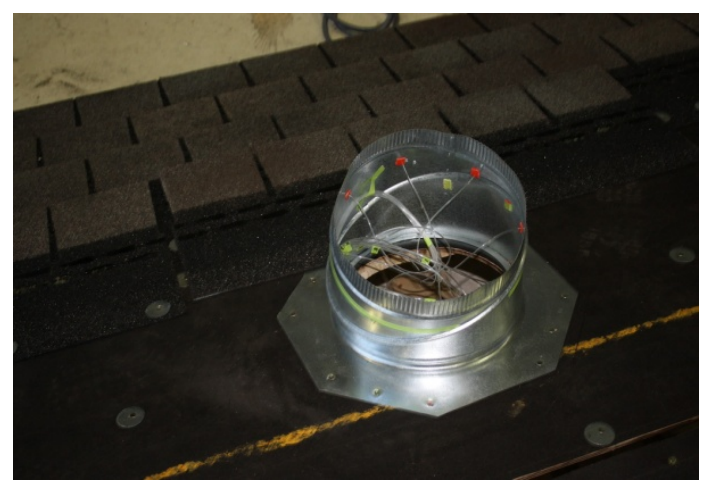

(c)

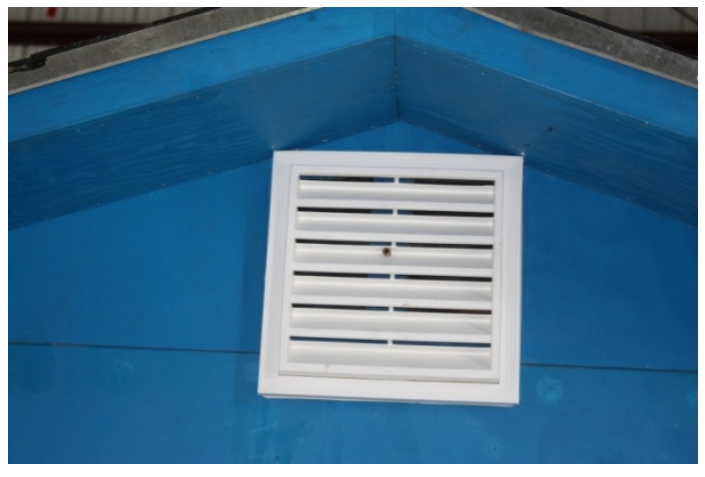

(b)

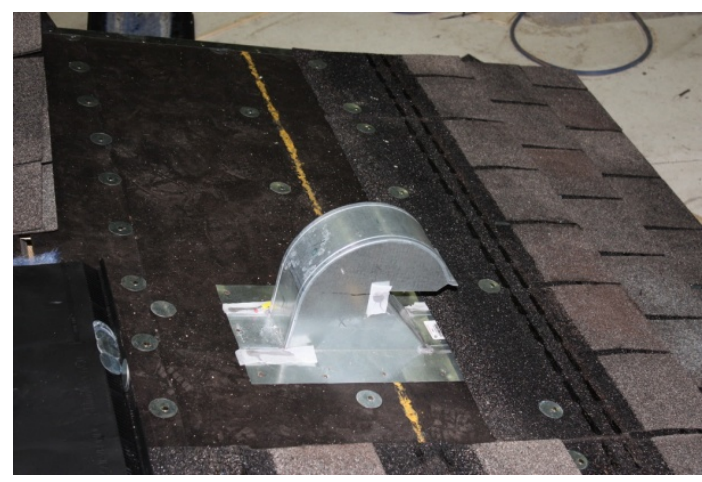

(d) 


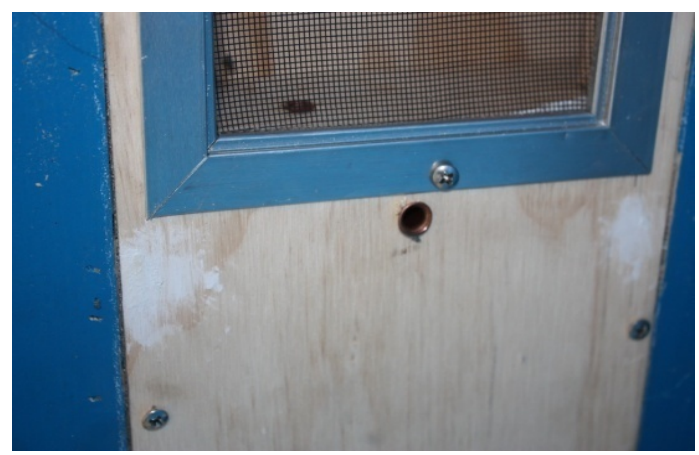

(e)

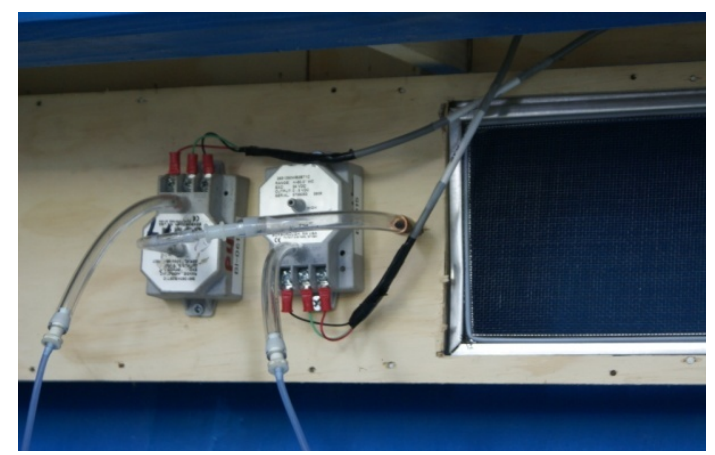

(f)

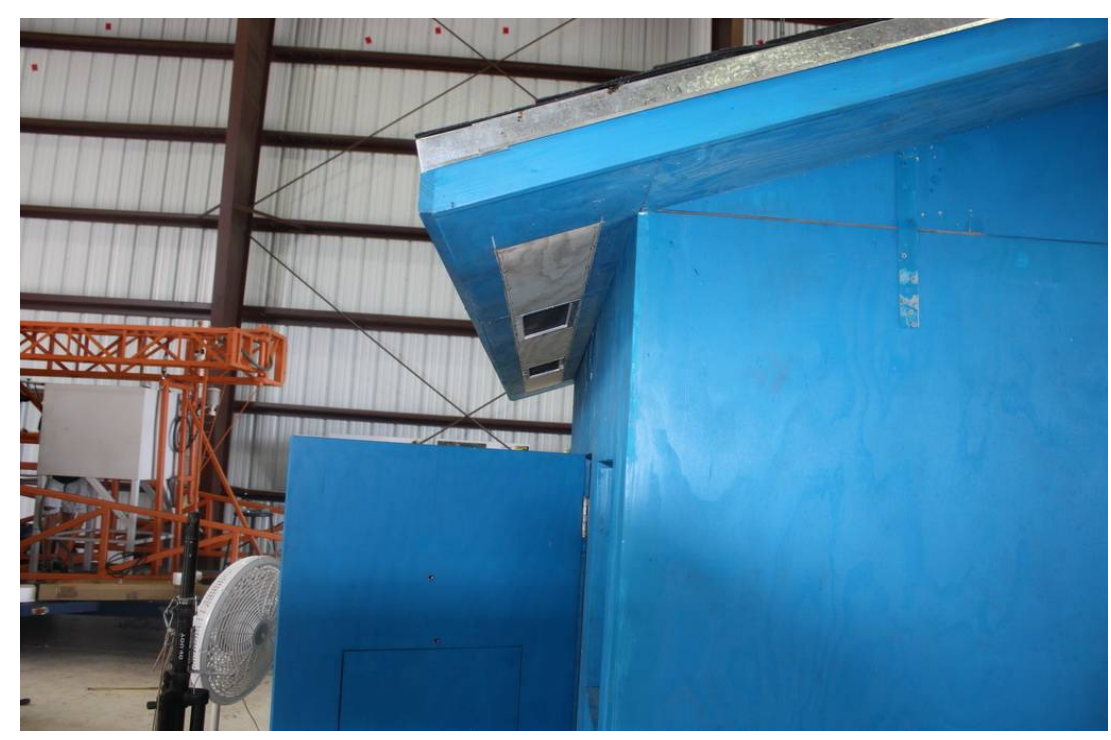

(g)

Figure 17. (a) Pressure tubing installed within the turbine vent base

(b) Pressure tap installed on gable vent

(c) Turbine vent setup on the roof specimen

(d) Goose neck vent setup on the roof specimen

(e) Pressure tab installation on soffit vent

(f) Transducer installation on soffit vent

(g) Soffit vent installed on a gable roof specimen 


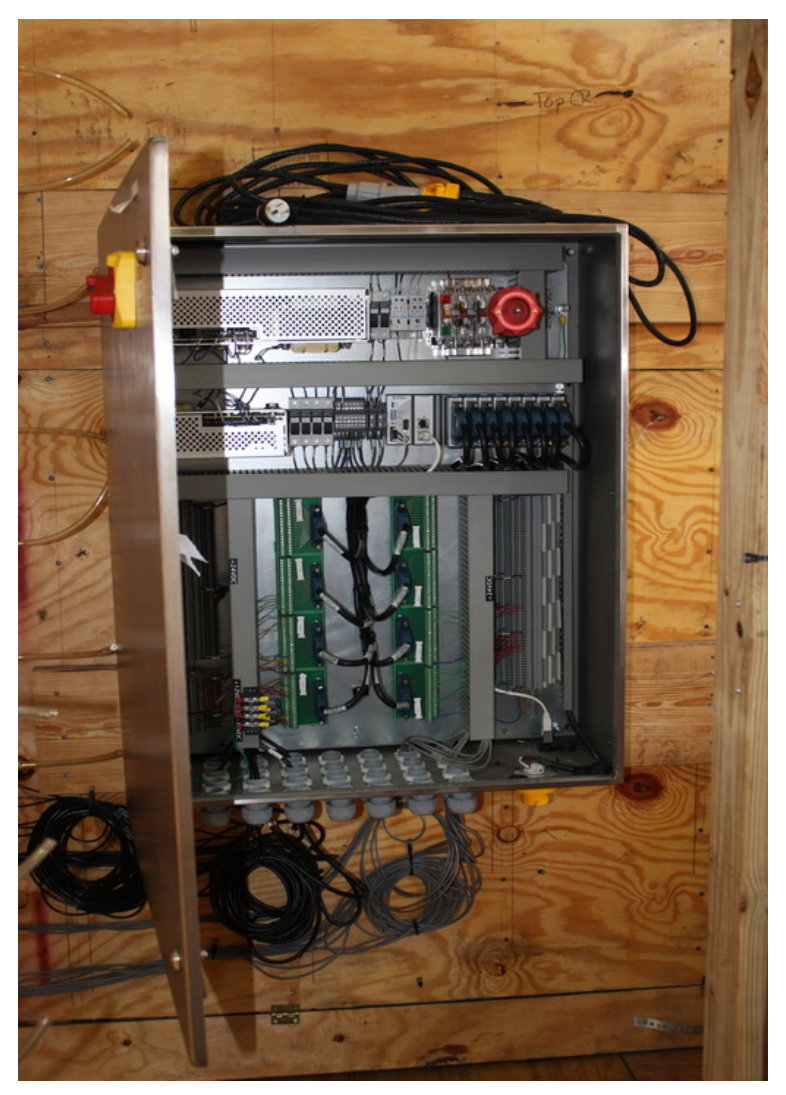

Figure 18. NI 9074 cRIO (Compact RIO)

\subsubsection{Water Intrusion Testing:}

Water intrusion tests were performed on the gable roof to quantify the volume of water entering the attic space through each of the vents installed on the roof. A piece of plastic sheeting was attached to the perimeter of the gooseneck, turbine, ridge, and gable end vents to contain the water entering the attic space through each vent, and direct the water toward collection buckets for each vent. The plastic sheeting was secured with the vents with aluminum tape, as shown in Figure 19 a to d. For the turbine and gooseneck vents, aluminum pans were placed underneath the plastic sheeting arrangement to collect the incoming water. For the ridge vent, a 4-inch I.D. PVC pipe was cut in half to create a 
trough that would collect the water after intrusion, and direct it into eight measuring buckets. Plastic sheeting was installed between the ridge vent and the PVC trough to ensure no water would bypass the collection system. A similar arrangement was constructed for the soffit vents (Figure 19 e). Air was allowed to exit the collection pans and the collection buckets for each vent, so that the airflow passing through the vents was not hindered by the collection system. Figure 20 shows all the containers used for the experiment.
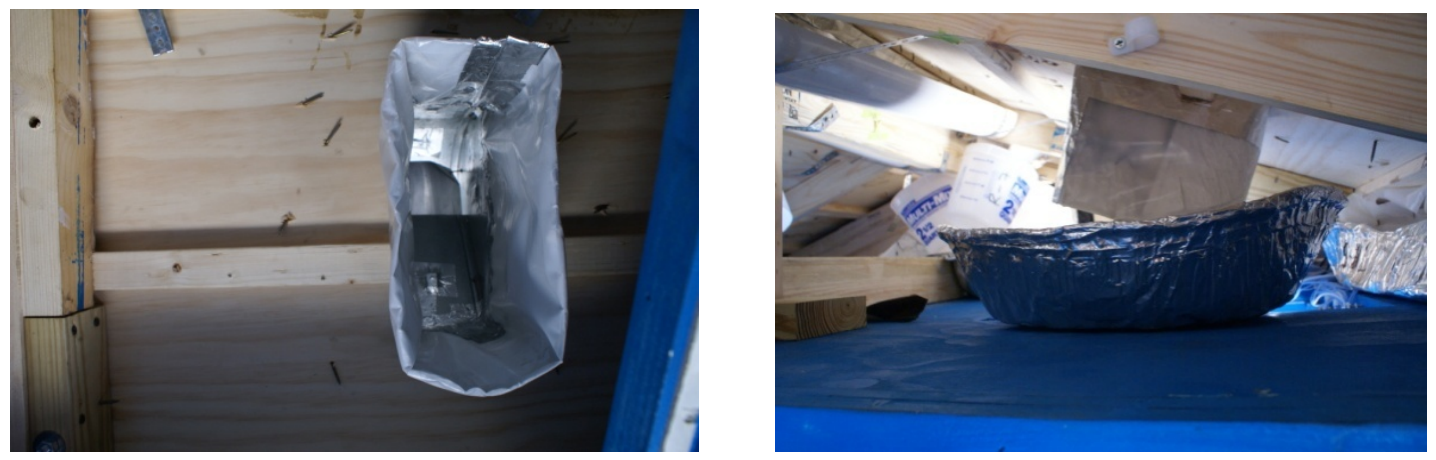

Figure 19 a. Water collection setup for the gooseneck vent
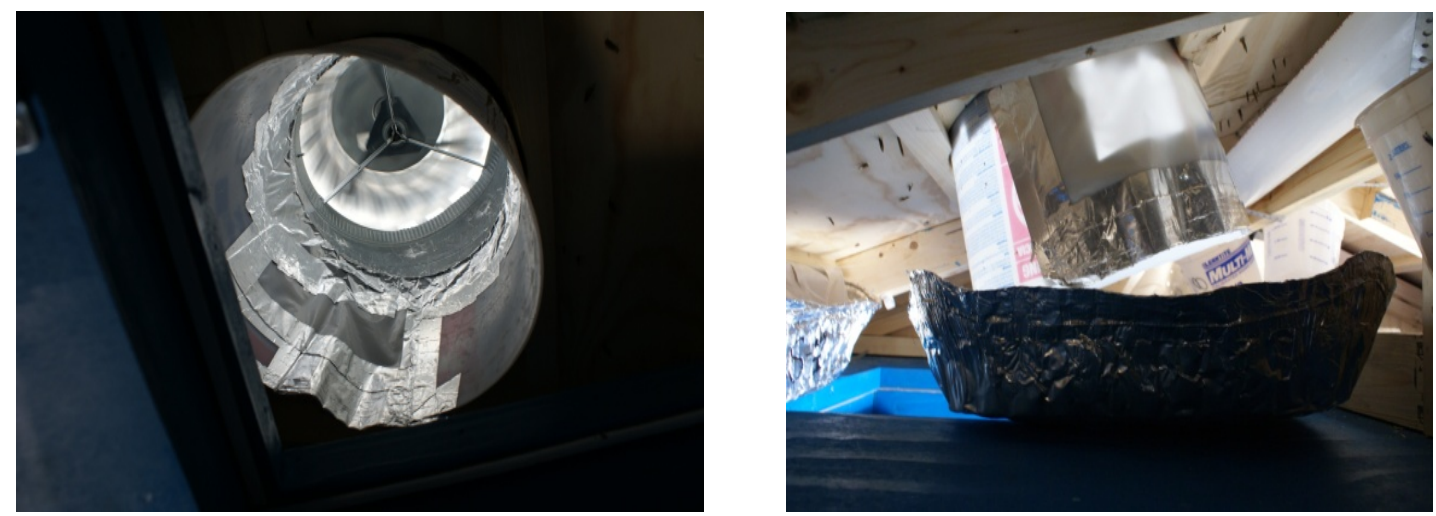

Figure 19 b. Water collection setup for turbine vent 

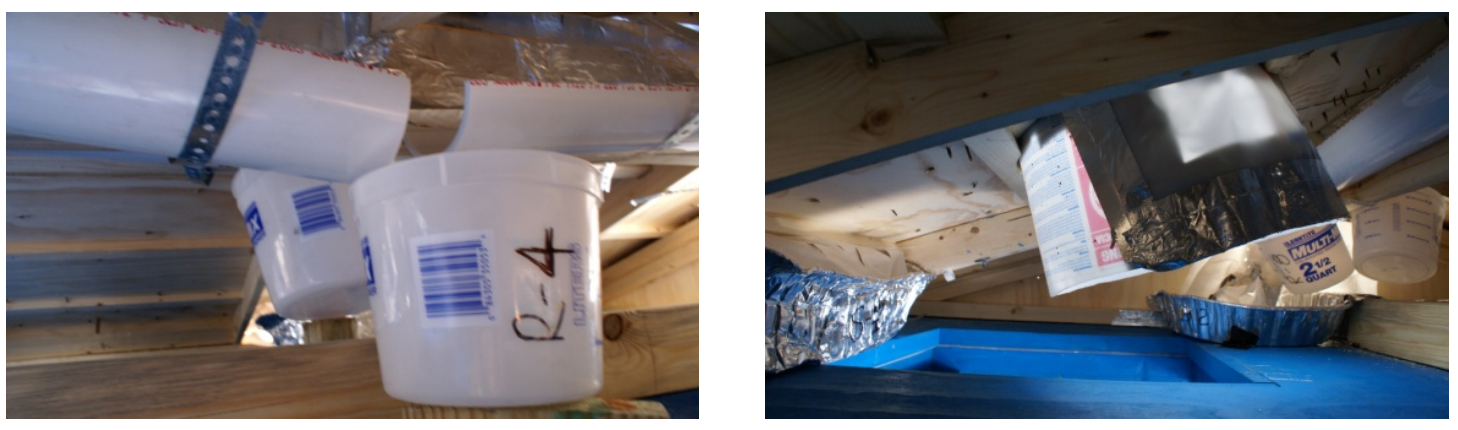

Figure 19 c \& d. Bucket setup for ridge vent and setup for gable end vent

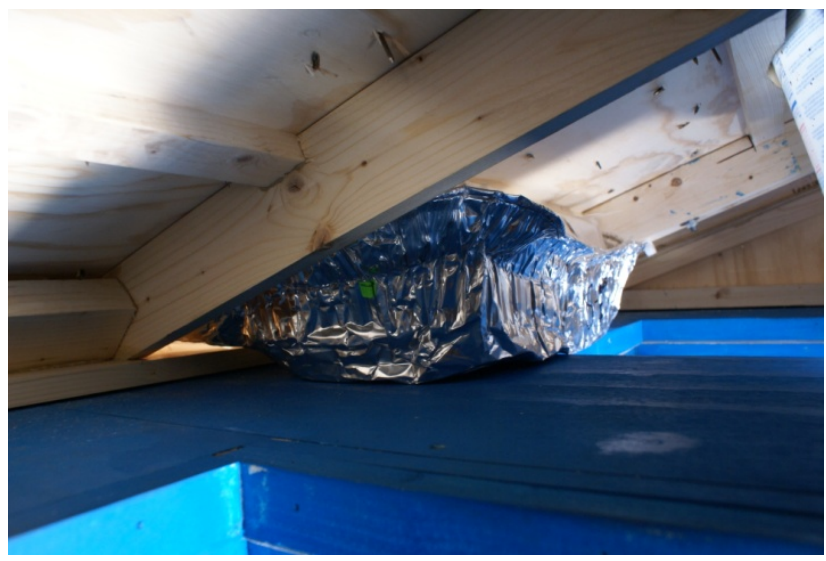

Figure 19 e. Setup for soffit vent.
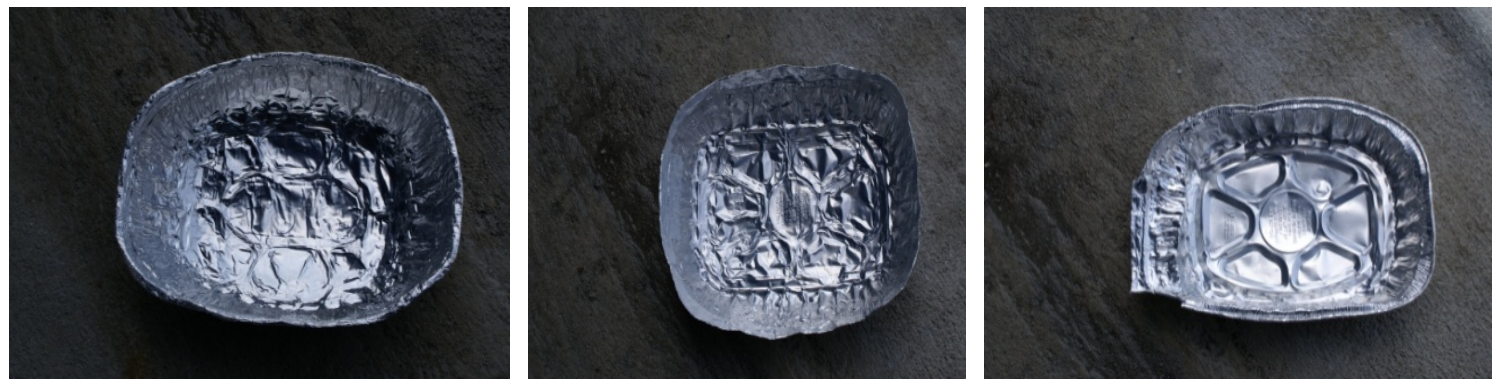

Figure 20. Aluminum pan used for water collection.

\subsection{Experimental Procedure}

\subsubsection{Pressure Testing:}

During this study, the roof vents were tested at five different angles with respect to the WoW flow field (Figure 21):0, 15, 45, 75, and 90 degrees. A 3-minute, 
quasiperiodic waveform was used to generate the wind conditions for each test (refer to Liu, 2008).

Prior to running the experiment at each angle, a 3-min baseline of pressure data was taken. During the quasiperiodic profile, 3 min of data was collected. Following each experiment, a second 3-min baseline was performed. All data were sampled at $100 \mathrm{~Hz}$. Both baseline datasets were used to establish the environmental conditions, and were averaged together and deducted from the actual data collected during the WoW run to determine the wind-induced pressure. Figure 22 a \& b shows the specimen setup for experimenting.

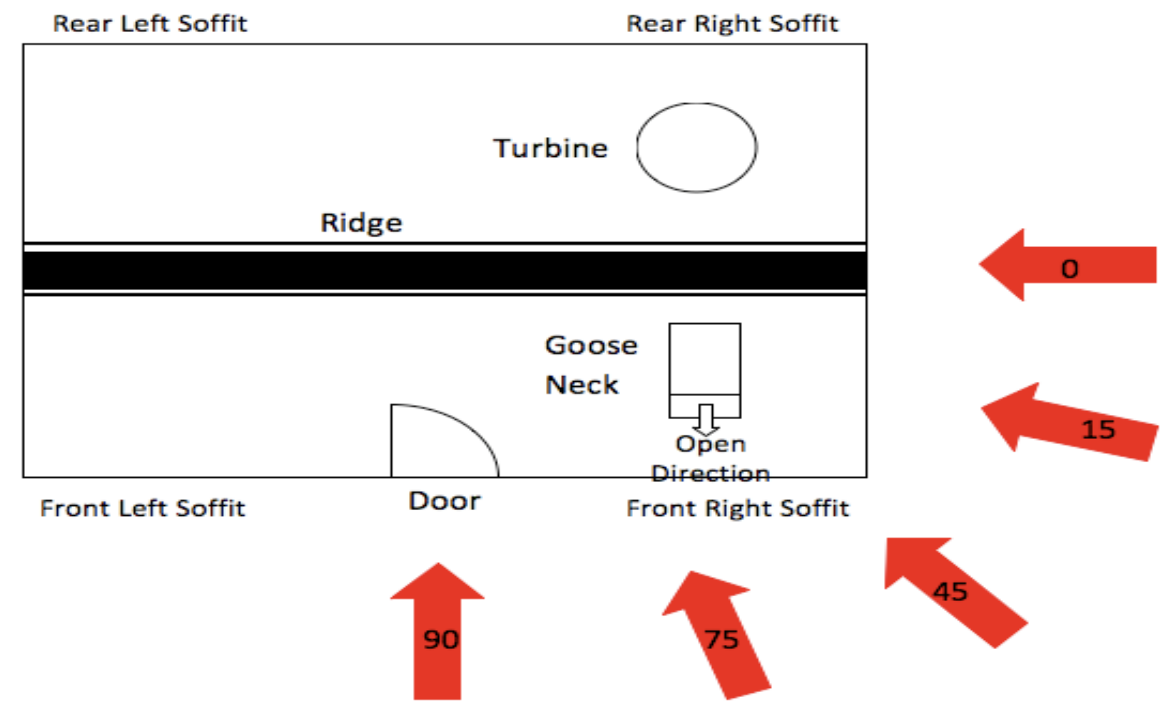

Figure 21. Angles of attack tested during this study 


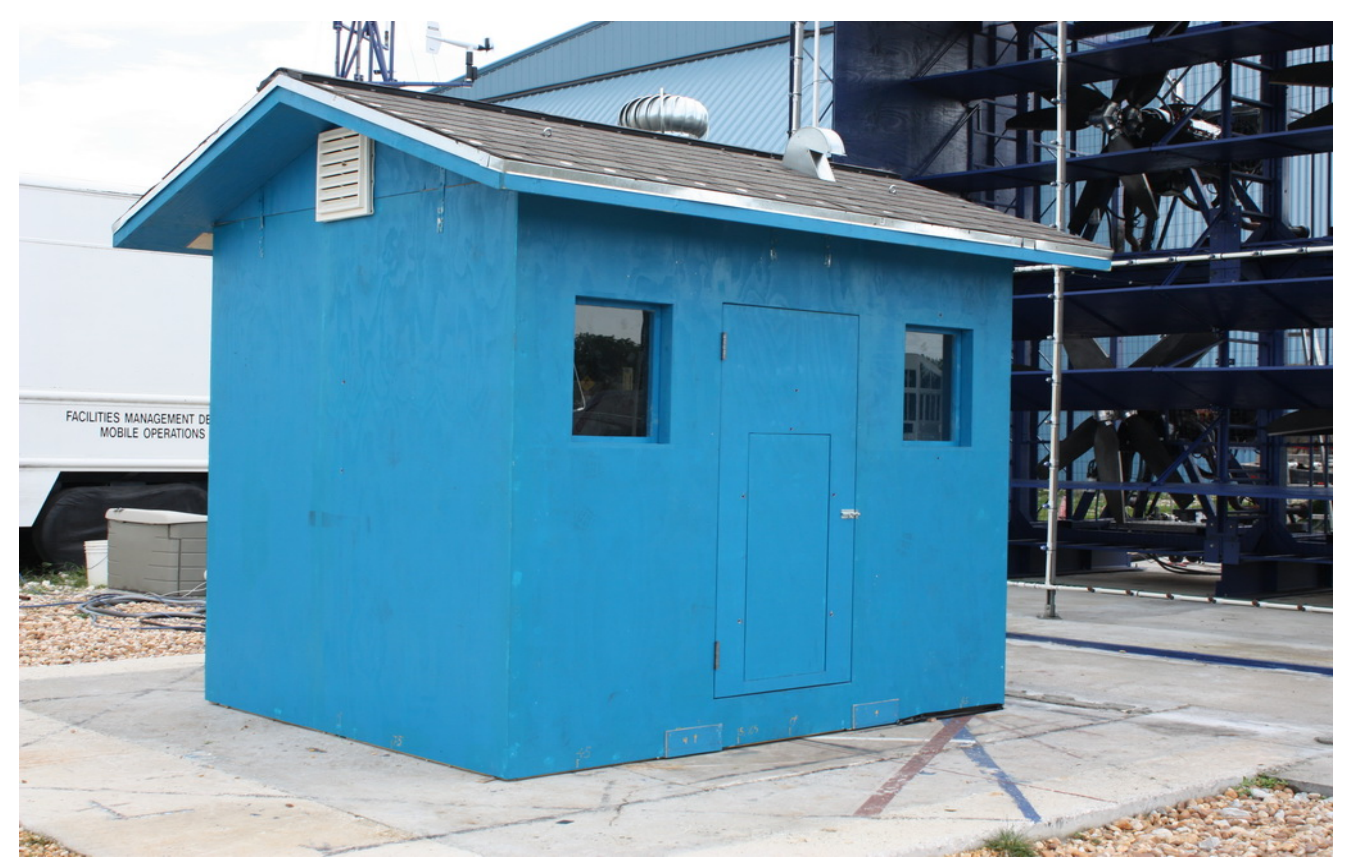

(a)

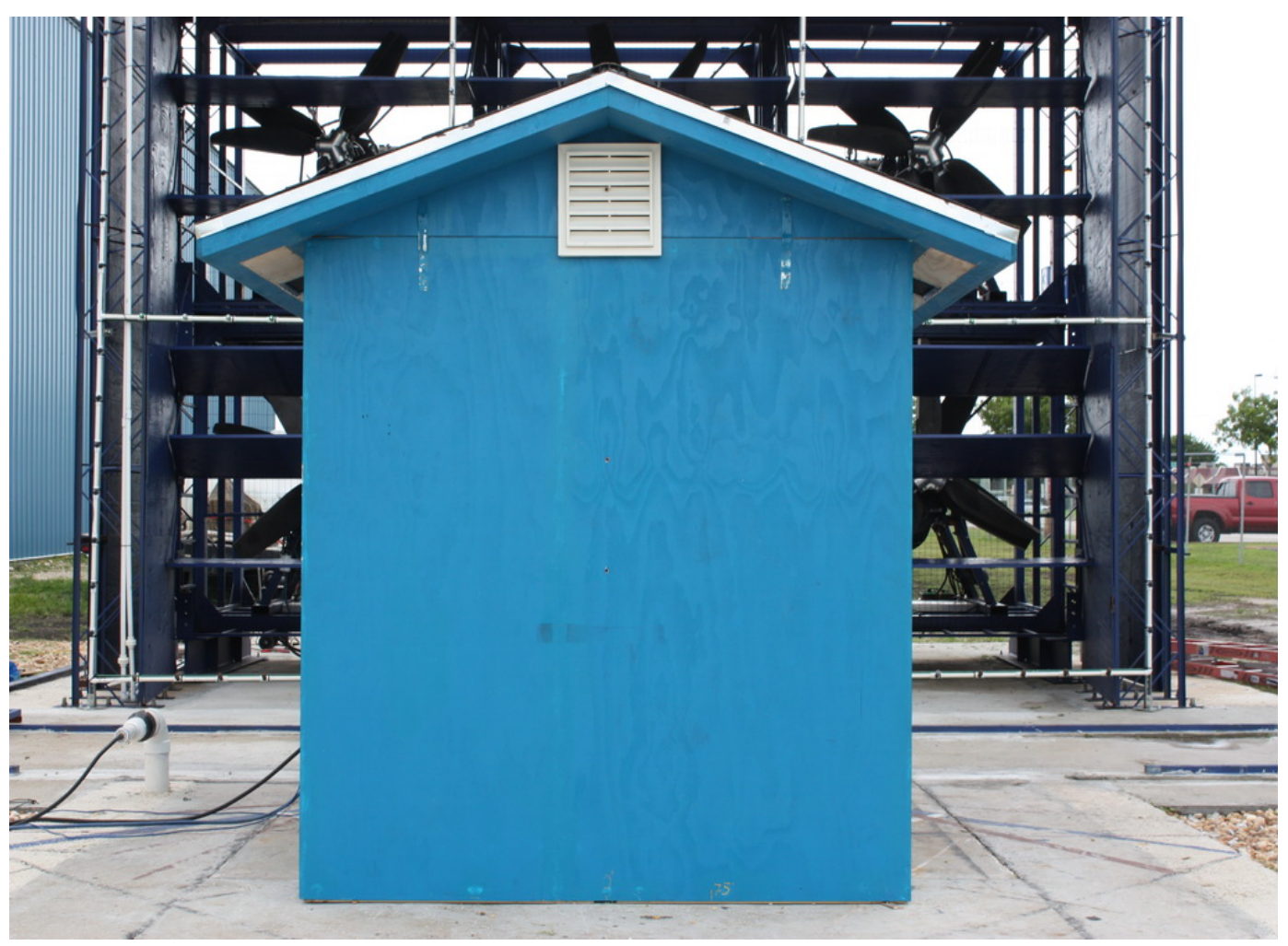

(b)

Figure 22. (a) Experimental setup with turbine, gooseneck and gable end vents. (b) Experimental setup showing gable end and soffit vents. 


\subsubsection{Water Intrusion Testing:}

For the water intrusion testing, a flow rate of $19 \mathrm{in} / \mathrm{hr}$ was used across the WoW flow field. The same three-minute quasiperiodic engine waveform was used for these experiments. Once the profile was initiated, an operator engaged the WoW waterinjection system for the duration of three minutes. After the profile was completed, the water collecting containers were removed from the building and weighed on a digital scale. The water was then drained from the containers, which were wiped dry with a cloth. The dry containers were then weighed to determine the amount of water intrusion for each vent. Figure 23 shows the water intrusion test.

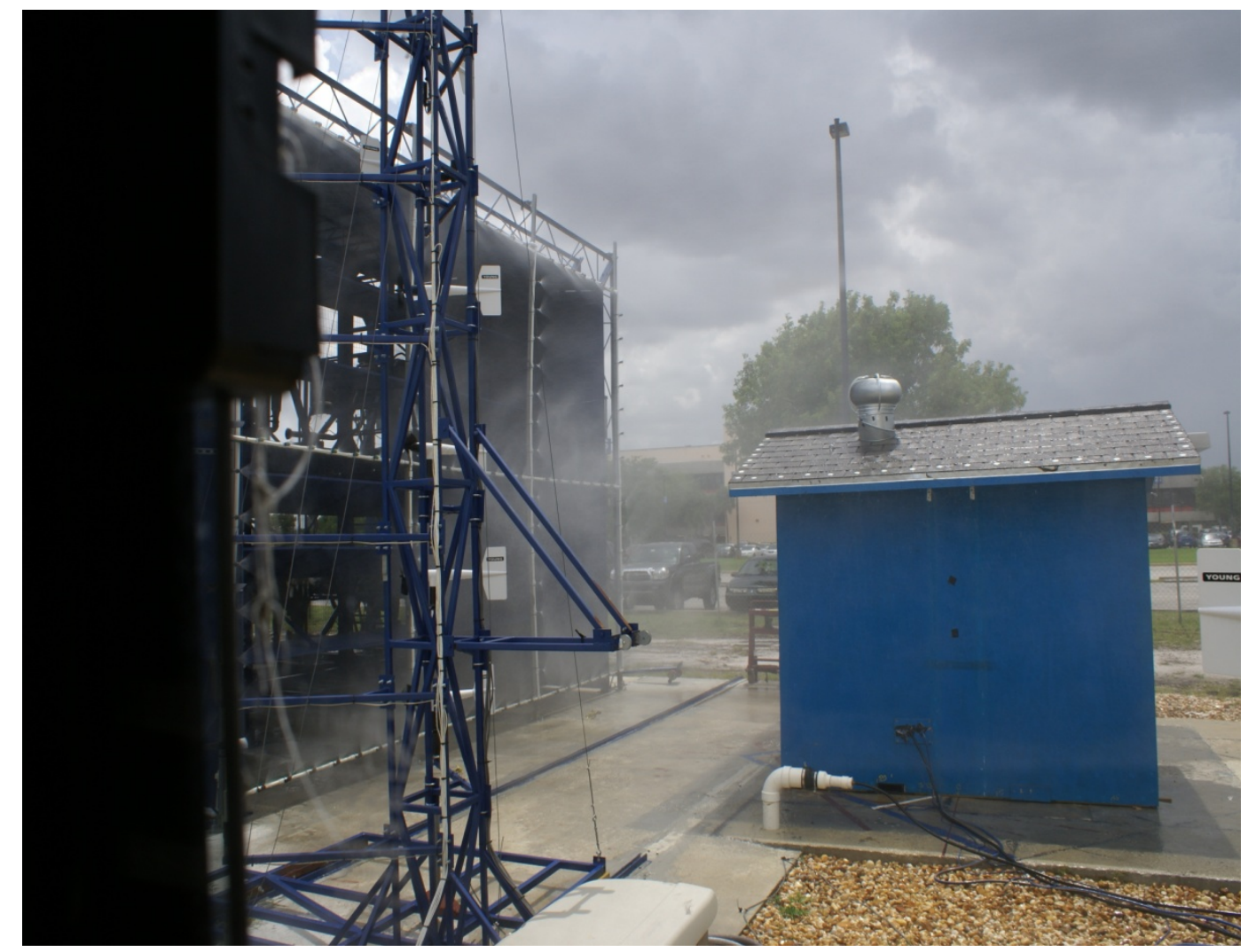

(a) 


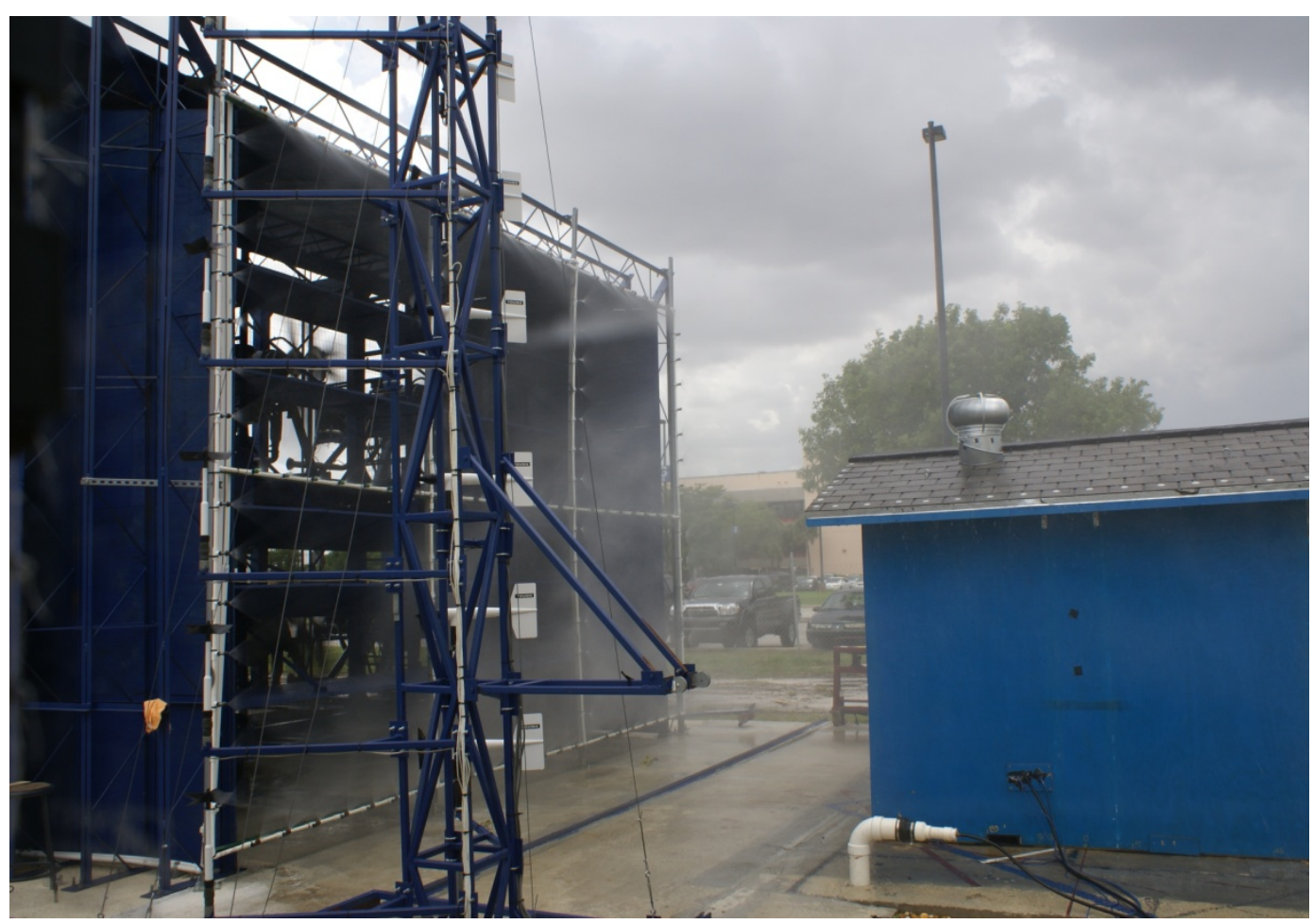

(b)

Figure 23. (a) \& (b) Water intrusion test on gable roof

\section{RESULTS AND DISCUSSION}

\subsection{Pressure Test Results:}

Figure 24 shows the time history data of typical pressure test. Each test duration is 3 minutes for both baseline and profile parts. Coefficients $\left(C_{p}\right)$ of mean and peak pressures are calculated based on the time history data. The mean wind speed at the mid height of the roof is used for pressure coefficients calculations. 


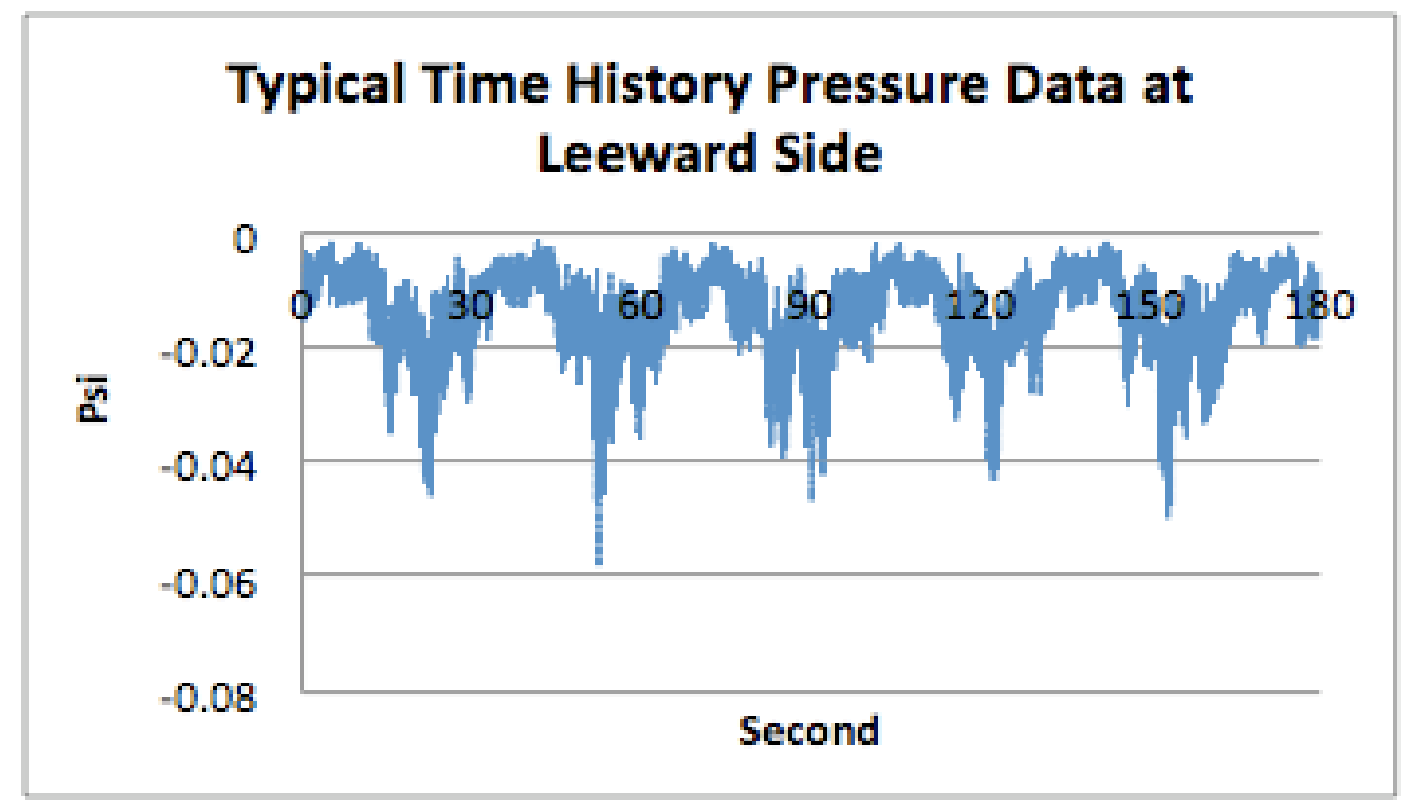

(a)

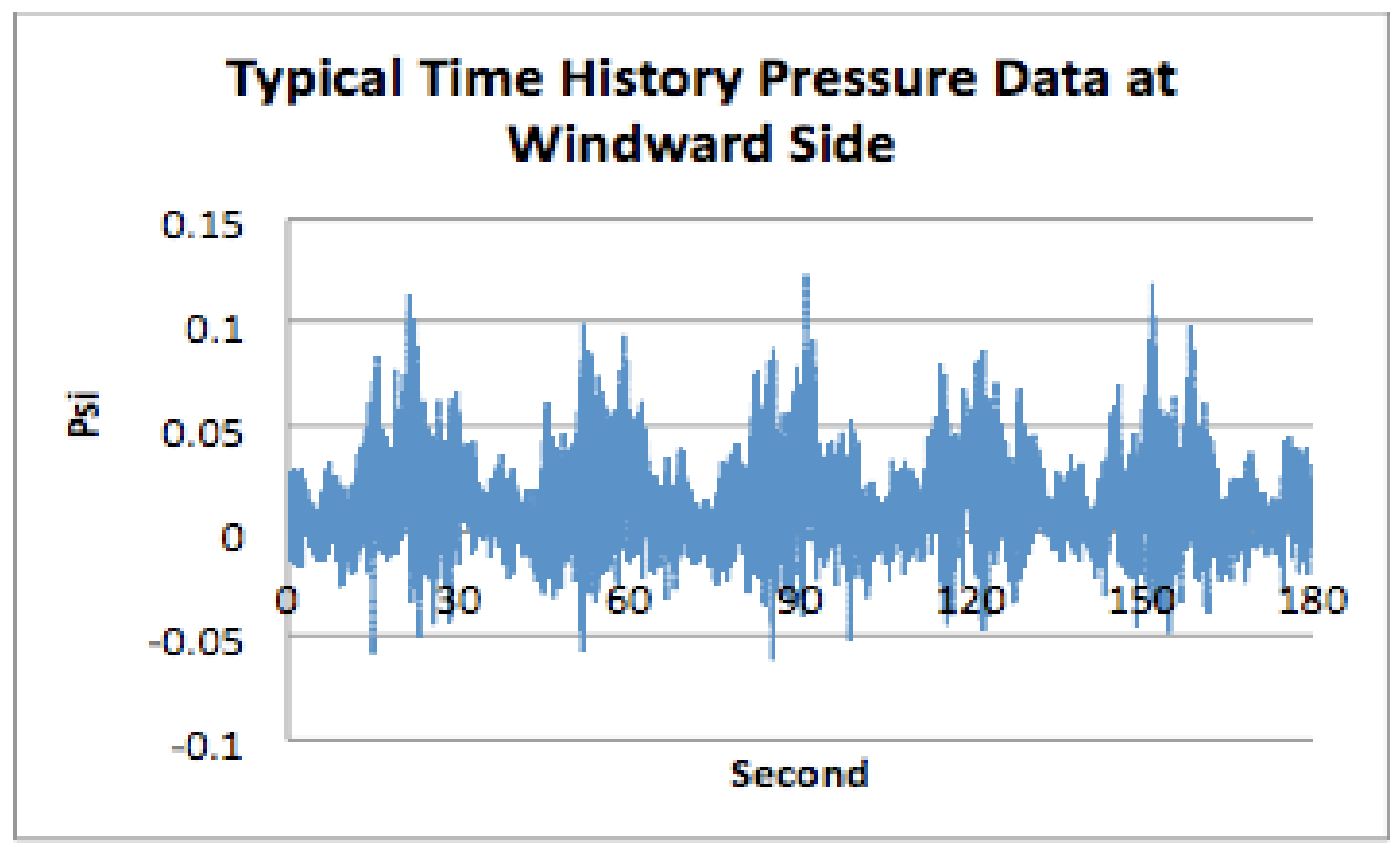

(b)

Figure 24. Typical time history pressure data at:

(a) Windward side and (b) Leeward side 


\subsubsection{Gable Roof Results:}

The following figures show average, standard deviation, maximum and minimum pressure coefficients for external pressure taps on the turbine and goose neck vents. The maximum $\mathrm{C}_{\mathrm{p}}$ values are obtained at the pressure taps facing the wind attack direction. For example, for 0 degree wind attack angle, turbine tap \#7 and goose neck tap \#13 are the taps facing to WoW. Therefore, the maximum $\mathrm{C}_{\mathrm{p}}$ values were observed for \#7 and \# 13 taps.

1) For "0" degree angle of attack:

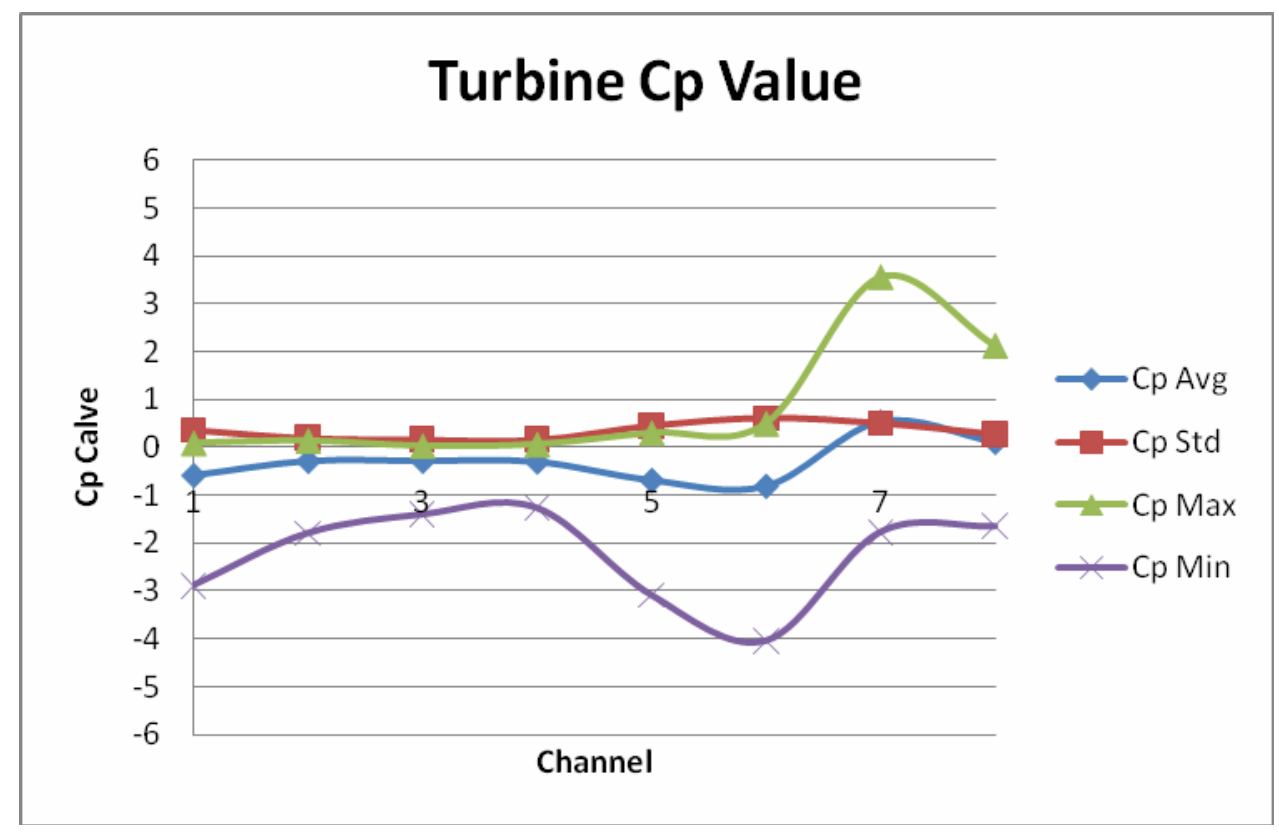

(a) 


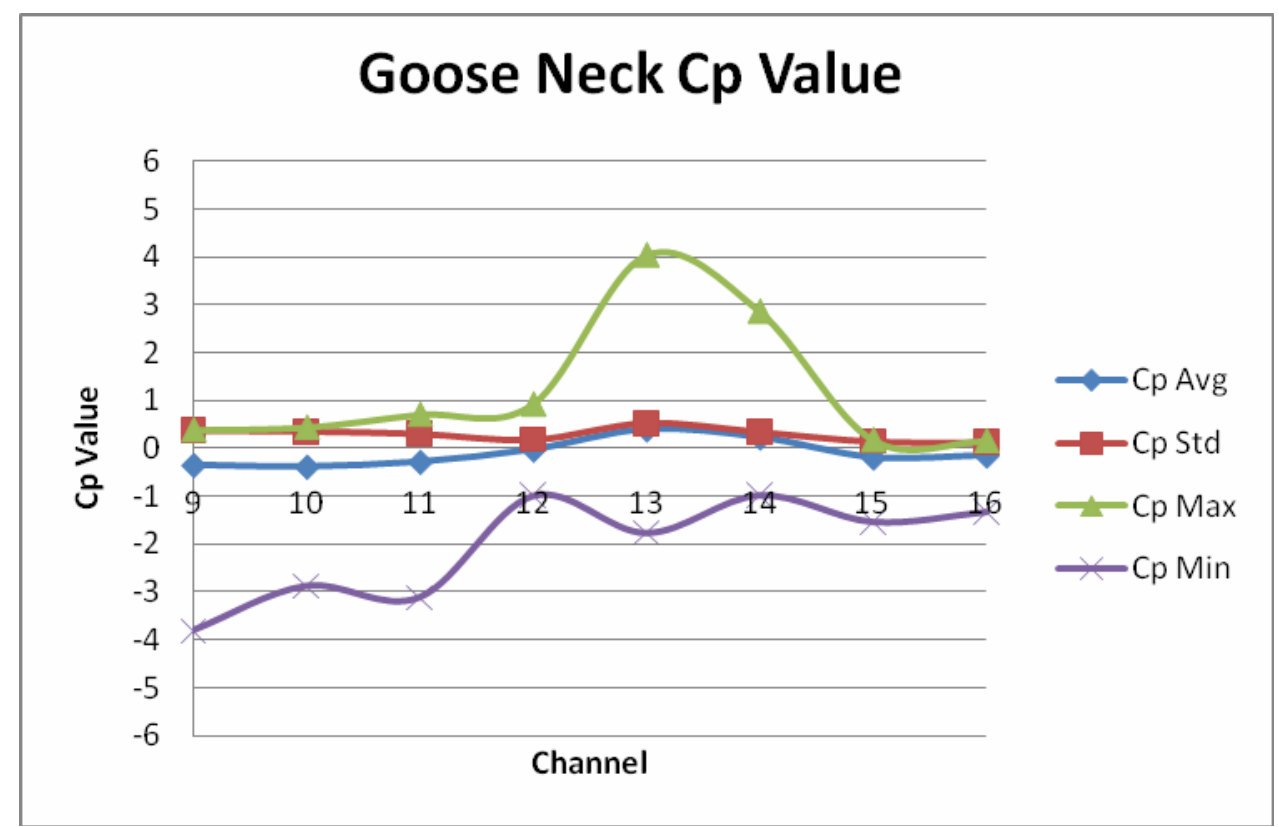

(b)

Figure 25. $\mathrm{C}_{\mathrm{p}}$ values for " 0 " degree angle of attack

2) For "15" degree angle of attack:

a) The turbine graph (Figure 26a) shows that the maximum pressure coefficient occurred at tap 7, having a value of approximately 2.8 . Taps 5,6 , and 7 measured positive mean $\mathrm{Cp}$ values as they were on the windward side of the vent. The remaining taps demonstrate suction pressure coefficients; with tap 8 having the maximum suction coefficient of -3.2 .

b) The gooseneck results (Figure 26b) show the maximum pressure coefficient occurred at windward tap 14, with a value of approximately 2.3. This value is the maximum positive pressure coefficient on the gooseneck among all the angles tested. Taps $12,13 \& 14$, all on the windward side of the vent at 15 degrees, show positive 
pressure coefficients. The remaining taps experienced suction. Tap 10 located on the inclined top face of the vent experienced the peak suction value of -3.2.

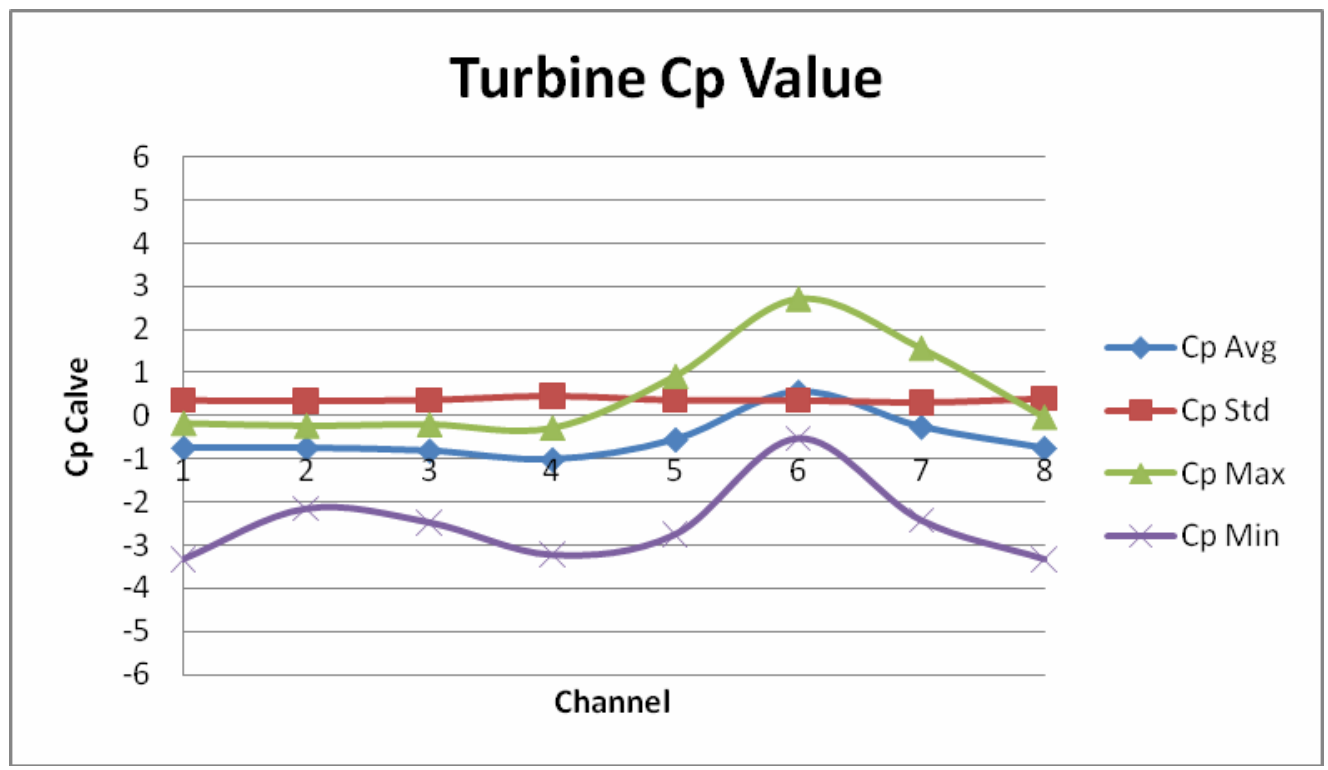

(a)

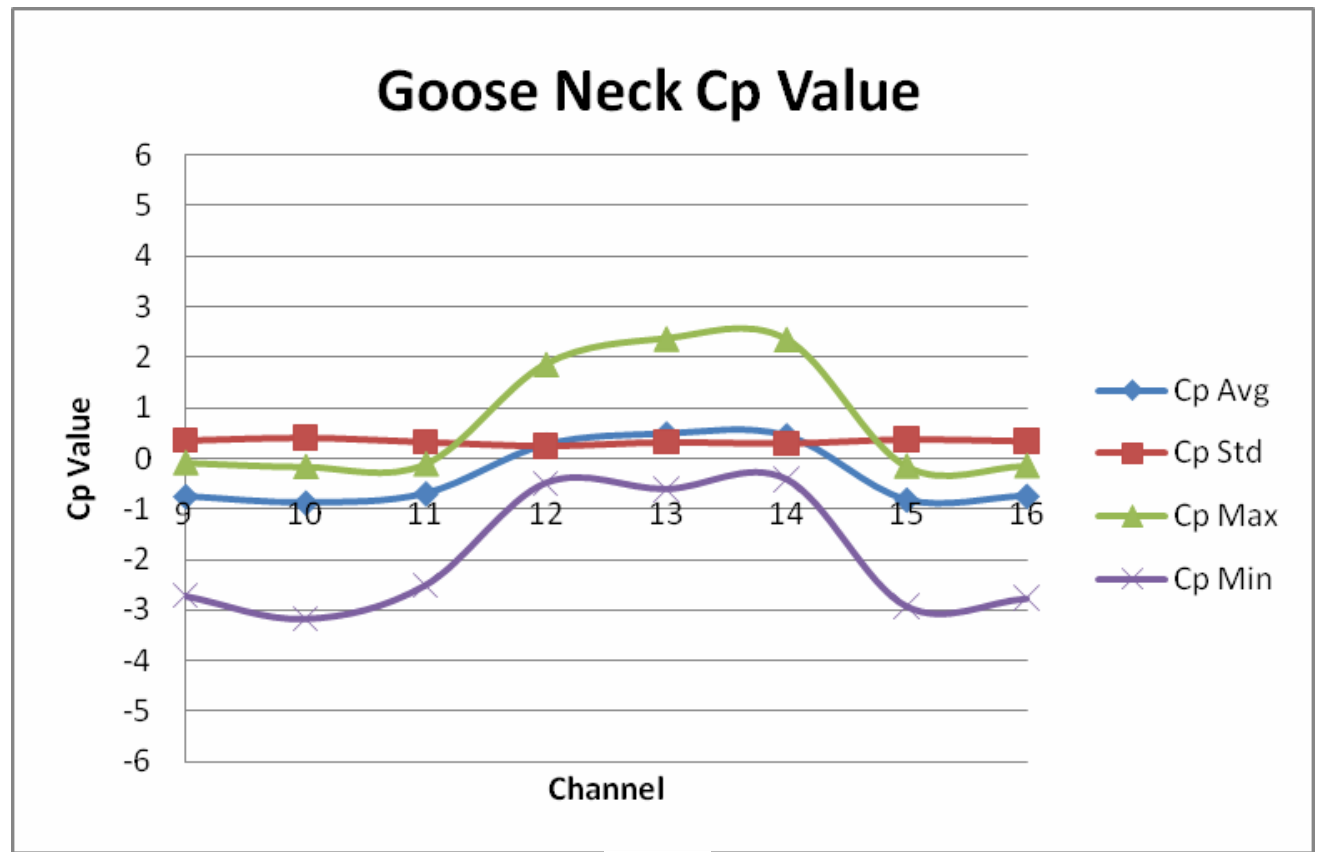

(b)

Figure 26. $C_{p}$ values for " 15 " degree angle of attack 
3) For " 45 " degree angle of attack:

a) The turbine graph (Figure 27a) shows that the maximum pressure coefficient occurred at tap 6, having a value of approximately 2.8. Taps5, 6 and 7 measured positive mean $\mathrm{Cp}$ values, as they were on the windward side of the vent. The remaining taps demonstrated suction pressure coefficients, with tap 1 having the maximum suction coefficient of -3.2 .

b) The gooseneck results (Figure 27b) show the maximum pressure coefficient occurred at windward tap 14 , with a value of approximately 2.5 . Taps $12,13 \& 14$, all on the windward side of the vent at 45 degrees, showed the positive pressure coefficients. The remaining taps experienced suction. Tap 10, located on the inclined top face of the vent experiences the peak suction value of -3.2 .

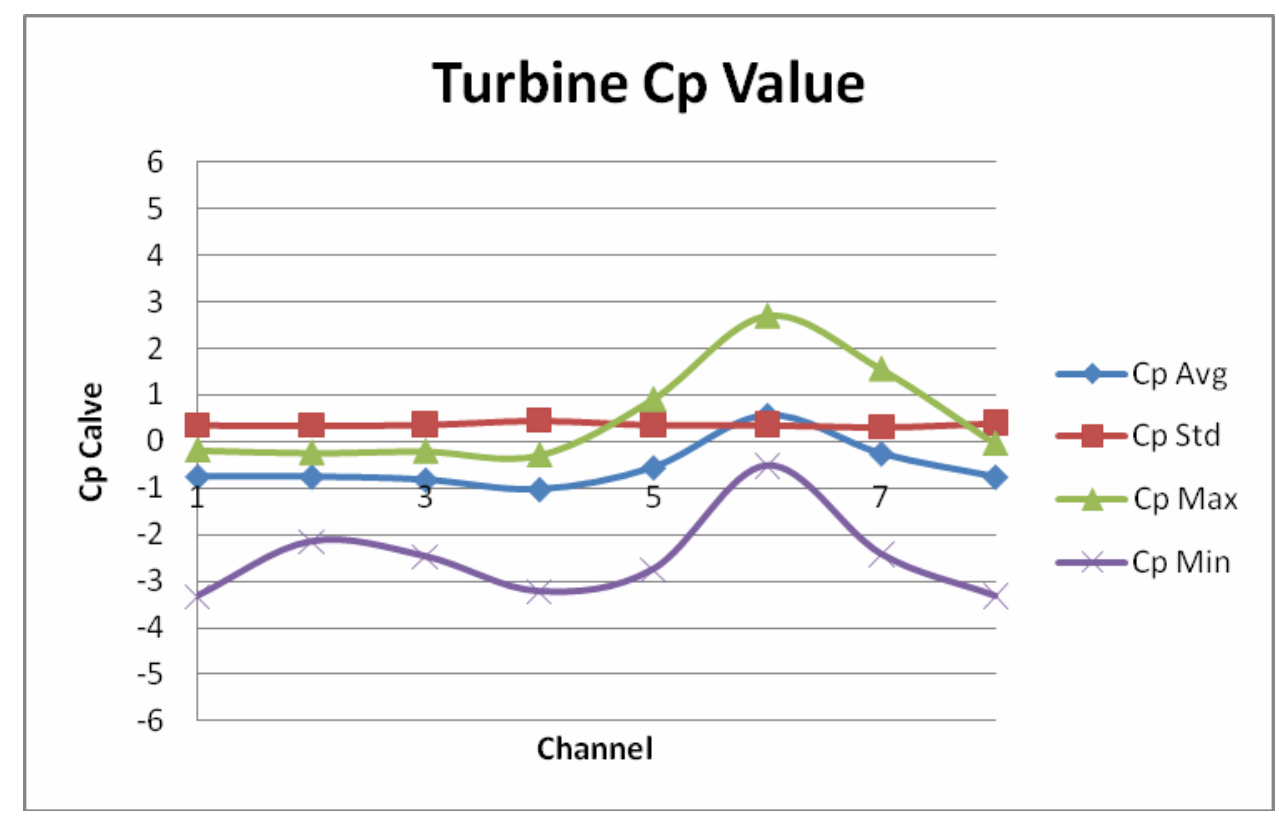

(a) 


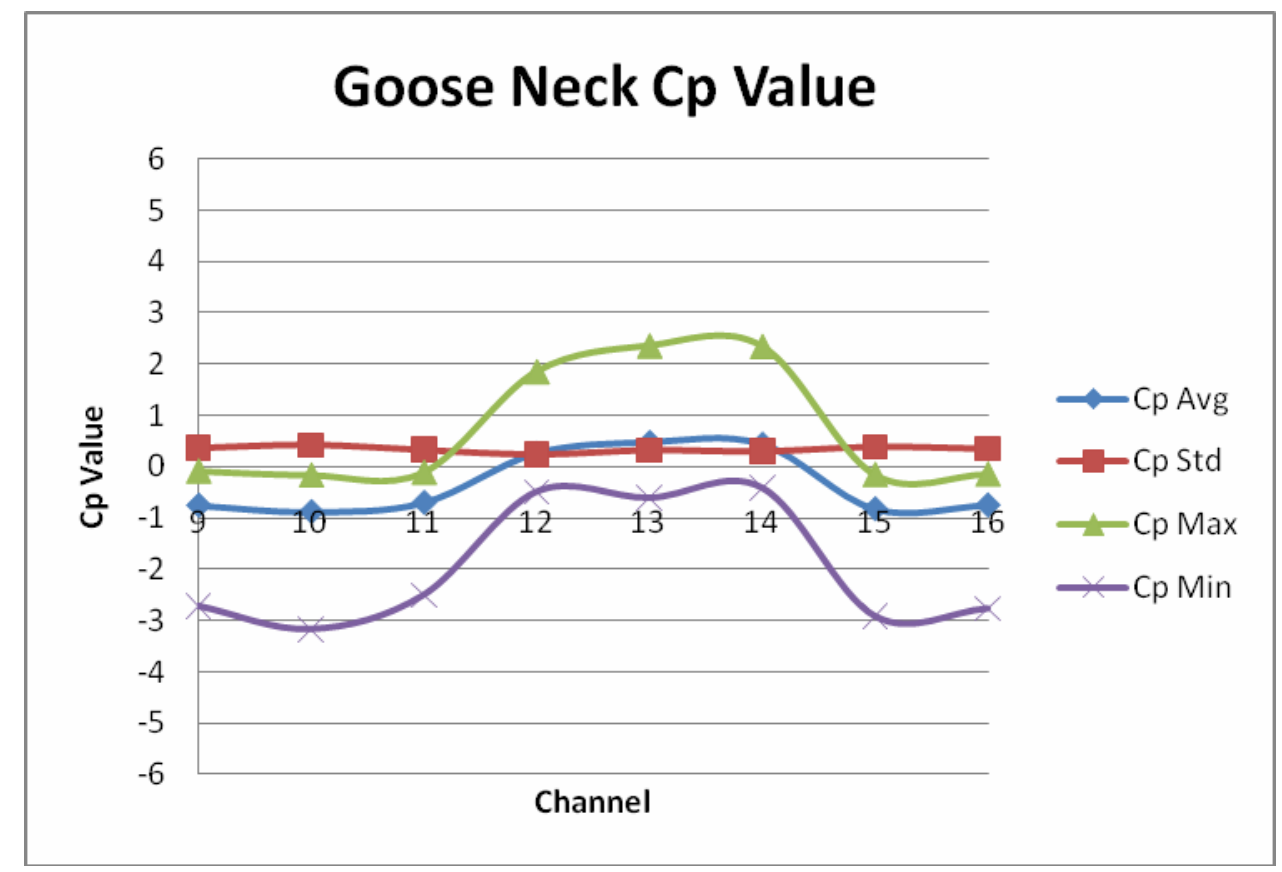

(b)

Figure 27. $C_{p}$ values for " 45 " degree angle of attack

4) For "75" degree angle of attack:

a) The turbine graph (Figure 28a) shows that the maximum pressure coefficient occurred at tap 5, having a value of approximately 2.3. Taps $5 \& 6$ measured positive mean $\mathrm{Cp}$ values, as they were on the windward side of the vent. The remaining taps demonstrated suction pressure coefficients; with tap 4 having the maximum suction coefficient of -3.1 .

b) The gooseneck results (Figure 28b) show the maximum pressure coefficient occurred at windward tap 12, with a value of approximately 2.9 . Taps $12,13 \& 14$, all on the windward side of the vent at 75 degrees, showed positive pressure coefficients. The remaining taps experienced suction. Tap 10, located on the inclined top face of the vent experienced the peak suction value of -3.1 . 


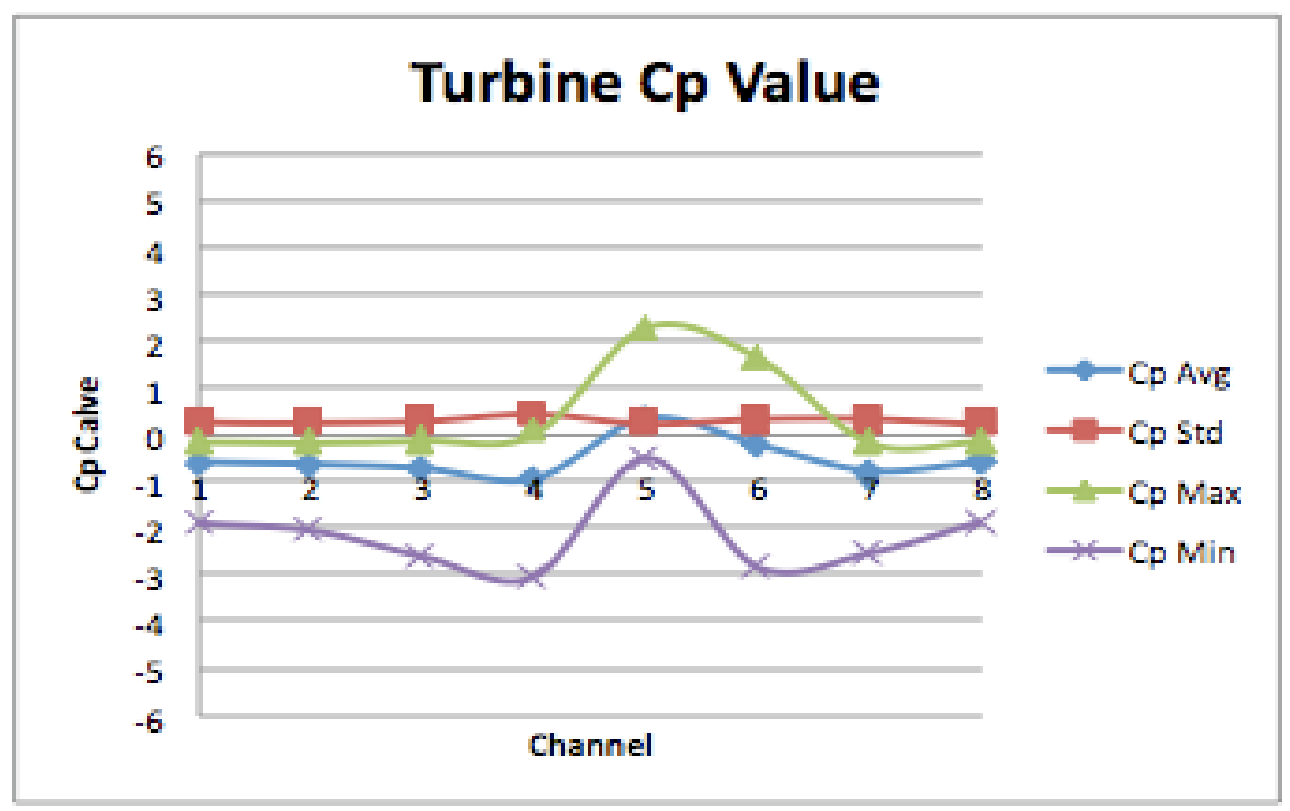

(a)

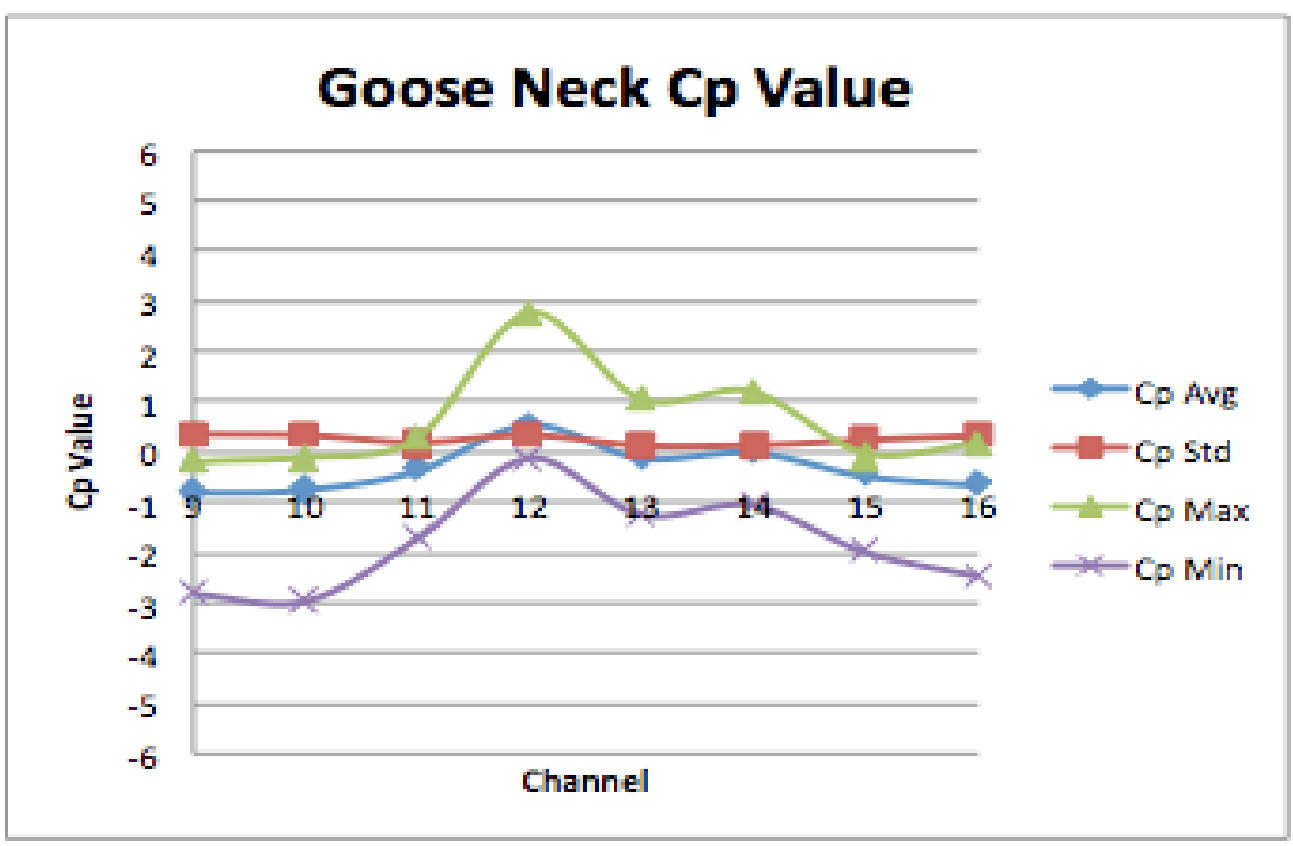

(b)

Figure 28. $C_{p}$ values for " 75 " degree angle of attack 
5) For "90" degree angle of attack:

a) The turbine graph (Figure 29a) shows that the maximum pressure coefficient occurred at tap 5 , having a value of approximately 2.2. Taps $5 \& 6$ measured positive mean $\mathrm{Cp}$ values, as they were on the windward side of the vent. The remaining taps demonstrated suction pressure coefficients; with tap 4 having the maximum suction coefficient of -2.9.

b) The gooseneck results (Figure 29b) show the maximum pressure coefficient occurred at windward tap 12 , with a value of approximately 2.5 . Taps $12,13,14,15 \&$ 16, all on the windward side of the vent at 90 degrees, show positive pressure coefficients. The remaining taps experienced suction. Tap 9, located on the top face of the vent experienced the peak suction value of -3.1

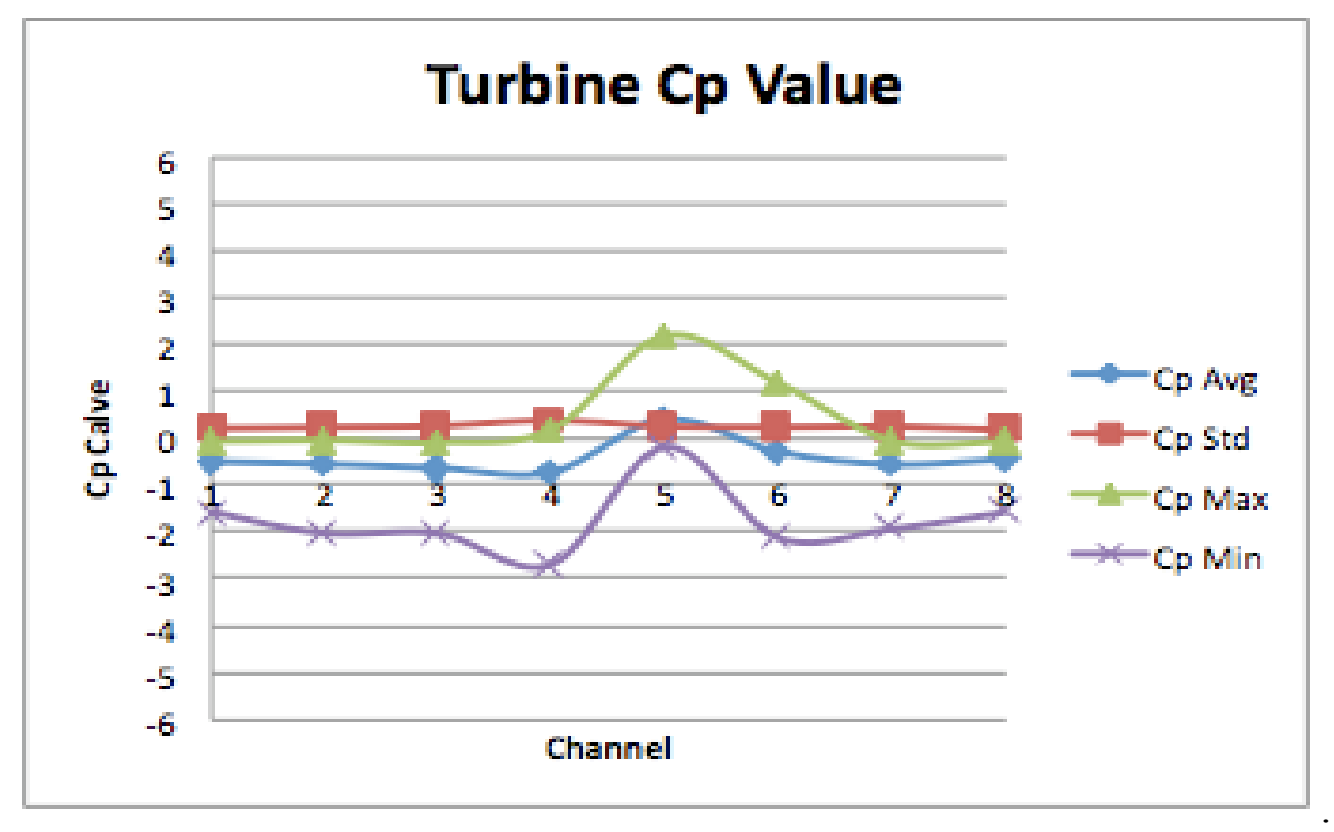

(a) 


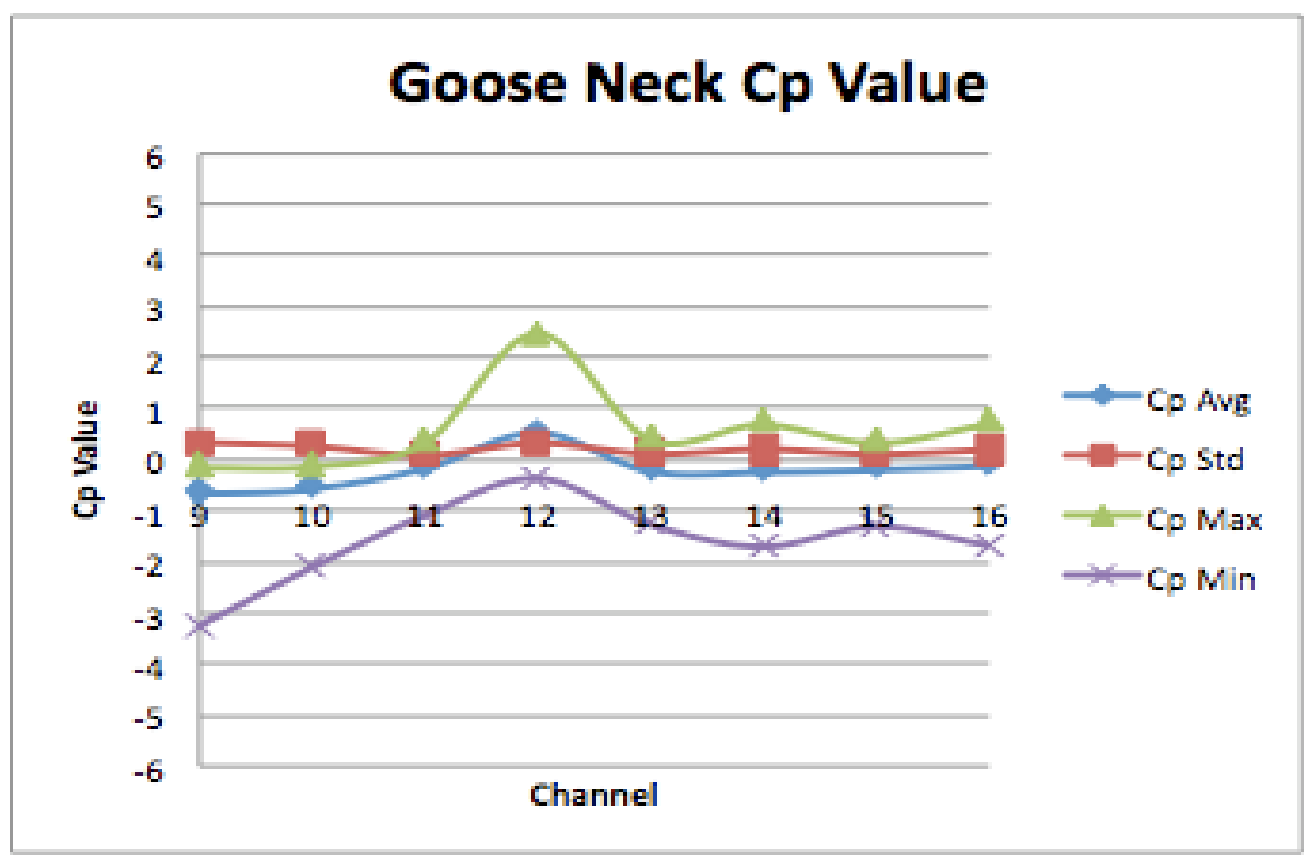

(b)

Figure 29. $\mathrm{C}_{\mathrm{p}}$ values for " 90 " degree angle of attack

\subsubsection{Visualization of Turbine Pressure Coefficients for Gable Roof:}

a) For " 0 " degree angle of attack:

It appears from the graph that the gable roof does not allow a symmetric pressure distribution around the vent. Figure 30 shows for 0 degree angle of attack negative and positive pressure coefficients on the turbine vent. The leeward sides of the turbine show a good symmetry where as the windward side does not. 


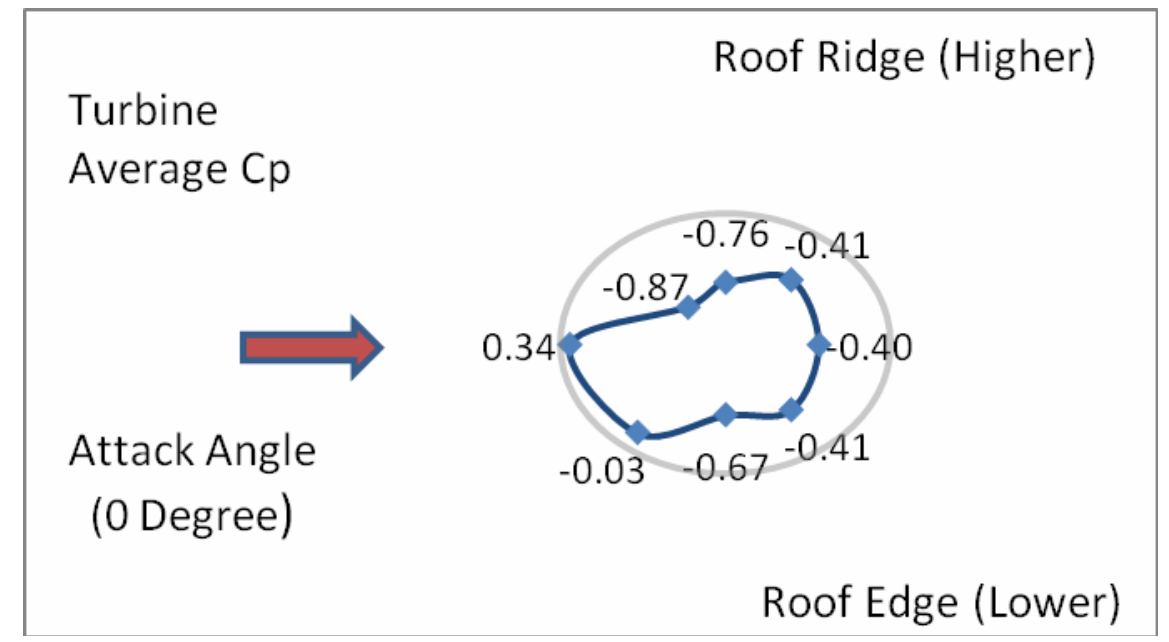

Figure 30. Average $C_{p}$ values for angle of attack at 0 degree

b) For " 15 " degree angle of attack:

Figure 31 shows for 15-degree angle of attack negative and positive pressure coefficients on the turbine vent. It appears from the graph that the gable roof specimen does not allow a symmetric pressure distribution around the vent. The leeward sides of the turbine show some symmetry where as the windward side does not.

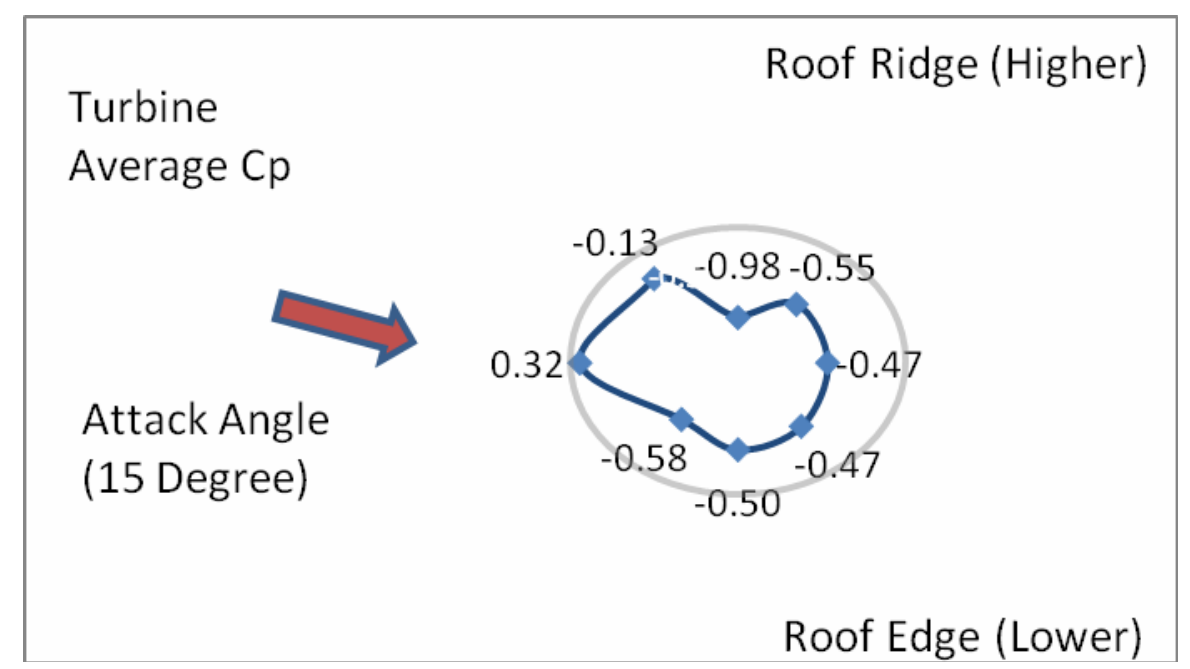

Figure 31. Average $C_{p}$ values for angle of attack at 15 degree 
c) For " 45 " degree angle of attack:

Figure 32 shows for 45 -degree angle of attack negative and positive pressure coefficients on the turbine vent. Similar to the earlier cases the leeward sides of the turbine show somewhat good symmetry as compared to the windward side.

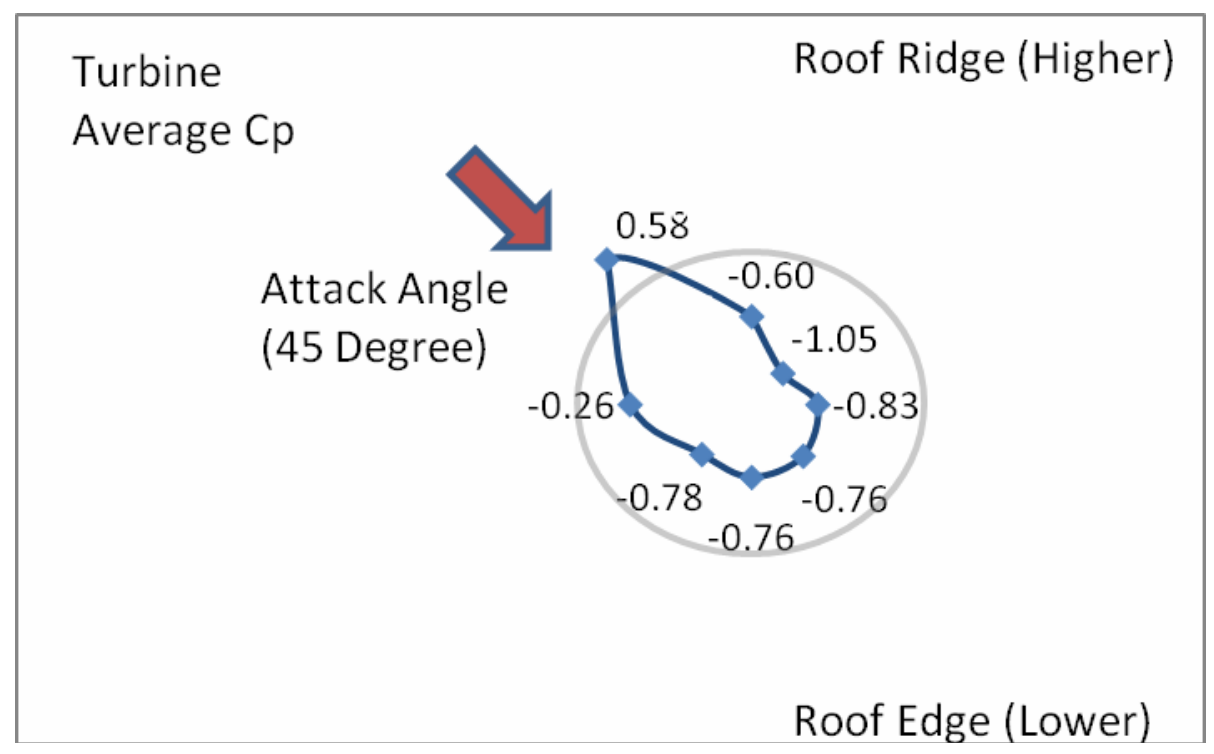

Figure 32. Average $C_{p}$ values for angle of attack at 45 degree

d) For "75" degree angle of attack:

Figure 33 shows for 75-degree angle of attack negative and positive pressure coefficients on the turbine vent. The leeward sides of the turbine show a good symmetry as compared to the windward side. 


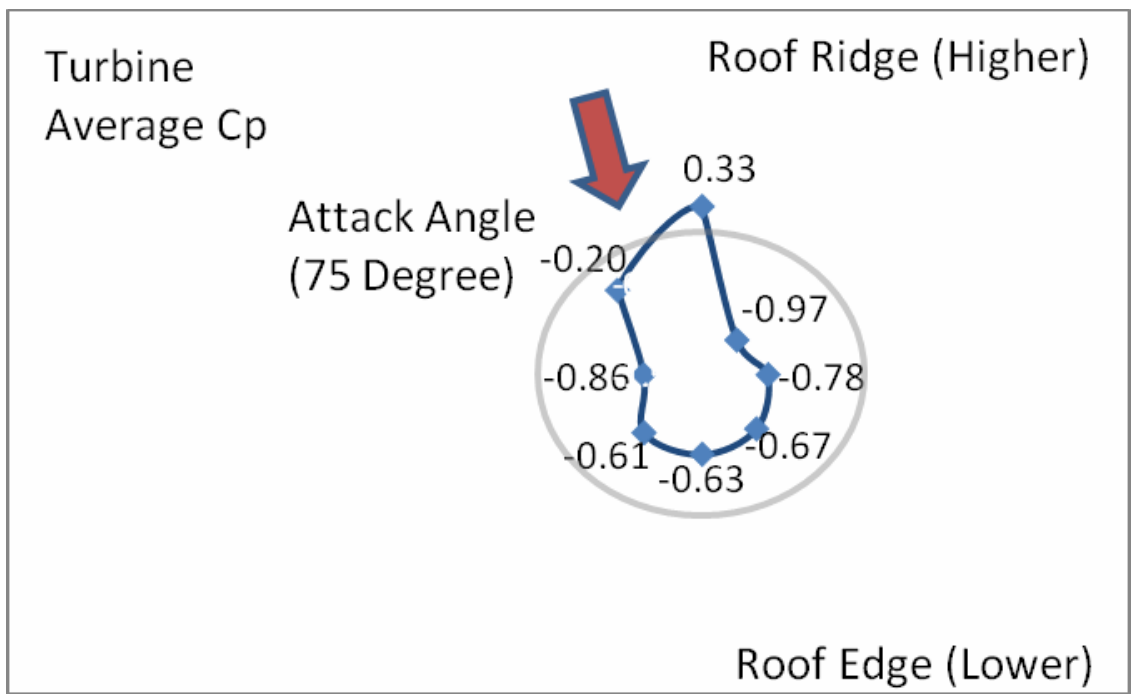

Figure 33. Average $C_{p}$ values for angle of attack at 75 degree

e) For "90" degree angle of attack:

Figure 34 shows for 90-degree angle of attack negative and positive pressure coefficients on the turbine vent.

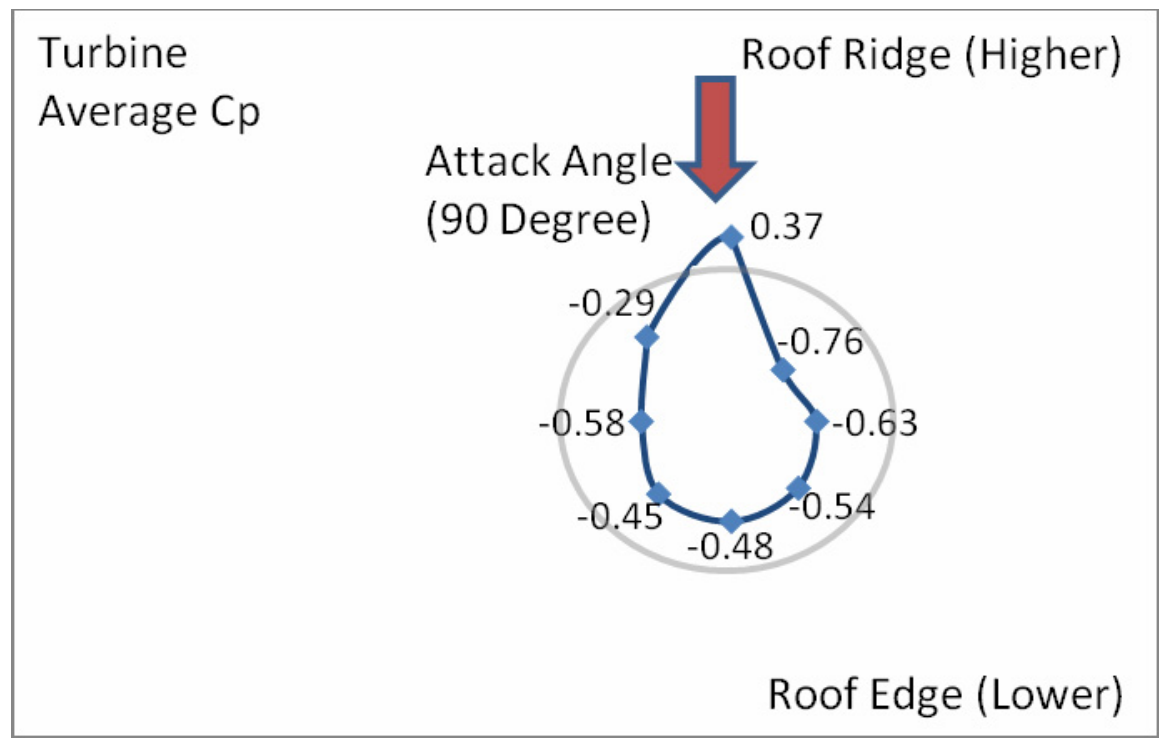

Figure 34. Average $C_{p}$ values for angle of attack at 90 degree 


\subsubsection{Hip Roof Results:}

Figure 35 to 39 shows the mean, standard deviation, maximum and minimum pressure coefficients. The pressure coefficient toward the wind direction is the greatest. The maximum pressure coefficient value is found to be +4.0 at an angle 0 degree and the minimum pressure coefficient occurring at an angle 0 degree is -3.9 .

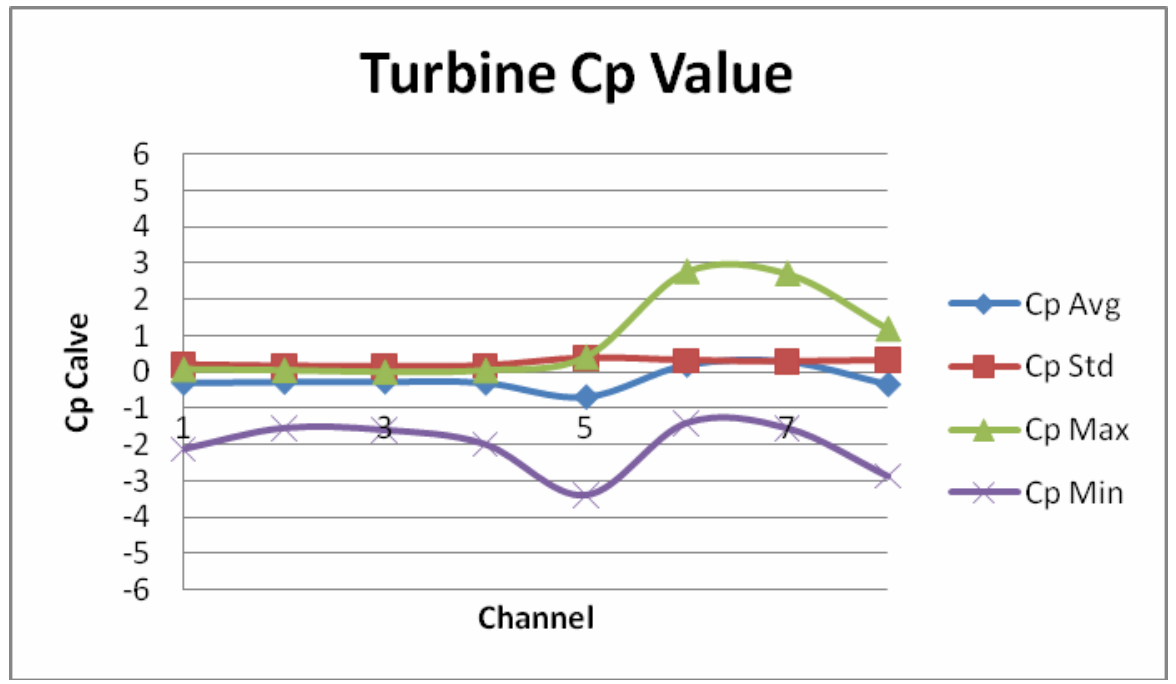

(a)

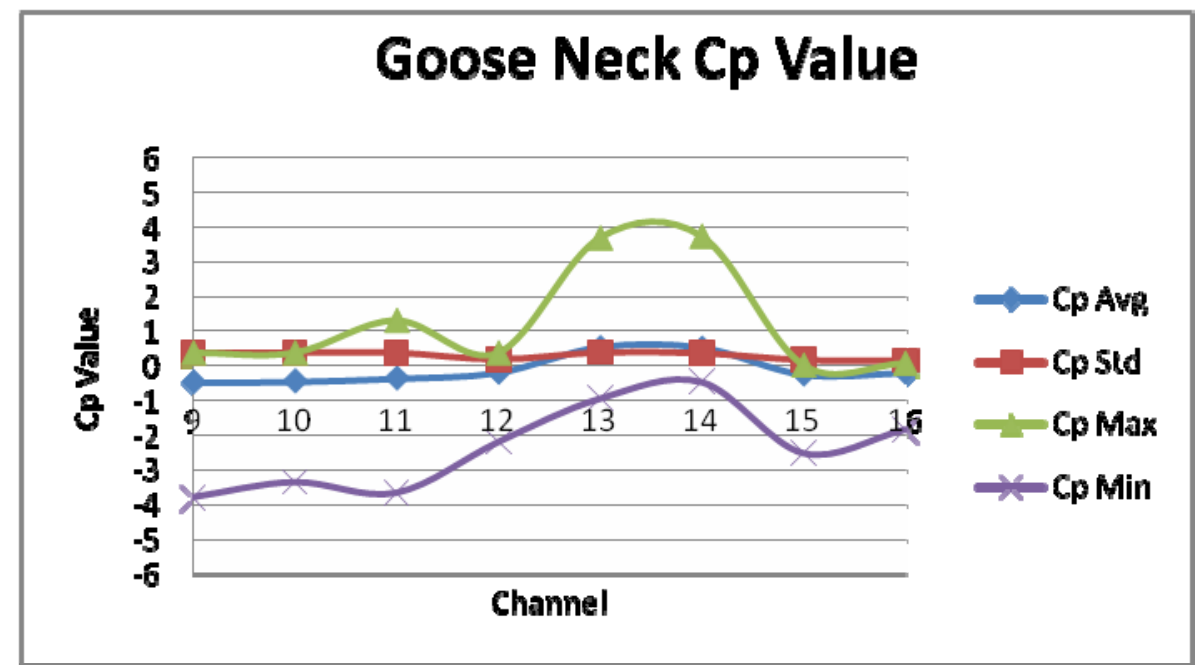

(b) 
Figure 35. $C_{p}$ values for " 0 " degree angle: (a) turbine vent, (b) gooseneck vent

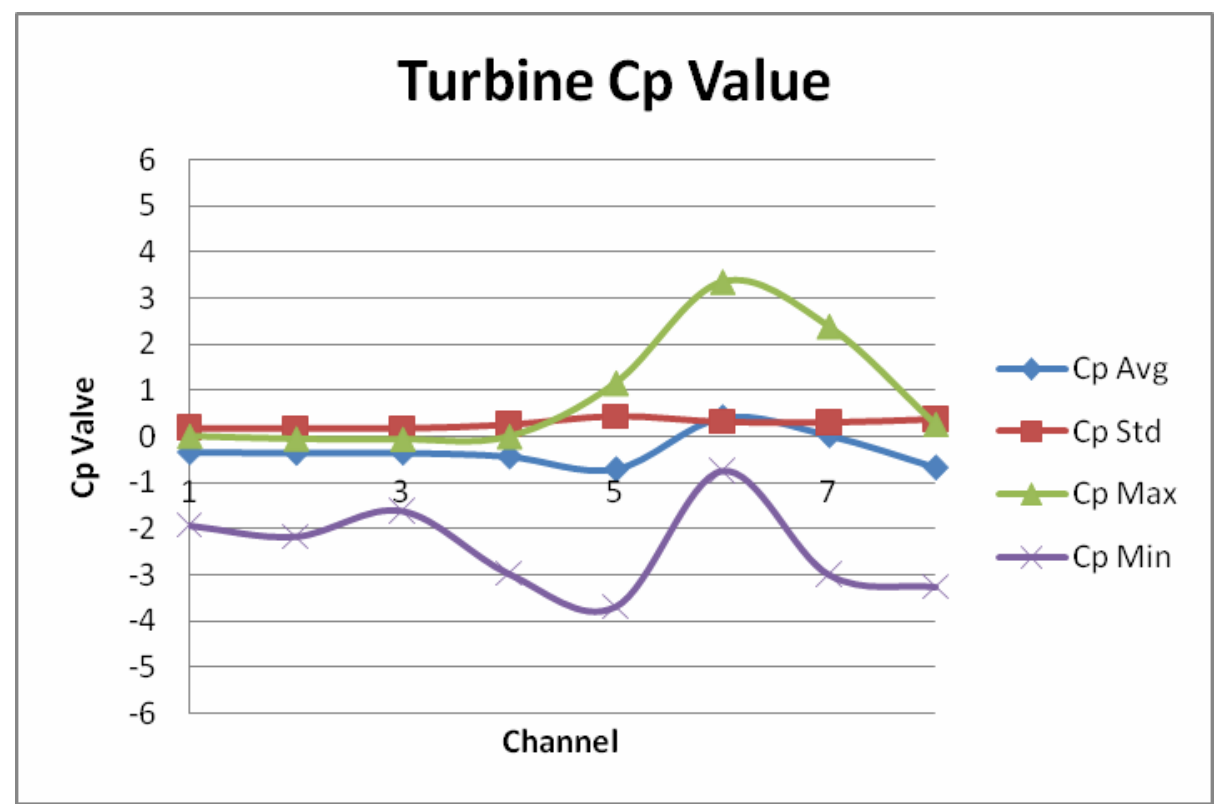

(a)

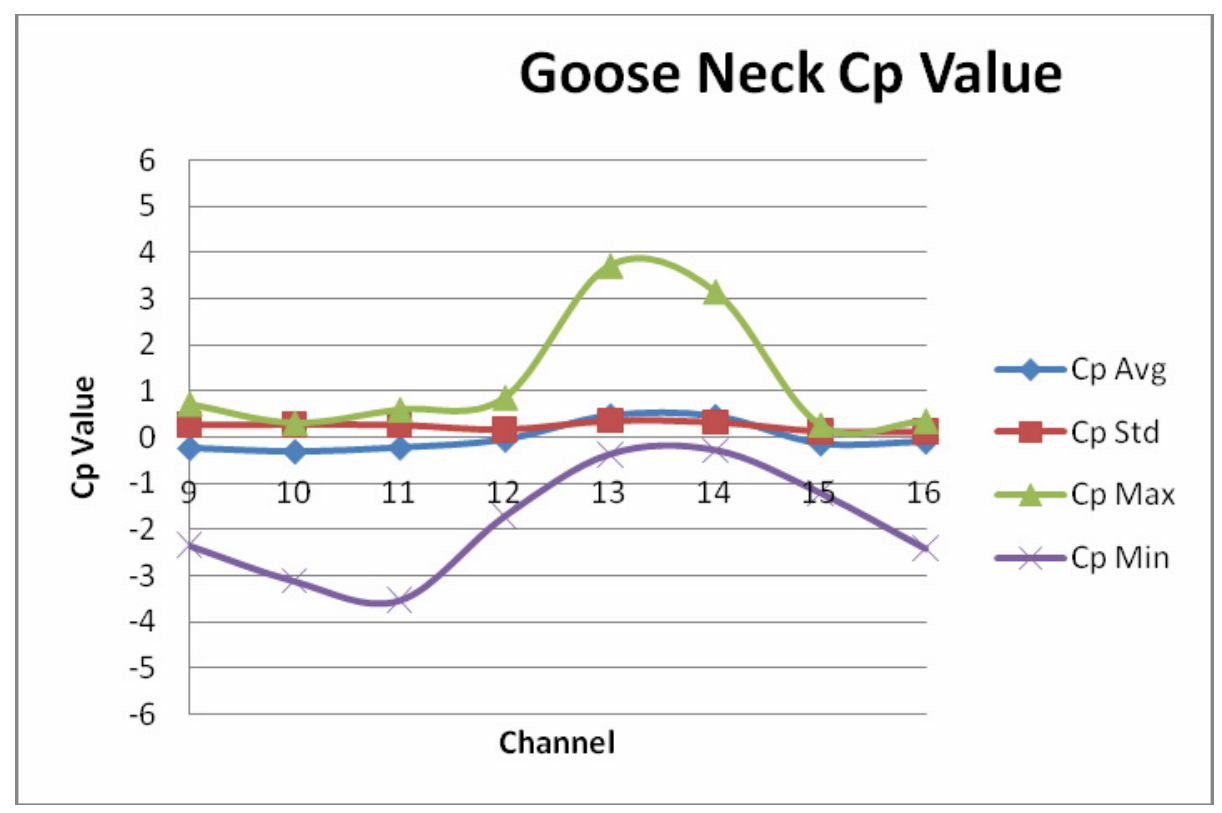

(b)

Figure 36. $\mathrm{C}_{\mathrm{p}}$ values for "15" degree angle: (a) turbine vent, (b) gooseneck vent 


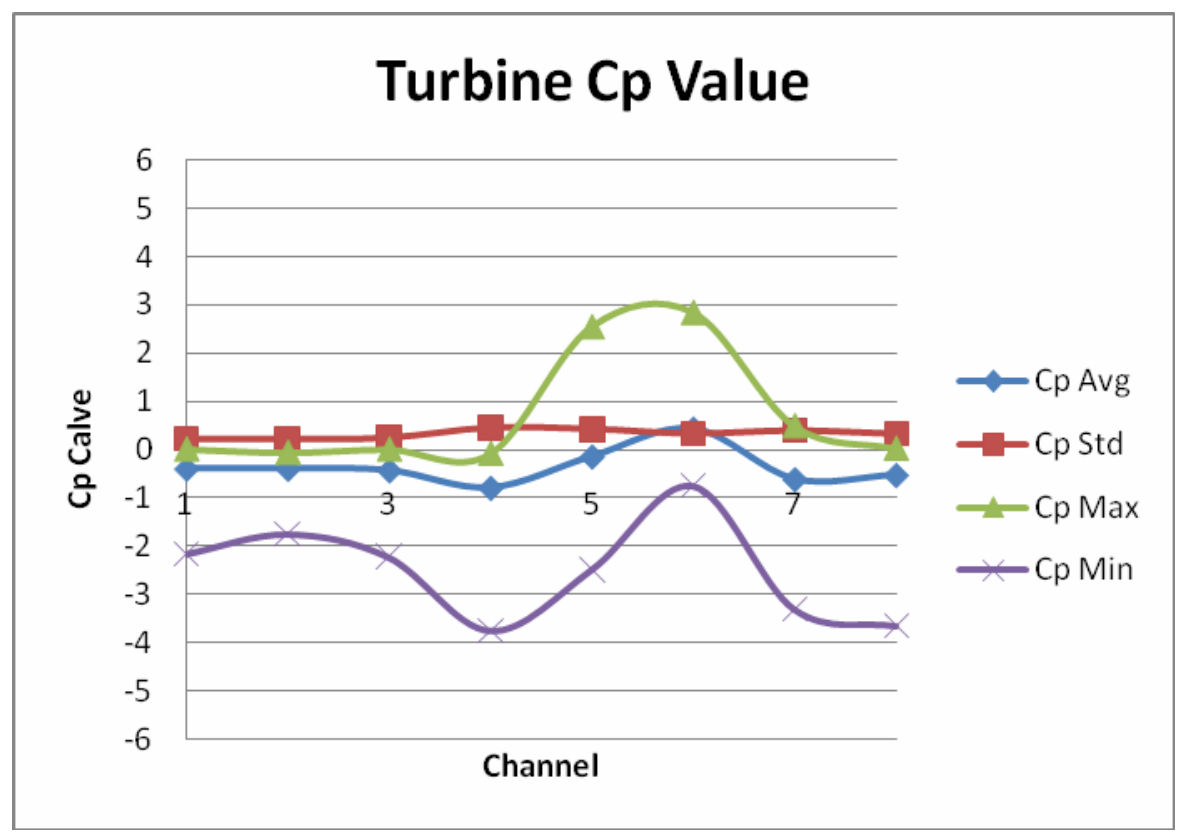

(a)

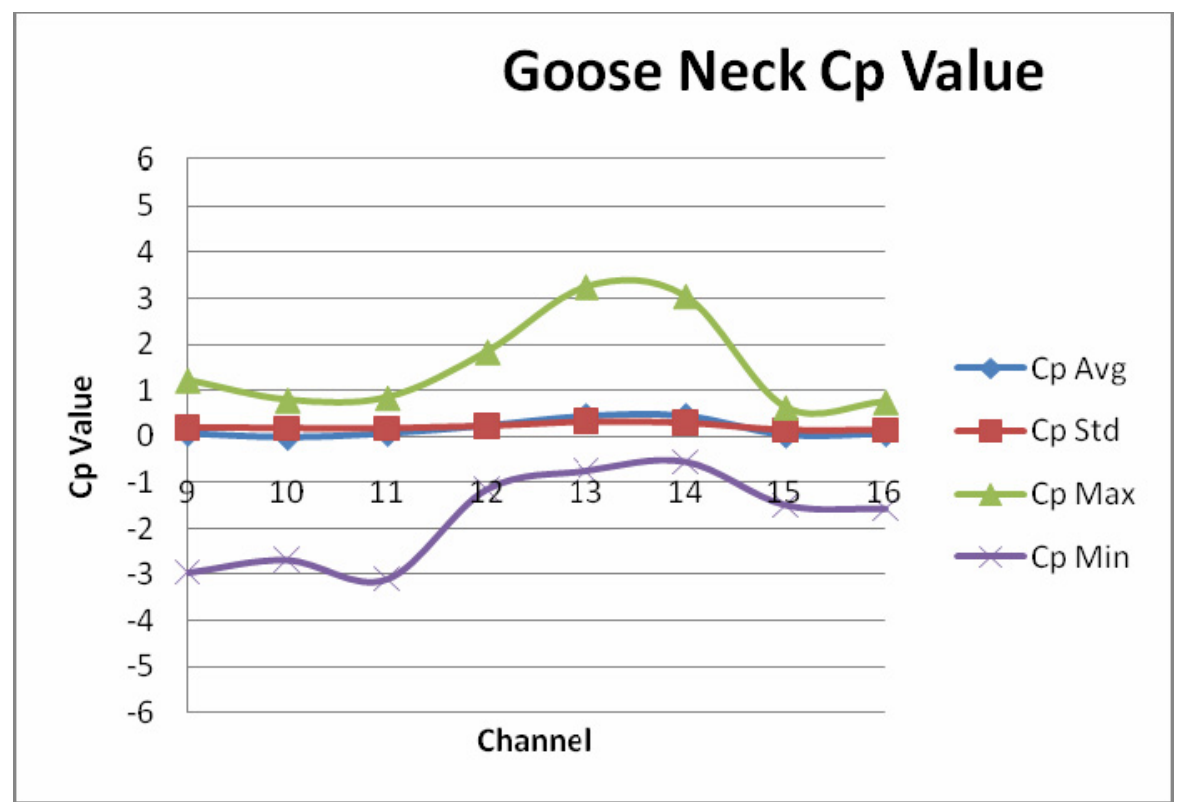

(b)

Figure 37. $C_{p}$ values for " 45 " degree angle: (a) turbine vent, (b) gooseneck vent 


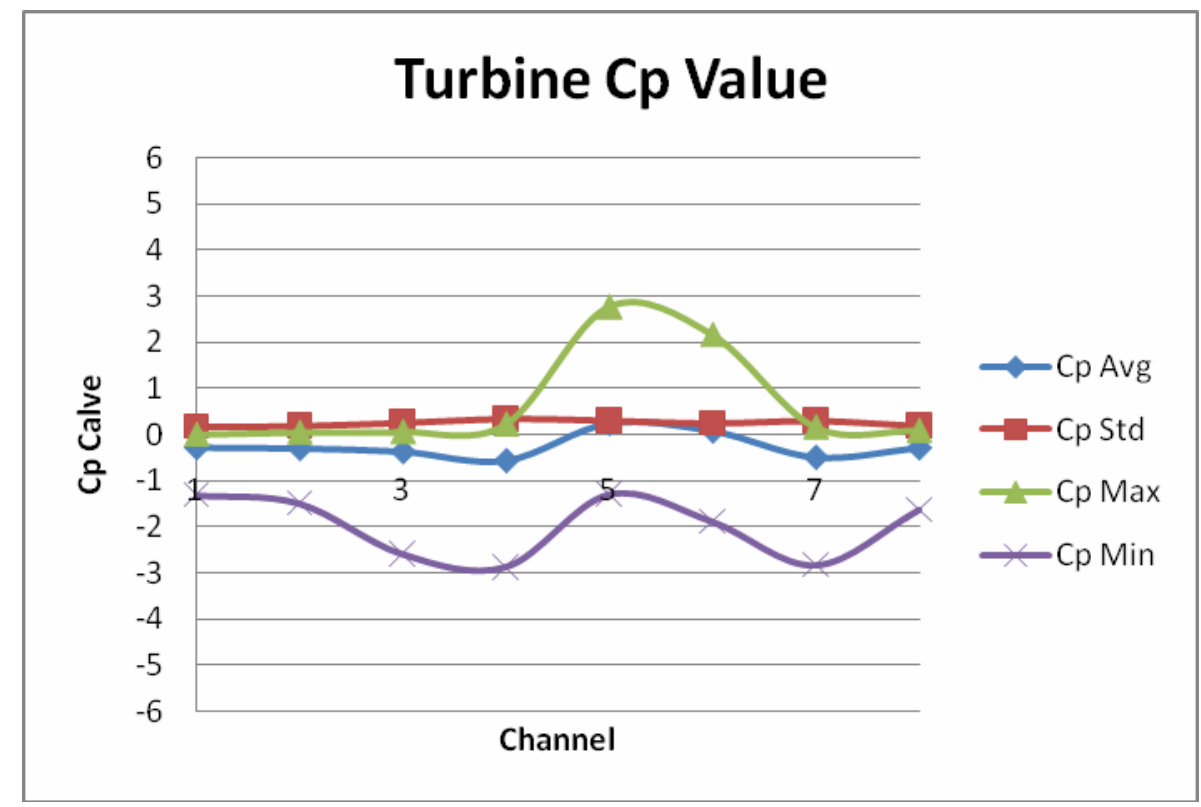

(a)

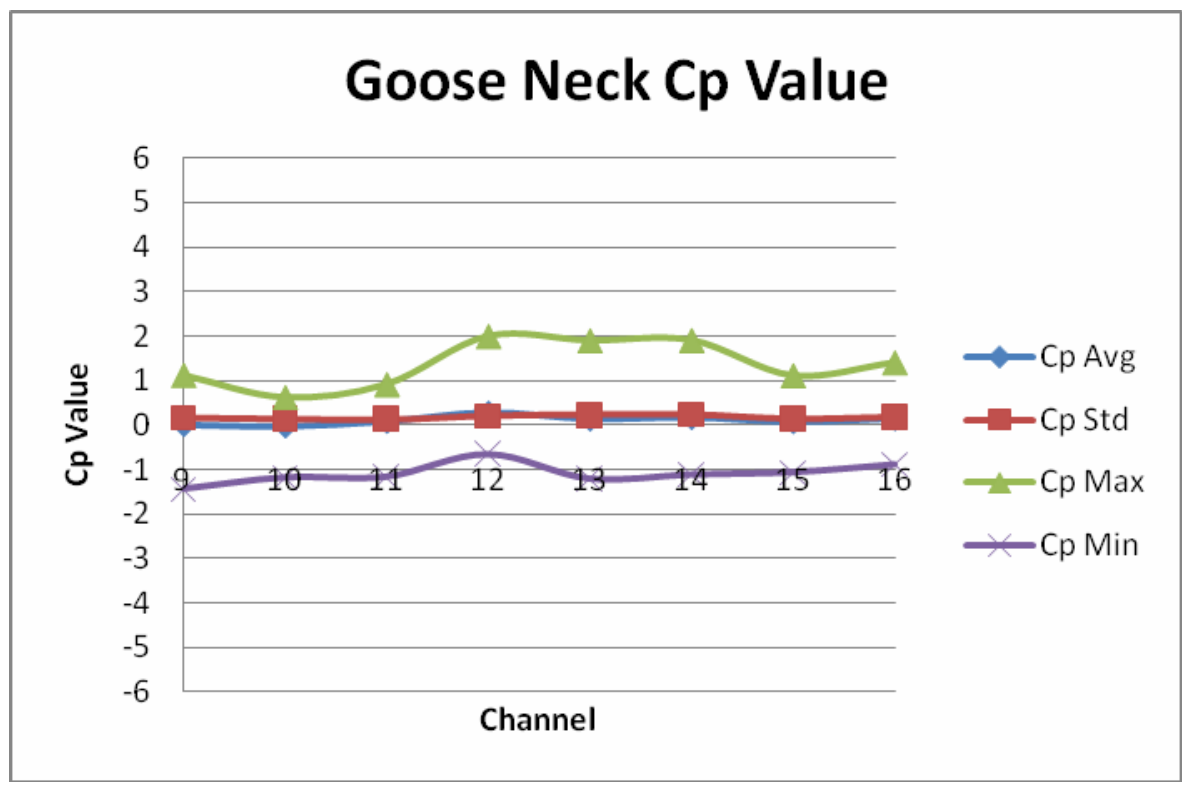

(b)

Figure 38. $C_{p}$ values for " 75 " degree angle: (a) turbine vent, (b) gooseneck vent 


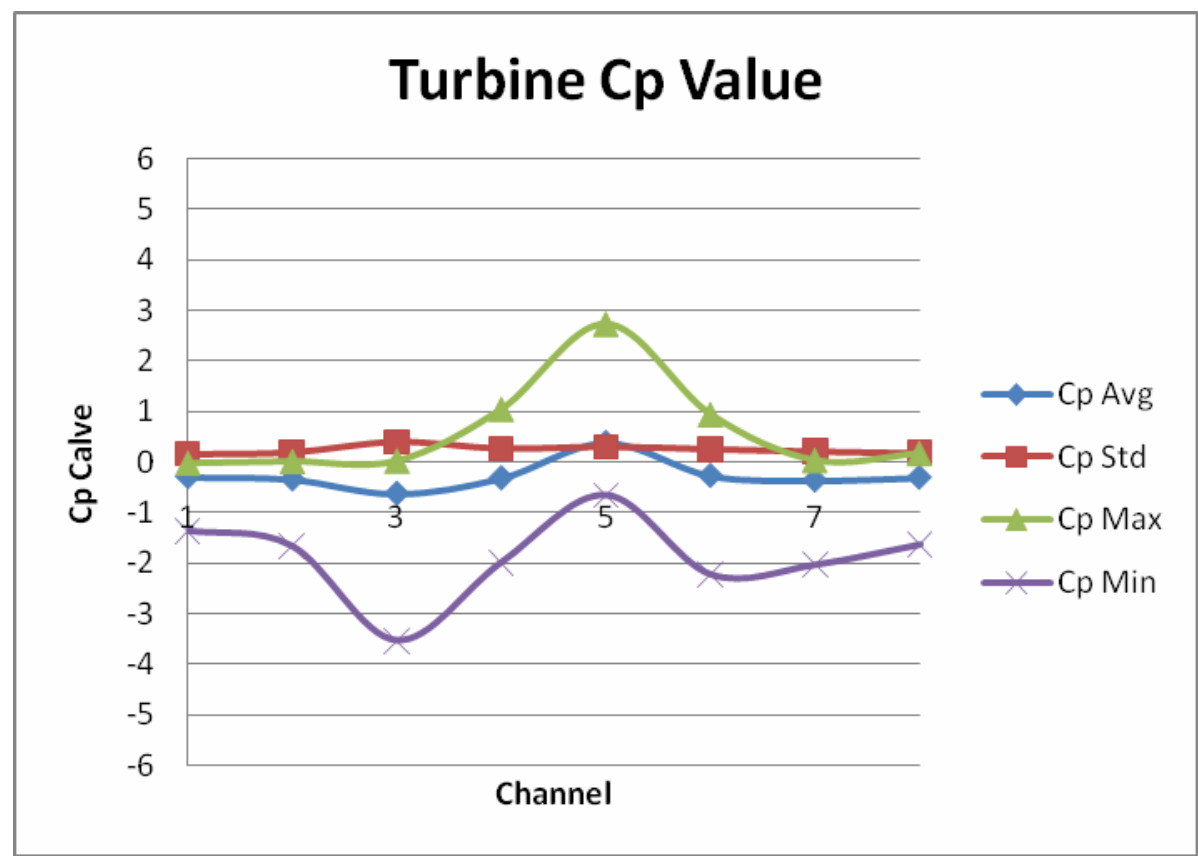

(a)

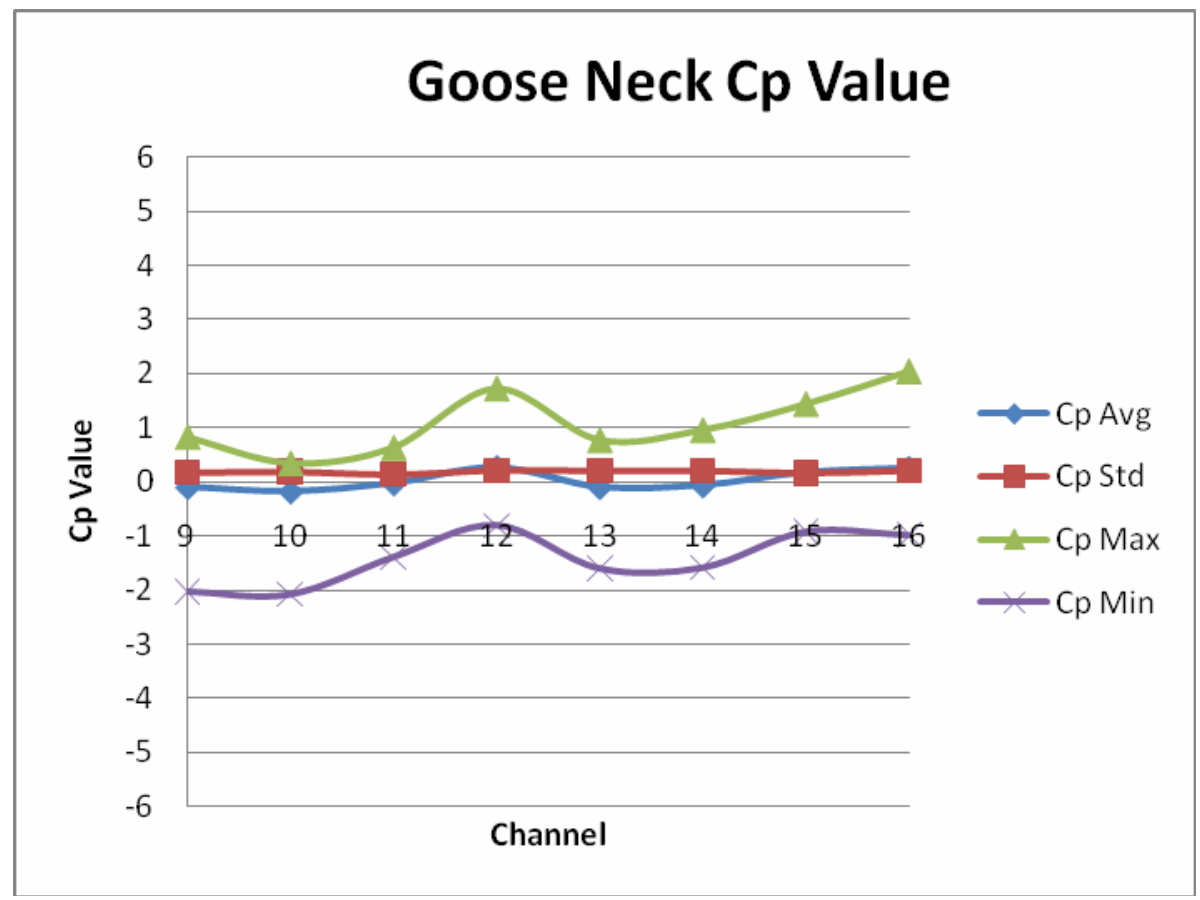

(b)

Figure 39. $C_{p}$ values for " 90 " degree angle: (a) turbine vent, (b) gooseneck vent 


\subsection{Water Intrusion Test Results:}

Water intrusion tests were also conducted to evaluate the performance of different ventilation systems regarding rainwater infiltration. Two water rates were used in the gable roof water tests, one is $9 \mathrm{inch} / \mathrm{hr}$ and another one is $19 \mathrm{inch} / \mathrm{hr}$. Only $19 \mathrm{inch} / \mathrm{hr}$ was used for the hip roof water intrusion test. The amount of water intrusion and the differential pressure coefficients $\Delta \mathrm{Cp}$ (difference of external and internal pressure coefficients) are compared in this section. Figures 42 and 44 show the water intrusion tests results. Figures 41 and 43 show the differential pressure coefficients. There was no water infiltration through the ridge and soffit vents for gable roof. However, there was small amount of water infiltration through the ridge vent on hip roof at 90 -degree wind attack angle. In addition, there are no significant changes in water infiltration through the turbine vent for different wind angles.

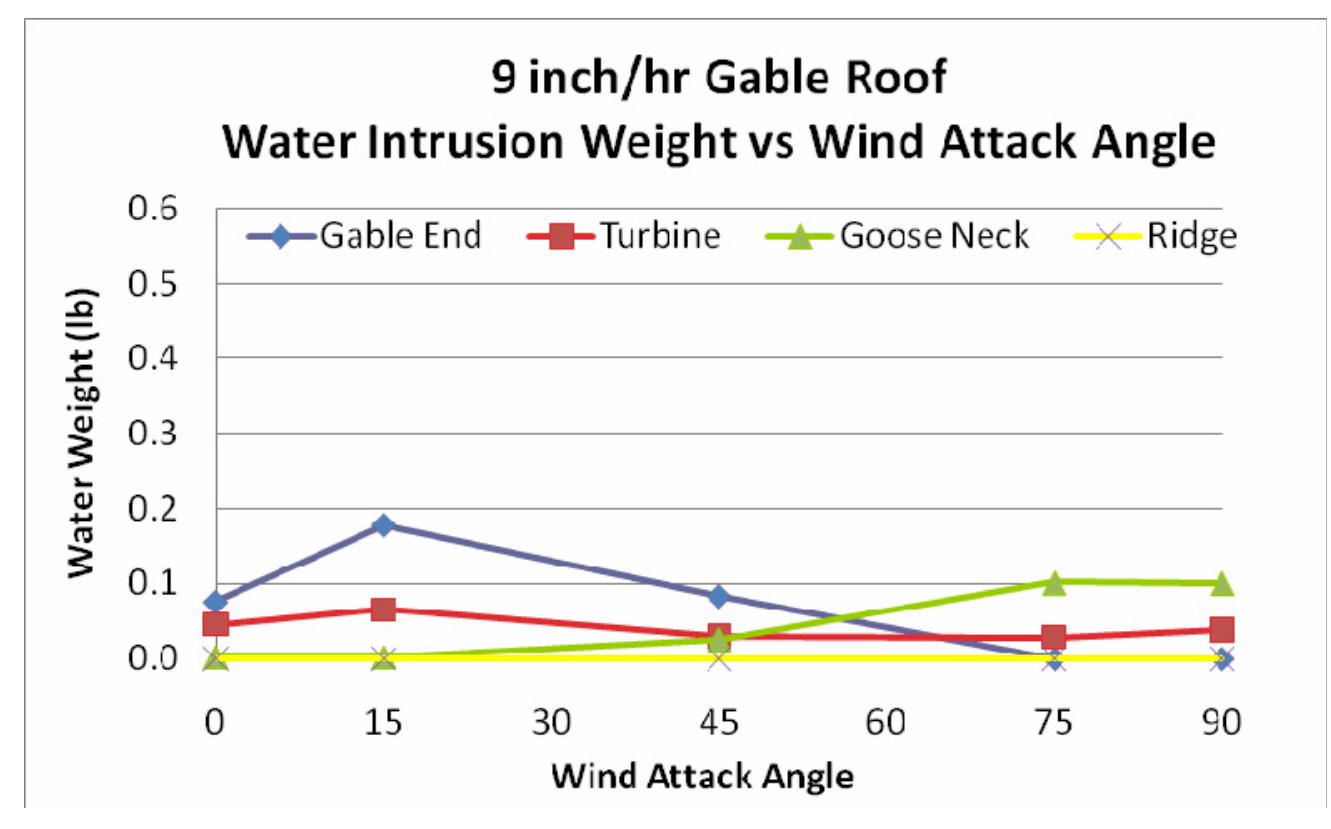

(a) 


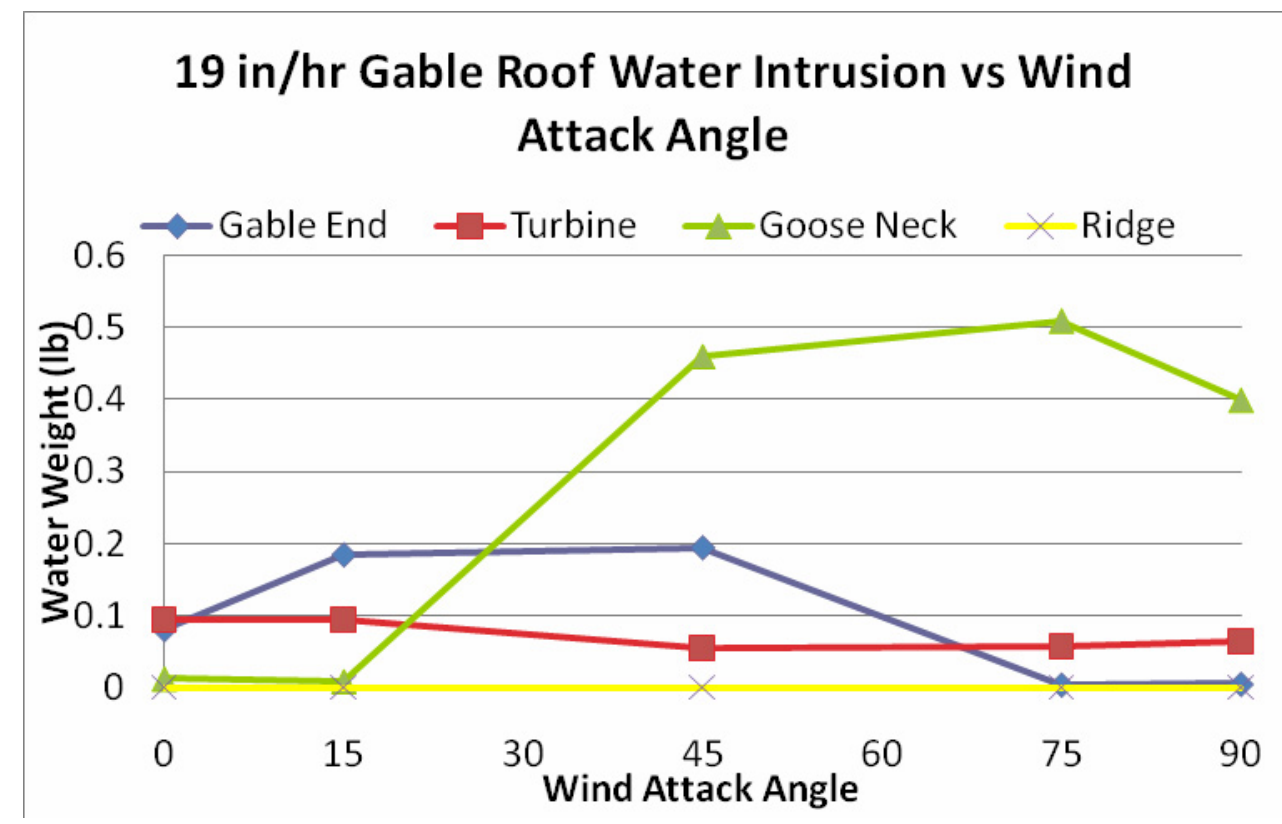

(b)

Figure 40. Water intrusion test resultsfor gable roof: (a) $9 \mathrm{in} / \mathrm{hr}$, (b) $19 \mathrm{in} / \mathrm{hr}$

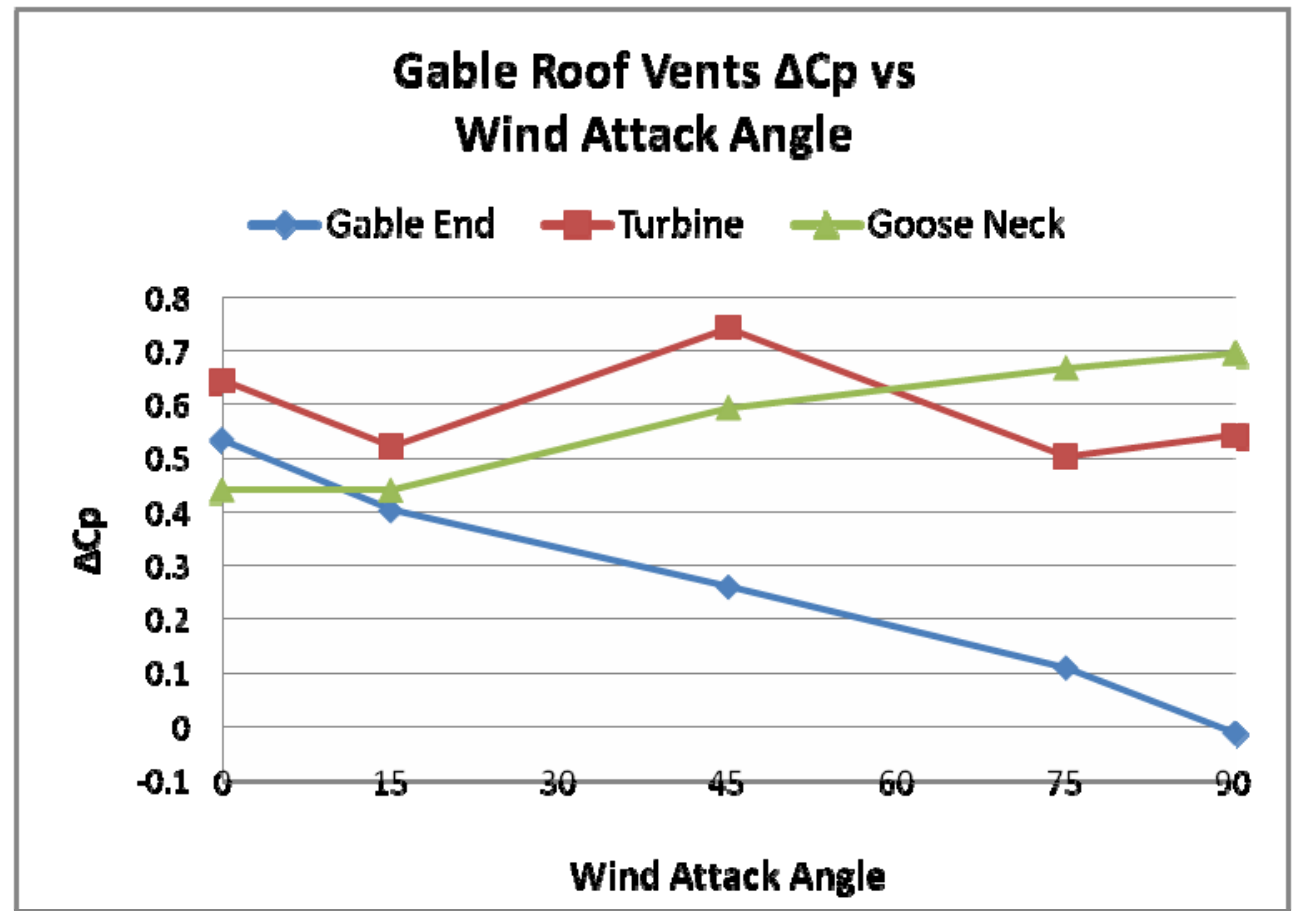

Figure 41. $\Delta \mathrm{Cp}$ values for gable roof specimen vents 


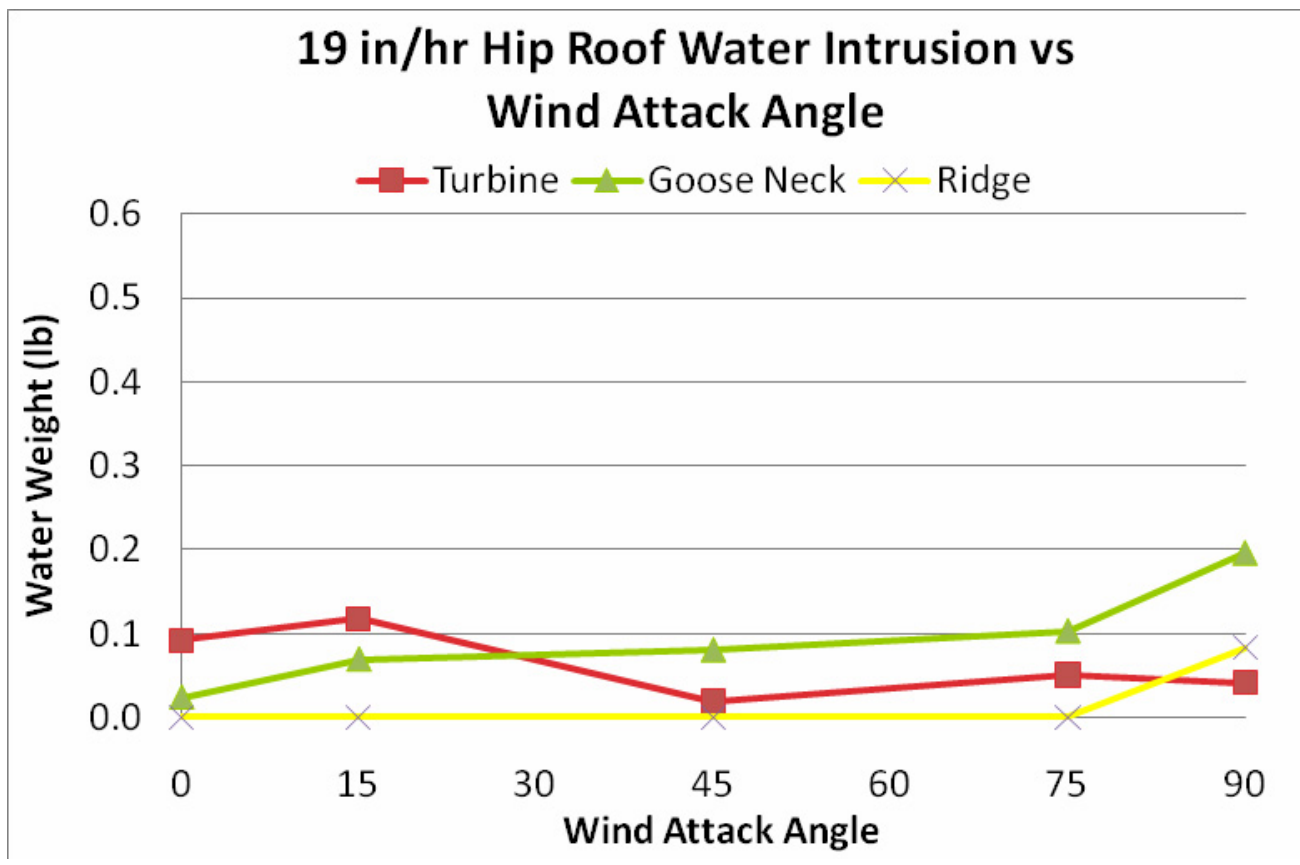

Figure 42. Water intrusion test resultsfor hip roof for $19 \mathrm{inch} / \mathrm{hr}$

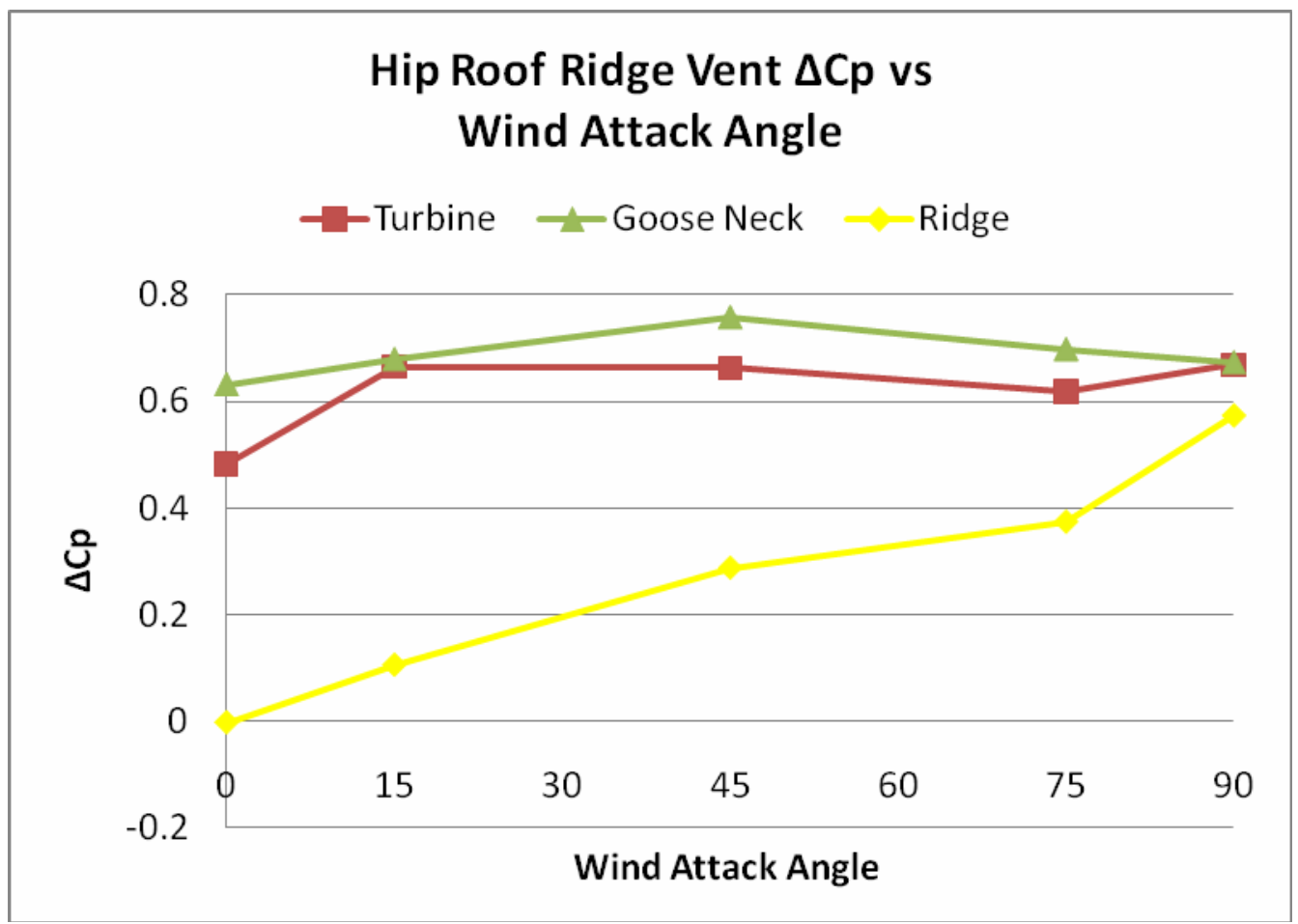

Figure 43. $\Delta \mathrm{Cp}$ values for hip roof specimen vents 
Figures 40 to 43 show somewhat similar trends between the water infiltration amount and the $\Delta \mathrm{Cp}$ values for each type of vent. This means that water intrusion amount can be correlated to the $\Delta \mathrm{Cp}$ values. As the value of certain $\Delta \mathrm{Cp}$ increases, there will be more water infiltration through a vent. The water amount collected by gable end and goose neck vents varied with the wind attack angle. This is because both types of the vents have frontal openings. The water amount will increase if the wind attack angle is aimed to the vent frontal openings. However, it was observed that at " 0 " degree angle of attack the amount of water infiltration through the gable end vent was not the maximum. This may be due to the mechanism of the gable end vent. Figure 44 shows the gable end vent with the blinds. When the water came from perpendicular direction of the vent surface, the blinds could block some amount of the water from getting into the vent.

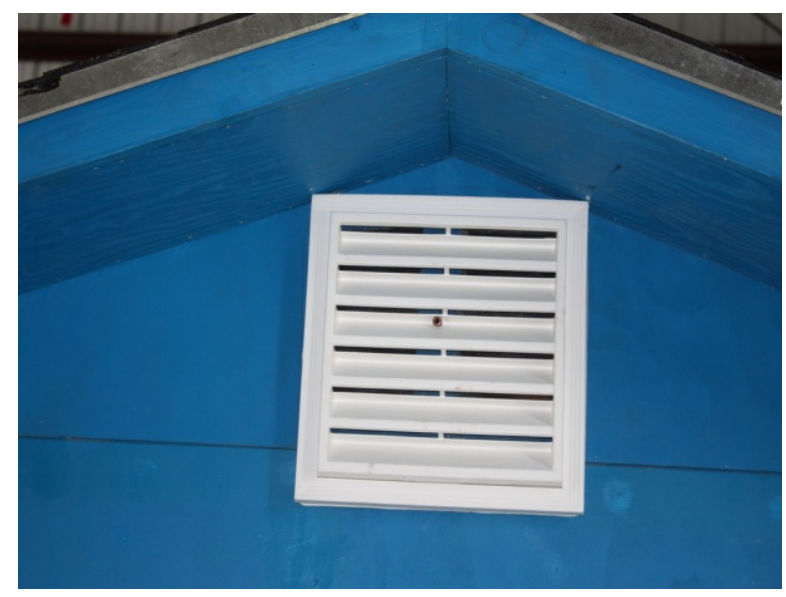

Figure 44. Gable end vent

Figures 45 and 46 show the $\Delta \mathrm{Cp}$ values of soffit and rigde vents on gable roof specimen. Most of the $\Delta \mathrm{Cp}$ values are less than 0.1 and all of the $\Delta \mathrm{Cp}$ values are less than 0.15 . The low $\Delta \mathrm{Cp}$ values explain why there was no water intrusion for the soffits and ridge vents in the gable roof tests. 


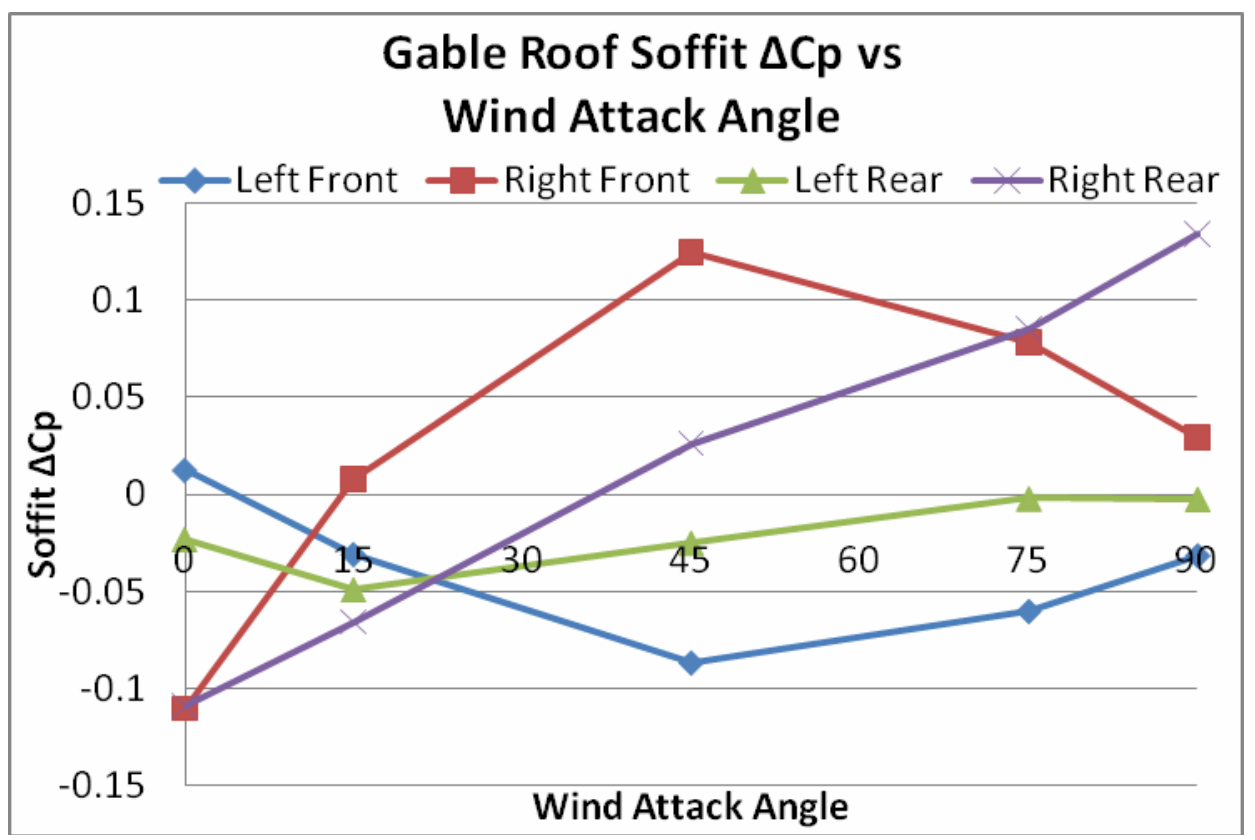

Figure 45. $\Delta \mathrm{Cp}$ values for soffit vents for gable roof specimen

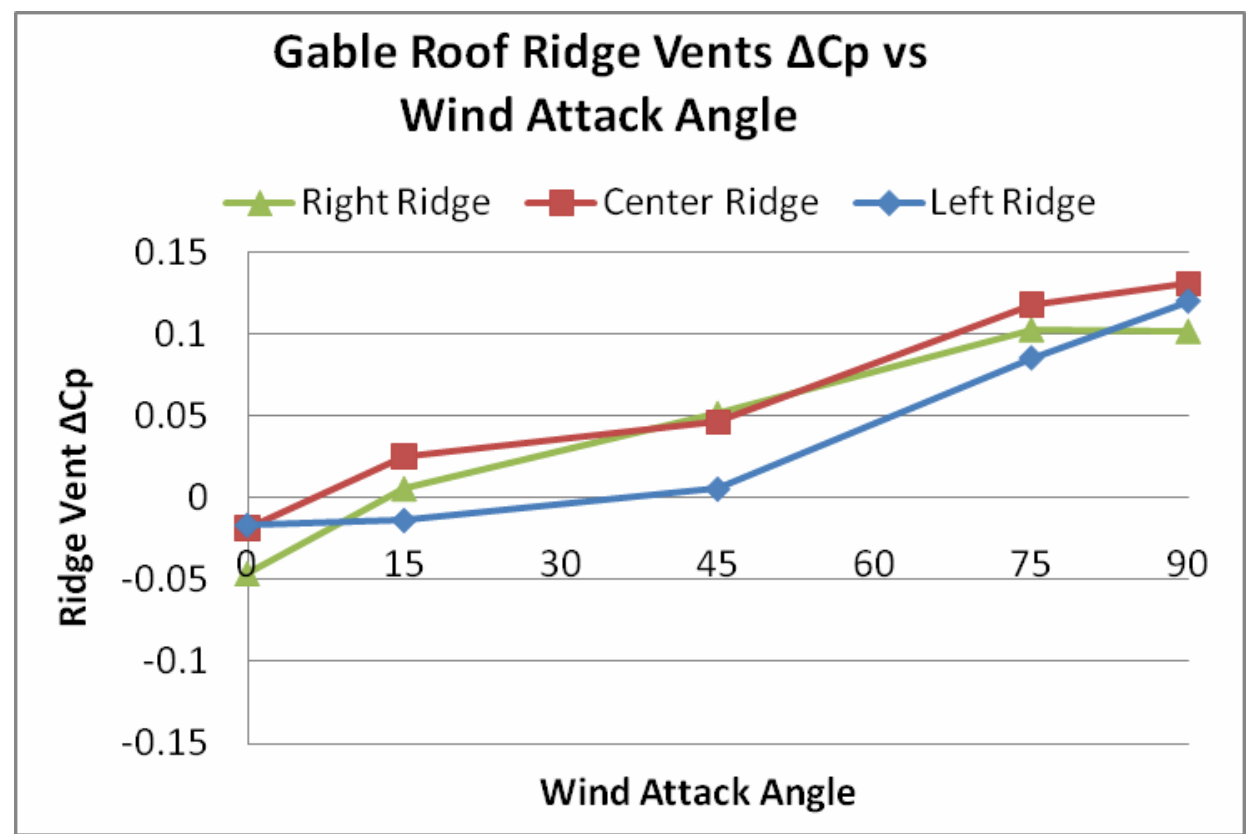

Figure 46. $\Delta \mathrm{Cp}$ values for ridge vents for gable roof specimen 
Figure 47 shows the $\Delta \mathrm{Cp}$ values for soffit vents for the hip roof specimen. Since most of the values are negative, there will be no water intrustion for these soffit vents.

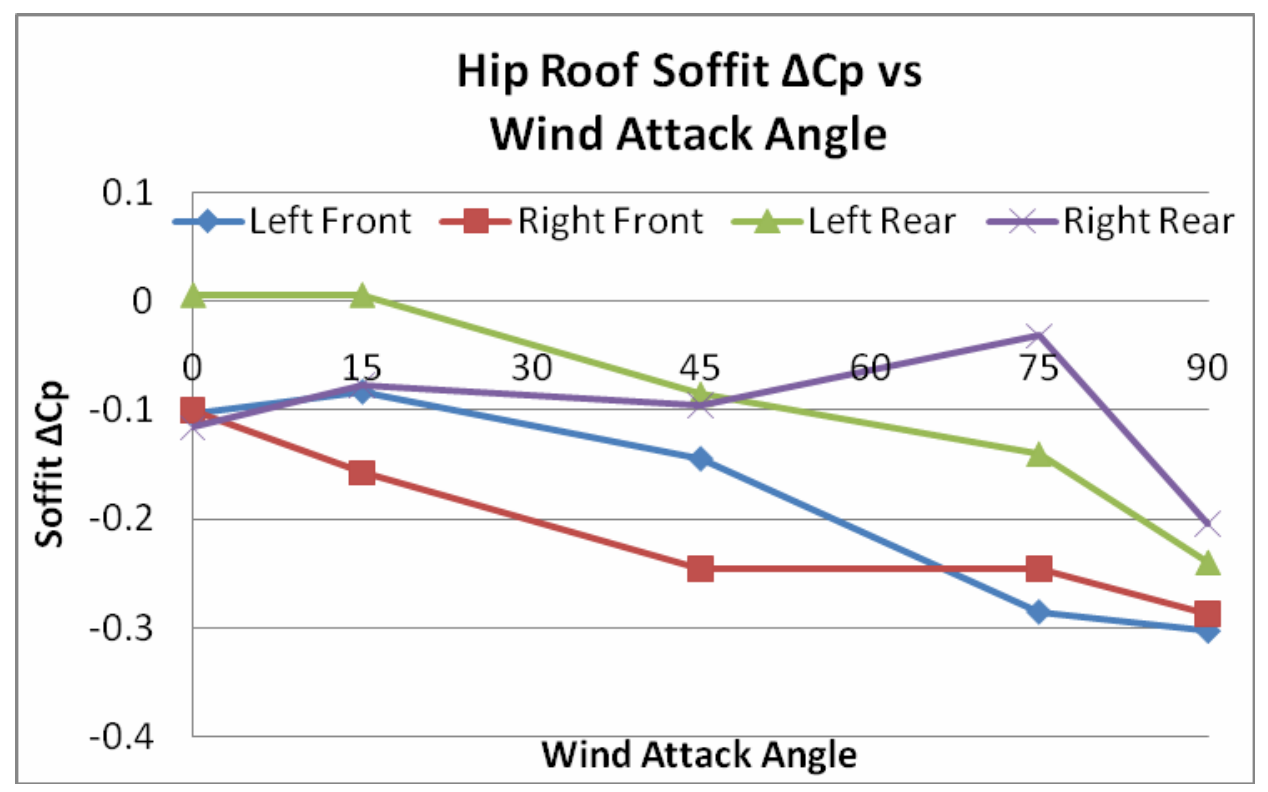

Figure 47. $\Delta \mathrm{Cp}$ values for soffit vents for hip roof specimen

Figure 48 shows the $\Delta \mathrm{Cp}$ values for ridge vents on hip roof specimen. It was noticed that there was some water coming through the ridge vent at 90-degree wind attack angle

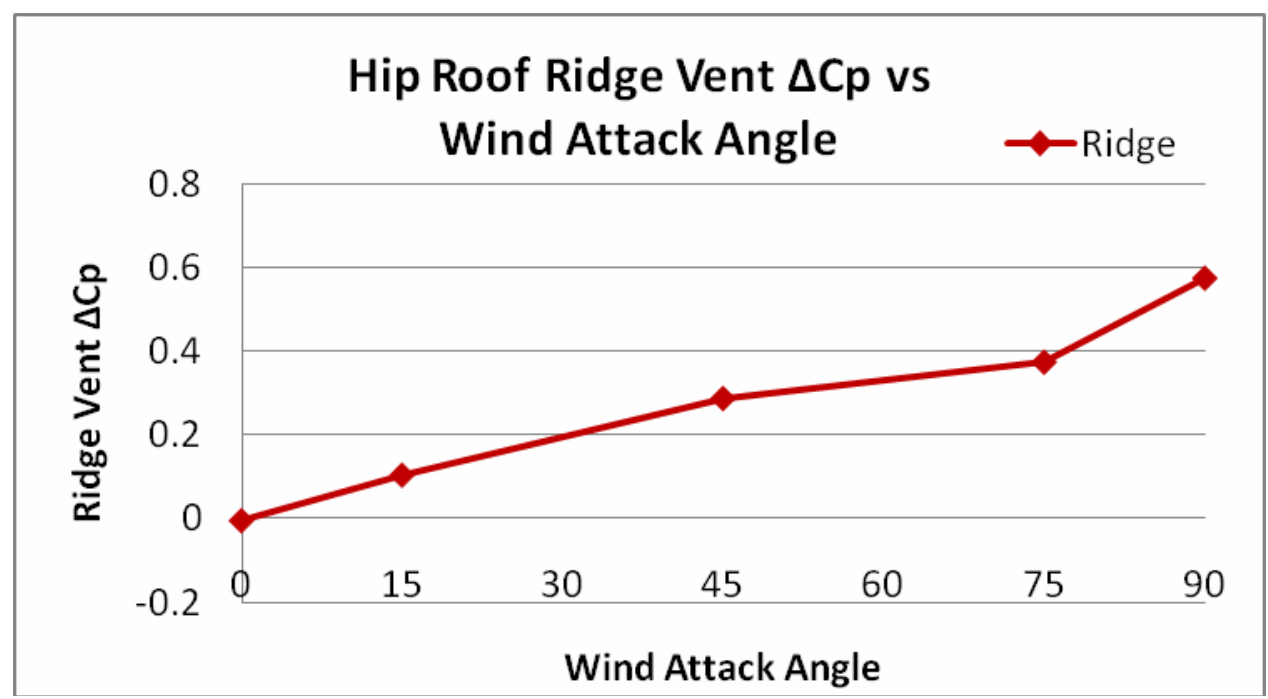

Figure 48. $\Delta \mathrm{Cp}$ values for ridge vent for hip roof specimen 
(Figure 42 the yellow curve). Figure 48 also shows that at 90-degree wind attack angle, the $\Delta \mathrm{Cp}$ increased to 0.6 sharply, which increased the chances for water infiltration.

\subsection{Influence of Reynolds Number on Pressure Distribution over Cylindrical Vent with Circular Cross Section (Turbine Vent)}

Drag coefficient is a function of Reynolds number (Re) (Simiu and Scanlan, 1996). Figure 49 shows typical curve for drag coefficients $C_{d}$ Vs Re. In the current pressure testing, the $\mathrm{Re}$ has been calculated as: $\mathrm{Re}=67000 \times \mathrm{V} \times \mathrm{L}$. Where $\mathrm{V}$ is the mean wind speed at men roof height and $\mathrm{L}$ is the dimension of the object. In our case, $\mathrm{L}$ can be considered as the diameter of turbine, which is 12 inch $(0.305 \mathrm{~m})$. Therefore, the $\operatorname{Re}=67000 \times 20.27 \mathrm{~m} / \mathrm{s} \times 0.305 \mathrm{~m}=4.14 \times 10^{5}$ and the corresponding $C_{d}$ value is 0.32 (Figure 47). However, as the Re decreases below $4 \times 10^{5}$, the $C_{d}$ value increases sharply, e.g., $C_{d}=1.1$ for $R e=2 \times 10^{5}$.

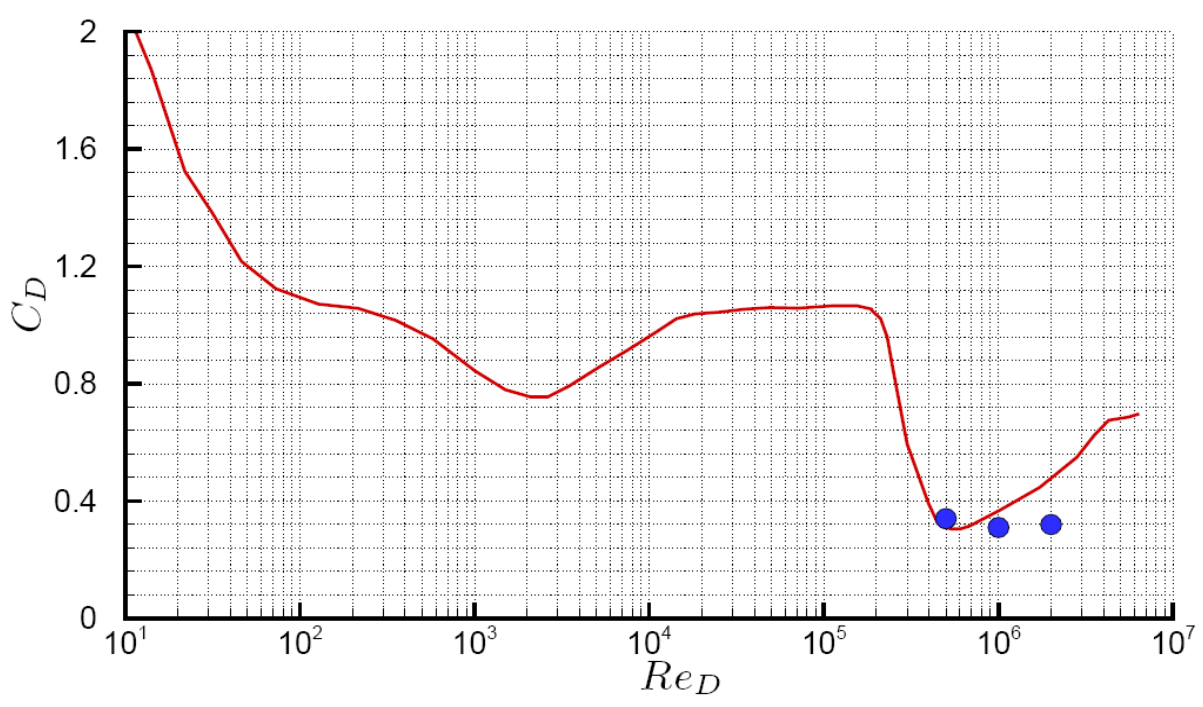

Figure 49. Drag Coefficient as a function of Reynolds number (Wang, 2001) 
Figure 50 shows the pressure coefficients over the turbine circumstantial surface. Compared to the results presented by Simiu and Scanlan (1996), the data obtained from Wall-of-Wind is close to that for $\mathrm{Re}=1.1 \times 10^{5}$. In addition, the $\mathrm{C}_{\mathrm{p}}$ values for hip roof test are smaller than the $C_{p}$ values for gable roof test.

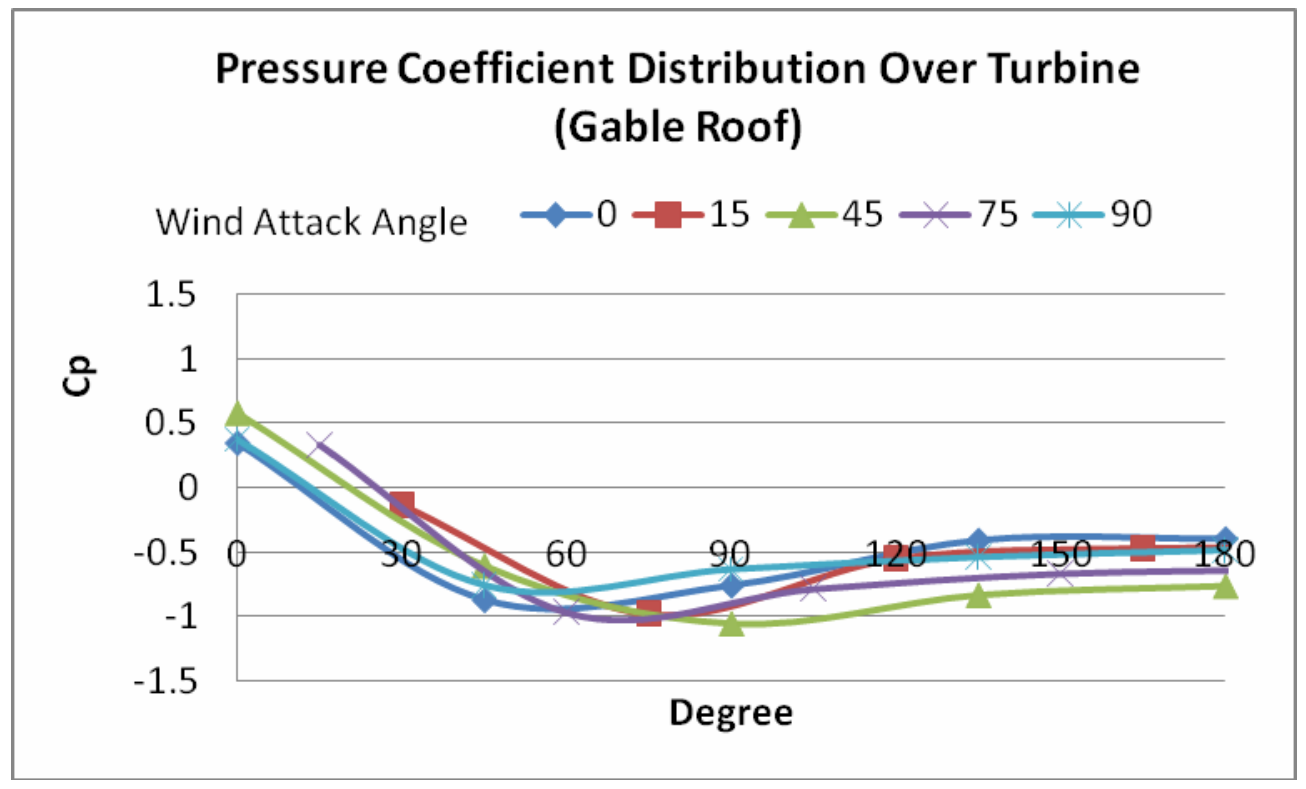

(a)

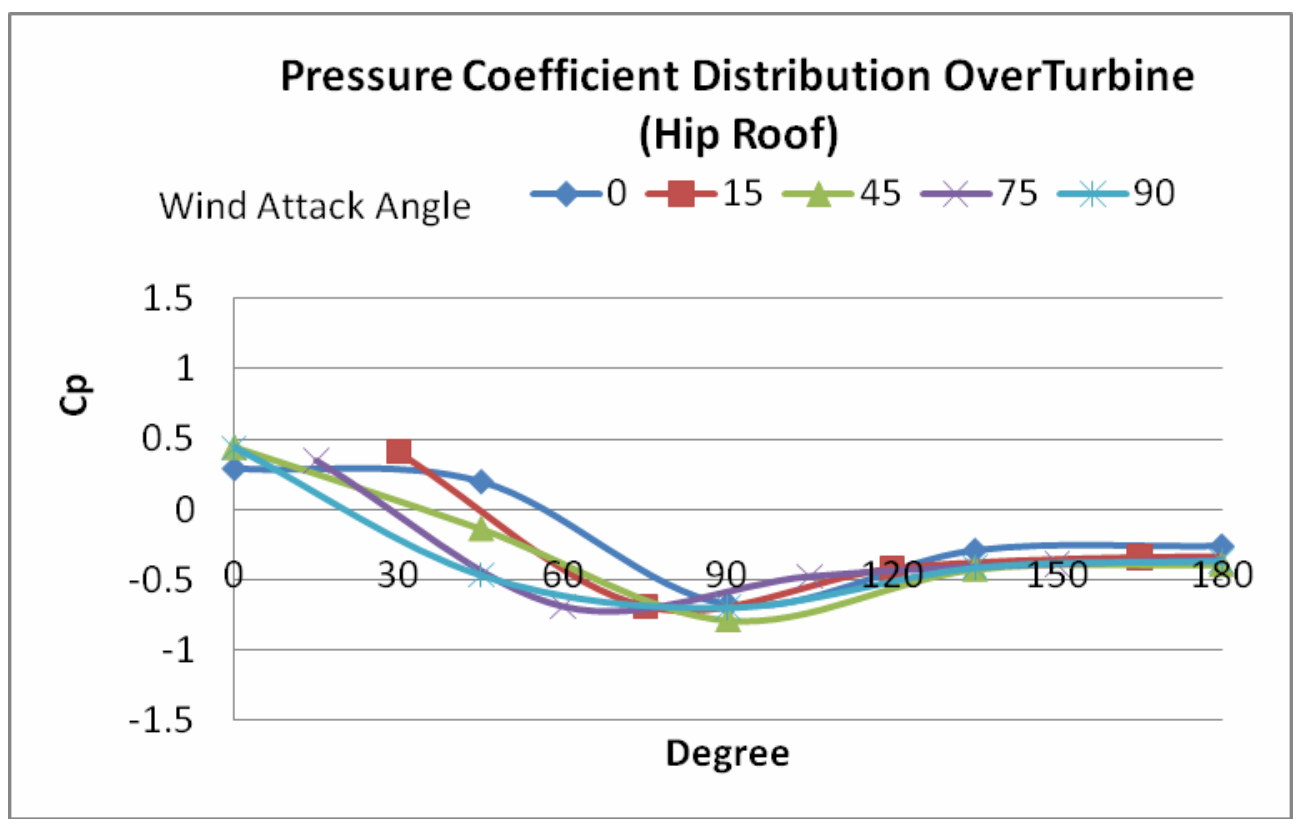

(b) 


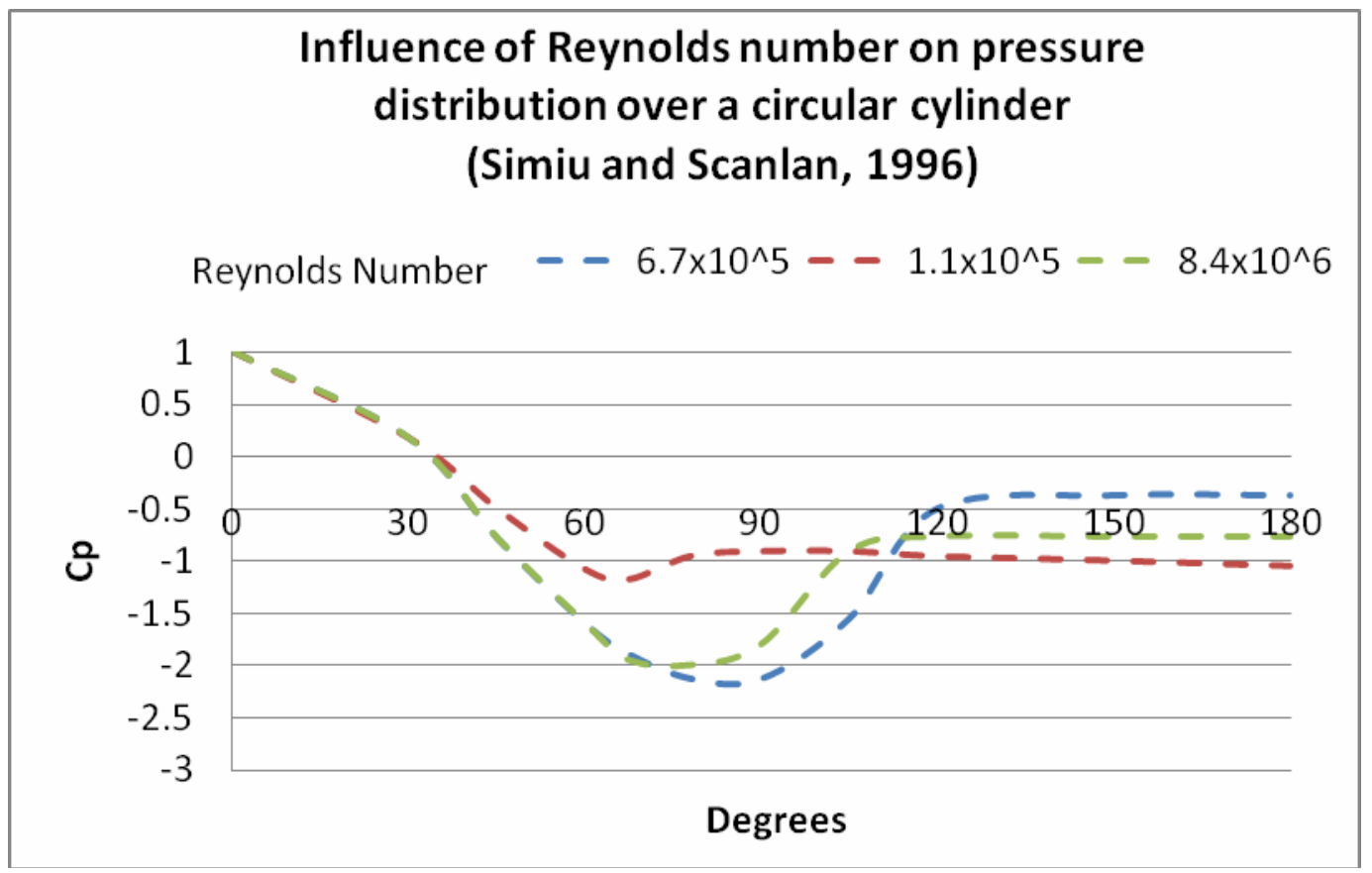

(c)

Figure 50. Cp values distribution along (a) Turbine vent for gable roof, (b) Turbine vent for hip roof, (c) Circular cylinder (Simiu and Scanlan, 1996)

\subsection{Uplift and Drag Coefficients}

\subsubsection{Uplift Coefficient}

The uplift coefficients $C_{L}$ are also calculated for gooseneck vent and shown in Figure 51. In the figure, the $C_{L}$ values observed for gable and hip roofs are not only different at the minimum values, but also the trends of the curves are quite dissimilar. For hip roof, gooseneck vent is subjected to uplift forces from all wind attack angles. However, for the gable roof, gooseneck vent is only subjected to uplift forces at 0 and 15degree wind attack angles. At 45, 75, and 90-degree wind attack angles, gooseneck is subjected to push down forces. 


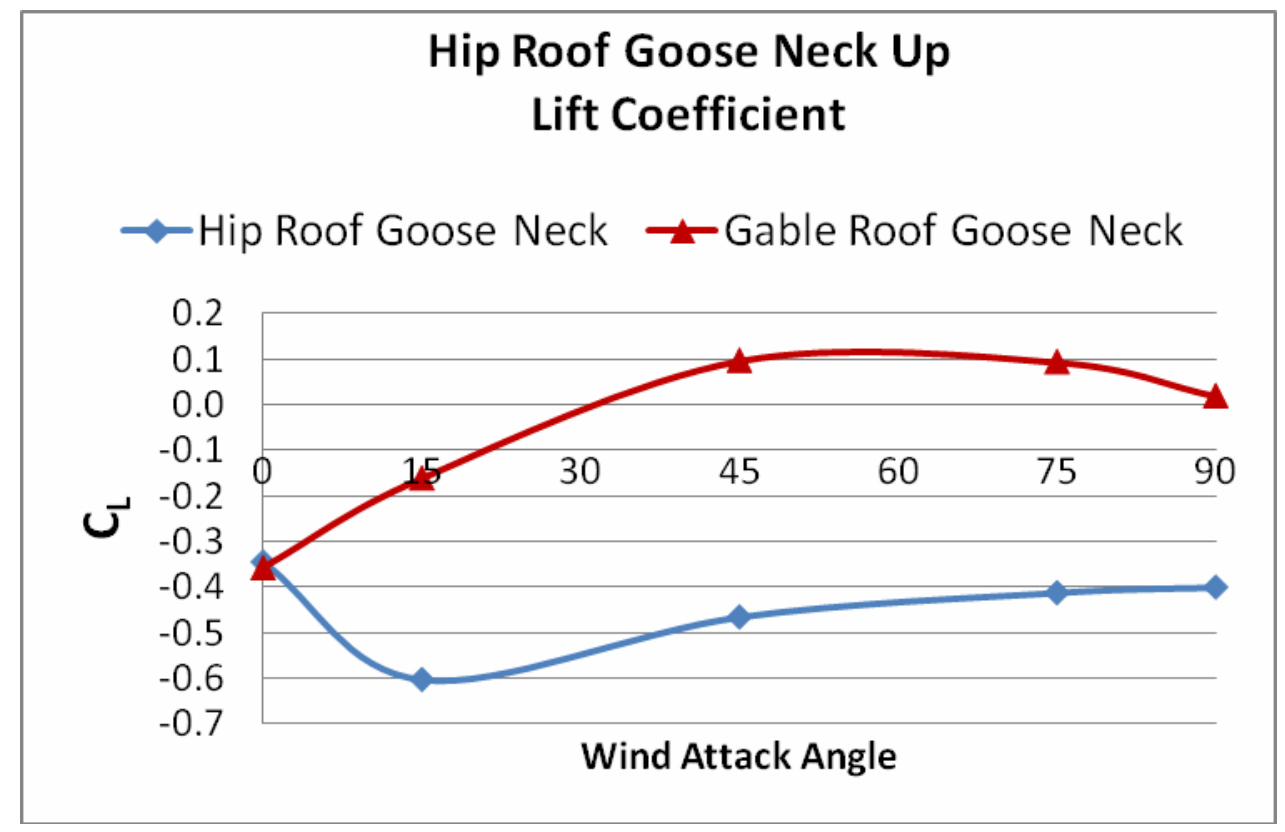

Figure 51. Goose neck vent uplift coefficients for gable roof and hip roof

\subsubsection{Drag Coefficient}

The turbine vent drag coefficient for different wind attack angles on both gable roof and hip roof are shown in Figure 52. For gable roof, $\mathrm{C}_{\mathrm{d}}$ coefficient is between 0.3 and 0.75 . For hip roof, the $C_{d}$ value for turbine vent is about 0.3 . The maximum gooseneck vent $C_{d}$ value is 1.25 on gable roof and 0.75 on hip roof. It is noticed that both turbine and goose neck vents are subjected to higher $C_{d}$ values on the gable roof. For the hip roof, the maximum $C_{d}$ values of turbine and gooseneck vents are about half of the $C_{d}$ values for the gable roof. By comparing the $C_{d}$ values for turbine, which are between 0.3 and 0.7 with the $C_{d}$ values in Figure 46, the Re obtained from Figure 46 is between 3 $\times 10^{5}$ and $5 \times 10^{5}$. This range includes the Re value calculated previously as $4.14 \times 10^{5}$ for current testing. 


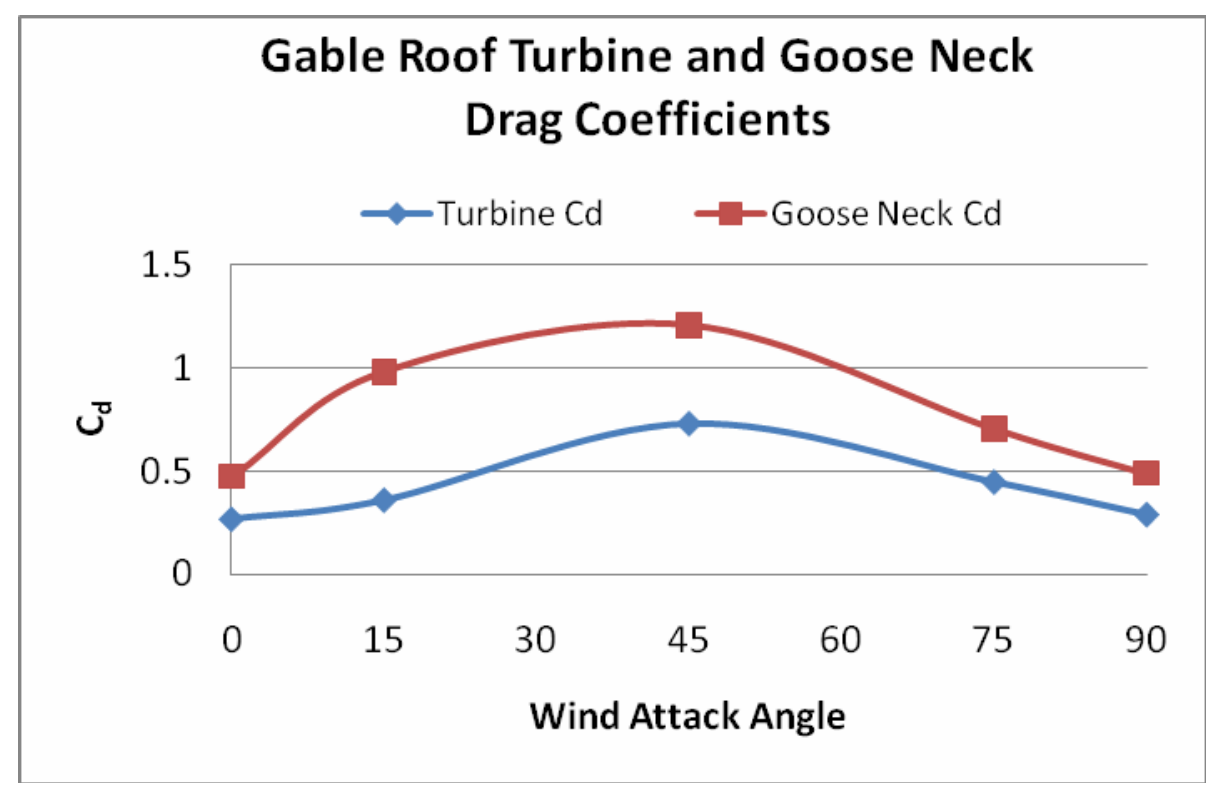

(a)

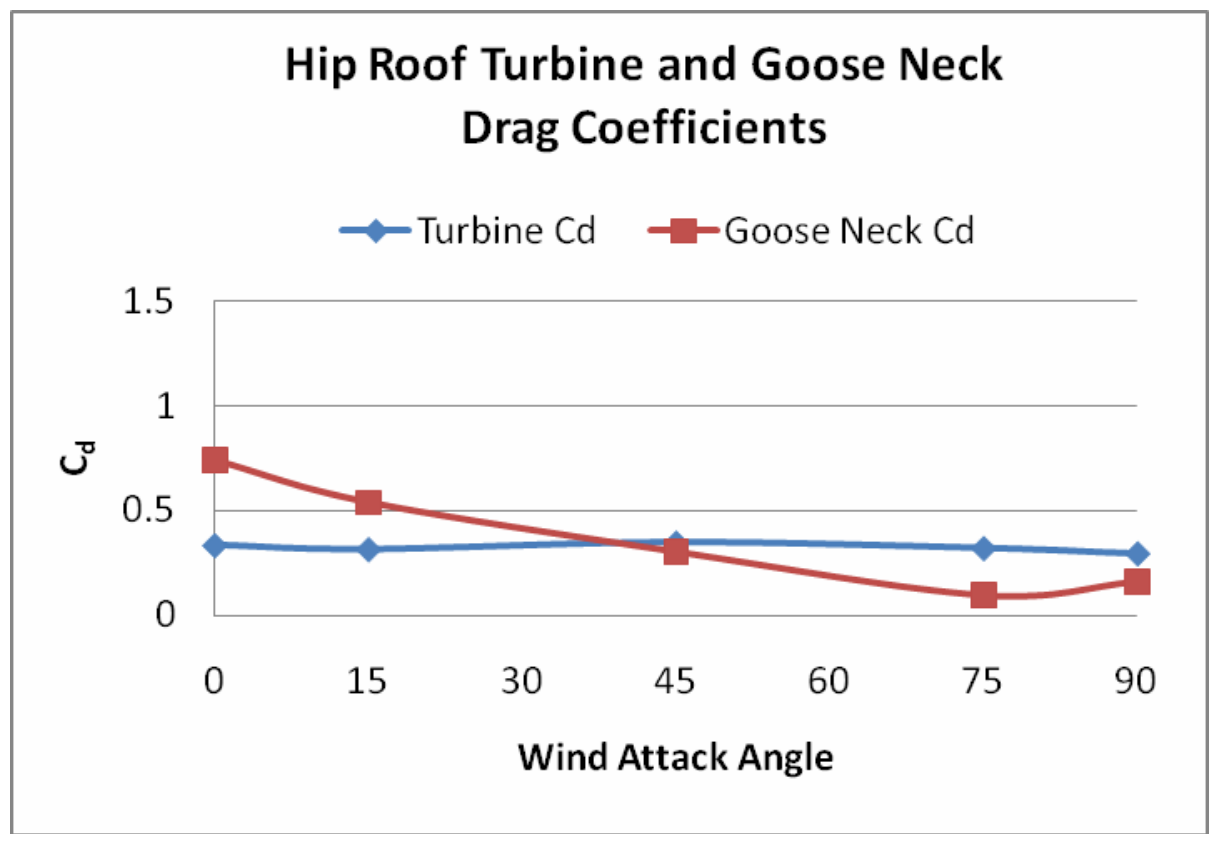

(b)

Figure 52. Vent drag coefficients for gable roof and hip roof 


\section{CONCLUSIONS:}

The tests indicate that water infiltration through a vent system is dependent upon the differential pressure as well as the vent mechanism. For vents experiencing higher differential pressures, vent covers can be used during storms to reduce water infiltration. Active controls can also be designed to close the vents automatically as differential pressure increases based on the wind speed and wind angle of attack. The later strategy is a topic of future research.

Based on the test results, in general, the overall volume of water intrusion between 0 and 30 degrees angles of attack was significantly smaller than that for angles of attack between 45 through 90 degrees. This can be attributed to the gooseneck vent, which allowed the most water to enter between 45 and 90 degrees. This is because the opening on the gooseneck was facing the wind for angles of attack between 45 through 90 degrees.

The volume of water intrusion through the gable end vent for perpendicular winds (0 degree) is less than that for slightly oblique winds (say, 15 degree) though the different pressure is higher for the former case. The reason behind this can be the louver mechanism, which doesn't allow perpendicular wind or water to get into it that easily. However at slight inclination the wind-driven rain can get through the opening under the louver. For the gable end vent no water intrusion was seen at 75 degree and 90 degree angles of attack and a linear trend is visible for 15 degree to 75 degree.

Water infiltration through the turbine vent is pretty much consistent and is somewhat independent of the wind angles of attack (angles from 0 degree to 90 degree). 
As the top of the turbine vent is always spinning at the time of wind attack it lessens water intrusion through it.

For the gooseneck vent a consistent trend of increasing water infiltration is observed with the increase in the differential pressure based on the angle of attack. The gooseneck vent has maximum water infiltration when the opening on the gooseneck vent faces the wind which allows maximum pressure differentials for angles of attack between 45 through 90 degrees.

For the ridge vent differential pressure coefficient is minimal and no water intrusion is seen for most of the angles of attack (except 90 degree for hip roof for which differential pressure increases abruptly). Similarly, for the soffit vent no water intrusion was seen for any of the angles of attack. This is unusual, as soffit vent water intrusion had been observed during many past hurricanes. For the current tests the roof eave inclination might have prevented the water infiltration through the soffit vents (see Fig. 22b).

The relationships obtained between Reynolds number and the drag coefficients or pressure coefficients were comparable with previous studies. 


\section{REFERENCES AND RELATED LINKS}

A. Revel, "Testing of 2 wind driven roof ventilators, 1998, available from www.edmonds.com.au (accessed 13/03/2007)

AIR VENT INC., available at:

[http://www.airvent.com/homeowner/whyVent/whyVent.shtml]

Baffled attic Vent, Richard S. Duncan et al

[http://www.google.com/patents?id=Rt6fAAAAEBAJ]

Blessing, C.M. (2007), "Mitigation of Roof Uplift Through Vortex Sup pressure Techniques" MSc Thesis, Florida International University, Miami, Florida.

Bitsuamlak, G.T., Gan Chowdhury, A., Sambare, D. (2009), “Application of a Full-Scale Testing Facility for Assessing Wind-Driven-Rain Intrusion," Building and Environment, 44 (12), pp. 2430-2441.

Bitsuamlak, G. T., Tecle A. (2009), "Full-Scale External and Internal Pressure Measurements on Low-Rise Building Roofs," Report submitted to IHRC, Research Project funded by The State of Florida Department of Community Affairs.

C. Lai, "Experiments on the ventilation efficiency of turbine ventilators used for building and factory ventilation,” Energy \& Buildings 35 (2003) 927-932.

C. Lai, "Prototype development of the rooftop turbine ventilator powered by hybrid wind and photo-voltaic energy," Energy \& Buildings 38 (2005) 174-180.

C. Lai, I.S. Kuo, "Assessment of the potential of roof turbine ventilators for bathroom ventilation,” Building Services Engineers: Technical note 26.2, 2005, pp. 173-179.

D.M.H. Rashid, N.A. Ahmed, "Study of Aerodynamic forces on a rotating wind driven ventilator," Journal of Wind Engineering 27 (2003) 63-72.

Huang, P., Gan Chowdhury, A., Bitsuamlak, G. T., Liu, R., (2009), "Development of Devices and Methods for Hurricane Wind Flow Simulation in a Full-Scale Testing Facility," Wind and Structures, 12 (2), pp.151-177.

J.D. Dale, M.Y. Ackerman, "Evaluation of the performance of attic turbine ventilators, ASHRAE Transactions 99 (1)(1993) 14-22, USA.

Lott, N., and Ross, T., (2006), "Tracking and Evaluating U.S. Billion Dollar Weather Disasters, 1980-2005," Forum on Environmental Risk and Impacts on Society: Successes and Challenges American Meteorological Society.

Liu, R. (2008) "Flow Characterization and Active Control of Turbulence," MSc Thesis, Florida International University, Miami, Florida. 
National Academy of Sciences. Meeting research and education needs in coastal engineering. National Academy Press; 1999. pp. 11.

Owens Corning Roofing. THE PINK PANTHER ${ }^{\text {TM }}$ \& (C) 1964-2009 Metro-Goldwyn-Mayer Studios Inc, available from:

[http://roofing.owenscorning.com/homeowner/accessories/ventilation/?s kwcid=roof $\% 20 \mathrm{vents} \%$ $\underline{7 \mathrm{C} 2522511830]}$

P. Havens, "A combined fan and wind turbine model for attic turbine ventilators," Energy Efficient and Healthy Buildings (2004), ARE 318-E.

P. Karava, T. Stathoupoulous, K.A. Athienitis, "Wind Induced Natural Ventilation," Solar Energy 81 (2006) 20-30.

Roof and Wall Venting System. Kind Code: A1. Document Number: 20080028704, available from:

[http://www.freepatentsonline.com/y2008/0028704.html?query=Wall+vents\&stemming=on]

Roof and Wall Venting System. Kind Code: A1. Document Number: 2007001195.Document type: United States Patent Application, available from:

[http://www.freepatentsonline.com/y2007/0011957.html?query=Wall+vents\&stemming= on]

Risk Management Solutions, available at:

[www.rms.com]

S. West, "Improving the sustainable development of building stock by the implementation of energy efficient, climate control technologies," Building \& Environment 36 (1999) 281-289.

Science Directory: Volume 31, Issue 10, (2009) available from:

[http://www.sciencedirect.com/science? ob=PublicationURL\& cdi $=5715 \&$ auth $=\mathrm{y} \& \mathrm{cct}=\mathrm{C} 0000$ 54271\& version $=1 \&$ urlVersion $=0 \&$ userid $=2139759 \&$ pubType $=J \& m d 5=628077 \mathrm{~b} 0$ eac596ab $\underline{\mathrm{b} 0913 \mathrm{ff} 26 \mathrm{~b} 275 \mathrm{c} 7 \mathrm{f}]}$

Simiu E., Scanlan R. (1996), "Wind Effects on Structures”, 3rd edition, New York: Wiley.

V. H. Meadows, US Patent 1,857,762, Rotary ventilator, 1929. 